NBER WORKING PAPER SERIES

\title{
MACROECONOMIC EFFECTS OF DEBT RELIEF: CONSUMER BANKRUPTCY PROTECTIONS IN THE GREAT RECESSION
}

\author{
Adrien Auclert \\ Will S. Dobbie \\ Paul Goldsmith-Pinkham \\ Working Paper 25685 \\ http://www.nber.org/papers/w25685 \\ NATIONAL BUREAU OF ECONOMIC RESEARCH \\ 1050 Massachusetts Avenue \\ Cambridge, MA 02138 \\ March 2019
}

\begin{abstract}
A previous version of this paper circulated under the title "Debtor Protections and the Great Recession." We are extremely grateful to Guido Imbens, David Scharfstein, and Andrei Shleifer for their help and support. We thank David Berger, Jediphi Cabal, John Campbell, Gabriel Chodorow-Reich, Fritz Foley, Sonia Gilbukh, Sam Hanson, Kyle Herkenhoff, David Laibson, Atif Mian, Kurt Mitman, Ben Moll, Matt Rognlie, Isaac Sorkin, Jeremy Stein, Ludwig Straub, Adi Sunderam, Jacob Wallace, Johannes Wieland, Danny Yagan, Crystal Yang, Eric Zwick, and numerous seminar participants for helpful comments and suggestions. We also thank Joanne Hsu, David Matsa, and Brian Melzer for sharing their data on state Unemployment Insurance laws. Daniele Caratelli, Sara Casella, Rebecca Sachs, and Bailey Palmer provided excellent research assistance. The views expressed are those of the authors and do not necessarily reflect those of the Federal Reserve Bank of New York, the Federal Reserve System, or the National Bureau of Economic Research. All remaining errors are ours.
\end{abstract}

NBER working papers are circulated for discussion and comment purposes. They have not been peer-reviewed or been subject to the review by the NBER Board of Directors that accompanies official NBER publications.

(C) 2019 by Adrien Auclert, Will S. Dobbie, and Paul Goldsmith-Pinkham. All rights reserved. Short sections of text, not to exceed two paragraphs, may be quoted without explicit permission provided that full credit, including $(\odot$ notice, is given to the source. 
Macroeconomic Effects of Debt Relief: Consumer Bankruptcy Protections in the Great Recession Adrien Auclert, Will S. Dobbie, and Paul Goldsmith-Pinkham

NBER Working Paper No. 25685

March 2019

JEL No. D14,E32,F45,K35

\section{ABSTRACT}

This paper argues that the debt forgiveness provided by the U.S. consumer bankruptcy system helped stabilize employment levels during the Great Recession. We document that over this period, states with more generous bankruptcy exemptions had significantly smaller declines in non-tradable employment and larger increases in unsecured debt write-downs compared to states with less generous exemptions. We interpret these reduced form estimates as the relative effect of debt relief across states, and develop a general equilibrium model to recover the aggregate employment effect. The model yields three key results. First, substantial nominal rigidities are required to rationalize our reduced form estimates. Second, with monetary policy at the zero lower bound, traded good demand spillovers across states boosted employment everywhere. Finally, the ex-post debt forgiveness provided by the consumer bankruptcy system during the Great Recession increased aggregate employment by almost two percent.

Adrien Auclert

Department of Economics

Stanford University

579 Serra Mall

Stanford, CA 94305-6072

and NBER

aauclert@stanford.edu

Will S. Dobbie

Industrial Relations Section

Louis A. Simpson International Bldg.

Princeton University

Princeton, NJ 08544-2098

and NBER

wdobbie@princeton.edu
Paul Goldsmith-Pinkham

Yale University School of Management

165 Whitney Ave

New Haven, CT 06511

paulgp@gmail.com 
There is a widespread view that the deterioration of household balance sheets contributed to the sharp decline in U.S. employment between 2007 and 2009. According to this view, the sudden fall in house prices and the simultaneous contraction in credit supply led to a large drop in aggregate consumption as households adjusted towards lower debt levels. Since monetary policy was unable to offset this fall in aggregate demand, employment levels collapsed nationwide (e.g., Eggertsson and Krugman 2012; Mian and Sufi 2014b). An important implication of this view is that ex-post debt forgiveness could have prevented such a collapse by mitigating the decline in aggregate demand. ${ }^{1}$ To date, however, there is little credible evidence on the macroeconomic effects of debt relief. Credible estimates of these effects are critical for understanding the contribution of consumer bankruptcy to the business cycle, as well as evaluating proposals for large-scale debt forgiveness during recessions.

In this paper, we use a combination of quasi-experimental estimates and a general equilibrium model to estimate the effects of ex-post debt forgiveness on macroeconomic outcomes during the Great Recession. We focus on the debt forgiveness provided the U.S. consumer bankruptcy system, the largest debt relief program in the United States. We overcome the endogeneity issues that bias simple time-series comparisons by first estimating the relative effect of ex-post debt forgiveness during the Great Recession, leveraging quasi-random variation in the generosity of bankruptcy asset exemptions across states. We then develop a general equilibrium model to recover the aggregate effect of this ex-post debt forgiveness from these relative cross-state effects.

The U.S. consumer bankruptcy system allows eligible households who file for bankruptcy to discharge most unsecured debts, after relinquishing assets above state-specific exemption limits. Eligible households are therefore insured against all financial risk above the level of assets that can be seized in bankruptcy in their state. Bankruptcy exemptions also provide a natural threat point in negotiations with creditors, thereby providing a form of informal debt relief even when these households do not formally file for bankruptcy (e.g., Mahoney 2015). Households benefiting from the consumer bankruptcy system are, naturally, more financially distressed than the general population (e.g., Dobbie, Goldsmith-Pinkham and Yang 2015), and, as a result, have very high marginal propensities to consume (MPCs, e.g., Gross, Notowidigdo and Wang 2016). The debt forgiveness provided by the bankruptcy system could therefore boost aggregate demand if the households who implicitly finance the bankruptcy system have relatively low MPCs. While this is a natural hypothesis, our paper is the

\footnotetext{
${ }^{1}$ For example, Mian and Sufi (2014a) argue that "severe recessions are special circumstances because macroeconomic failures prevent the economy from reacting to a severe drop in demand. [...] When such failures prevent the economy from adjusting to such a large decline in consumption, government policy should do what it can to boost household spending. Debt forgiveness is exactly one such policy, and arguably the most effective."
} 
first to test it systematically.

The formal and informal debt relief provided by the consumer bankruptcy system during economic downturns - and hence the potential boost to aggregate demand-is also economically large, both in absolute terms and compared to other social insurance programs. Figure 1 shows the employmentto-population ratio in the United States between 2000 and 2017, together with estimates of the amount of unsecured credit discharged in Chapter 7 bankruptcy and total net charge-offs on non-real estate consumer credit in each year. ${ }^{2}$ By way of comparison, we also show total payments by the Unemployment Insurance (UI) system, an important automatic stabilizer, and total payouts by the Home Affordable Modification Program (HAMP) and two other mortgage debt relief programs under the umbrella of the Troubled Asset Relief Program (TARP). Both the amount of unsecured debt formally discharged through Chapter 7 bankruptcy and total net charge-offs on consumer credit increased sharply in 2008, just as employment fell across the country, with total net charge-offs on consumer credit reaching a peak of almost 1.5 percent of PCE in 2010. UI payments also increased by a similar magnitude during this time period, with total payments peaking at about 1.5 percent of PCE in 2010. By comparison, HAMP payments peaked years later at only 0.2 percent of PCE.

Our empirical strategy exploits the economically significant variation in the generosity of the bankruptcy exemptions-and hence the informal and formal debt relief provided by the bankruptcy system-across states. The cross-state variation in bankruptcy exemptions is particularly large for home equity, the largest and most important exemption category. New York, for example, allowed households to protect up to $\$ 100,000$ of home equity in bankruptcy prior to the crisis, while Illinois allowed households to protect only $\$ 30,000$. The variation in homestead exemptions has also been remarkably stable over time. The initial variation in homestead exemption amounts largely emerged as states formalized their state-level approaches to bankruptcy in the late nineteenth century, in ways that are likely unrelated to current state characteristics (Goodman 1993; Skeel 2001). Consistent with this idea, we show that most state characteristics are uncorrelated with state bankruptcy protections in the years just prior to the financial crisis. The combination of substantial cross-state variation in bankruptcy exemptions and economically large transfers during the financial crisis makes the consumer bankruptcy system an ideal setting to study the aggregate effects of ex-post debt forgiveness.

In the first part of the paper, we use this variation in a difference-in-differences design that com-

\footnotetext{
${ }^{2}$ We report the face value of both net charge-offs and the amount of unsecured credit discharged in Chapter 7 . Total charge-offs are net of recoveries. We scale all program payouts by annual personal consumption expenditures (PCE) for comparability over time.
} 
pares outcomes in states with more generous bankruptcy exemptions (the "treated" states) to states with less generous exemptions (the "control" states). This difference-in-differences specification explicitly controls for any pre-existing differences between states with more and less generous exemptions, including any time-invariant effects of bankruptcy protections such as over-borrowing or negative effects on credit supply (Gropp, Scholz and White 1997; Severino and Brown 2017). We also explicitly control for any common time effects of the financial crisis, including any common general equilibrium effects such as changes in monetary policy (Nakamura and Steinsson 2014), aggregate labor supply (Beraja, Hurst and Ospina 2016), or aggregate total factor productivity. The identifying assumption for our difference-in-differences specification is that, in the absence of any variation in bankruptcy exemptions, outcomes in states with more and less generous exemptions would have evolved in parallel during the Great Recession. This "parallel trends" assumption implies that there are no other reasons why the Great Recession would impact high- and low-exemption states differently, an assumption that we provide extensive support for in our analysis.

Using a rich panel of county-level credit data and employment data, we find that states with more and less generous bankruptcy exemptions had statistically identical outcomes during the 2001 to 2007 period. Starting in 2008, however, the states with more generous bankruptcy exemptions had significantly smaller declines in local non-tradable employment and larger increases in consumer debt write-downs compared to the states with less generous exemptions. For example, we find that a one standard deviation increase in the generosity of bankruptcy protections (approximately $\$ 60,000$ on a base of $\$ 254,000$ ) leads to a 0.399 percentage point increase in non-tradable employment from 2008 to 2010, and a \$55 increase in annual debt charge-offs per person over the same time period. The employment results are also extremely persistent, remaining economically and statistically significant through at least 2013. In sharp contrast, we find only a small and statistically insignificant effect on local tradable employment in all years.

Our difference-in-differences estimates provide us with credible estimates of the relative effect of an increase in ex-post debt relief across states, holding fixed any common general equilibrium effects. In the second part of the paper, we show that the informativeness of these estimates for the aggregate effect of debt relief depends on the sign and the magnitude of these general equilibrium effects. We first develop a simple two-region framework in which debt relief in one region can have an effect on both regions. We then define the concept of the relative debt relief multiplier, which differs from the aggregate debt relief multiplier by the magnitude of the spillover effect in the control region. Calculating 
the relative debt relief multipliers from our empirical differences-in-differences estimates, we obtain a multiplier of 1.81 for non-tradable employment and approximately zero for tradable employment. These multipliers have the interpretation that every additional percent of state consumption charged off as a result of bankruptcy exemptions led to a 1.81 percentage point relative increase in non-tradable employment during the Great Recession. But our framework makes clear that a large relative multiplier might mask a small aggregate effect of ex-post debt forgiveness-for example, if local prices or monetary policy adjust to offset the effect on economic activity in the aggregate. Conversely, a small relative multiplier might mask a large aggregate effect of debt forgiveness-for example, if there are positive demand spillovers across states. Simple "scaling up" exercises that interpret relative multipliers as approximately equal to aggregate multipliers therefore rely on an implicit assumption of zero general equilibrium spillovers.

In the final part of the paper, we evaluate the potential importance of these general equilibrium effects by developing a New Keynesian model that captures regional linkages through trade, labor markets, and a common monetary policy. Our model combines elements from the closed-economy literature with borrower-saver heterogeneity (e.g., Eggertsson and Krugman 2012) with elements from the open economy currency union literature (e.g., Nakamura and Steinsson 2014). Specifically, we develop a two-agent, two-region, two-good model, where borrowers and savers are spread across high- and low-exemption regions and consume both tradable and non-tradable goods. We model expost debt relief as a transfer from savers to borrowers, so that it does not affect interest rates or credit supply ex-ante. In our baseline calibration with standard preferences and relatively sticky prices, we show that our model produces relative multipliers for both non-tradable and tradable employment that are in line with our empirical estimates, with relative debt relief multipliers larger than one for non-tradable employment and close to zero for tradable employment.

Three features of the model generate these contrasting relative debt relief multipliers for nontradable and tradable employment: (1) heterogeneity in marginal propensities to consume between borrowers and savers, (2) nominal price rigidities, and (3) trade linkages across regions. Because borrowers have higher marginal propensities to consume than savers, debt relief temporarily increases aggregate spending on all goods in the high-exemption region. Because of nominal price rigidities, this temporary increase in aggregate spending leads to an increase in both non-tradable and tradable employment in the high-exemption region. Because traded goods can also be imported, tradable employment rises in the low-exemption region as well. These three features therefore lead to a positive 
relative multiplier for non-tradable employment, and an approximately zero relative multiplier for tradable employment. However, we show that this result relies crucially on our calibration choice of relatively rigid prices. Under flexible prices, the higher spending in the high-exemption region instead translates into an appreciation of the terms of trade and a reallocation of tradable demand to the low-exemption region. This reallocation induces a negative relative tradable multiplier, and this multiplier becomes more negative as prices become more flexible. Hence, the fact that we do not observe a significant relative decline in tradable employment in high-exemption regions is macroeconomic evidence for a high degree of price rigidity over the period (see Mian and Sufi $2014 b$ for a related argument).

We use the model to recover an estimate of the aggregate effect of debt relief during the Great Recession. Under the assumption that monetary policy was at the zero lower bound throughout the period, the model implies that ex-post debt relief had positive effects on employment in both sectors and in both regions. Ex-post debt relief directly increases spending and employment in both sectors in the high-exemption region, which increases tradable employment in the low-exemption region through a demand spillover effect. The increase in tradable employment in the low-exemption region then increases non-tradable spending and employment in that region. Calibrating the model to the observed path of debt write-downs during the financial crisis, we find that average employment across regions in the second half of 2009 would have been almost 2 percent lower in both the non-tradable and the tradable sector in the absence of the ex-post debt forgiveness provided by the consumer bankruptcy system.

We conclude by using the model to conduct three policy counterfactuals. First, we ask how the effect of ex-post debt relief changes in normal times when the zero lower bound does not bind. We find that even with a relatively aggressive monetary policy response, debt relief continues to have positive effects in both regions and in both sectors. Second, we ask how the effect of debt relief changes with the size of the relief provided to borrowers. We find that the debt relief multiplier is initially invariant to the size of the relief provided to borrowers, but eventually falls as the size of debt relief grows large due to the concavity of borrowers' consumption functions. Finally, we ask how the effect of expost debt relief changes with the location of the savers that pay for the relief provided to borrowers. We find that the debt relief multiplier is invariant to the location of these savers, as savers smooth consumption in response to wealth transfers no matter where they are located.

Our results are related to a literature showing how deteriorating household balance sheets can 
amplify an economic downturn. Hall (2011), Eggertsson and Krugman (2012), Guerrieri and Lorenzoni (2017) and Midrigan and Philippon (2018) illustrate this mechanism theoretically. Mian, Rao and Sufi (2013) show an empirical link between the fall in house prices and household consumption in the United States during the Great Recession, and Mian and Sufi (2014b) study the subsequent effects on non-tradable and tradable employment. Most recently, Verner and Gyongyosi (2018) show that an increase in debt burdens led to higher default rates and a collapse in spending in Hungary, translating into a worse local recession and depressed house prices. ${ }^{3}$ We contribute to this literature by showing that the ex-post debt forgiveness provided by the consumer bankruptcy system stabilized employment levels in the United States during the Great Recession. Our findings are consistent with theoretical work showing that interventions in debt markets can increase welfare when the economy is depressed (Farhi and Werning 2016b, Korinek and Simsek 2016), as well as work arguing that the consumer bankruptcy system should include a macroprudential objective (Dávila 2016, Auclert and Mitman 2018). ${ }^{4}$

Our paper is also related to recent work estimating the effects of mortgage modifications made during the Great Recession. Agarwal et al. (2017) show that HAMP decreased the number of foreclosures and increased durable spending, but that the program only reached one-third of targeted households due to its uneven implementation across lenders. Building on this work, Ganong and Noel (2018) show that the principal write-downs made through HAMP had no impact on underwater borrowers, while the program's maturity extensions had a large positive impact. Finally, Piskorski and Seru (2018) find that regional variation in the extent and speed of the post-crisis recovery is strongly related to frictions affecting the pass-through of lower interest rates and debt relief to households. These frictions nearly doubled the time it took for house prices, consumption, and employment to recover after the financial crisis. We complement the work in this literature by showing that the unsecured debt relief provided by the consumer bankruptcy system also boosted aggregate demand during the Great Recession, and by explicitly addressing the theoretical issue of how to aggregate cross-regional results.

In another related contribution, Hausman, Rhode and Wieland (2019) analyze the effect of redis-

\footnotetext{
${ }^{3}$ The relative debt shock multipliers implicit in Verner and Gyongyosi (2018) are quantitatively similar to our relative debt relief multipliers. For example, the headline estimates in Verner and Gyongyosi (2018) translate into a relative debt shock multiplier of around 1.5 on auto spending and -0.08 on aggregate unemployment, while our calibrated model implies a relative debt relief multiplier of 0.8 on total consumption and 0.2 on aggregate employment. These results suggest that the aggregate effects of unexpected variation in the level of consumer debt may be similar over time and across countries.

${ }^{4}$ See McKay and Reis (2016) and Kekre (2018) for a similar argument related to the macroprudential objective of unemployment insurance.
} 
tribution from dollar devaluation during the early 1930s. They show that this redistribution led to a substantial economic response of farmers, especially in areas with a high farm debt burden, and they use a general equilibrium framework to scale up their estimates. Our work focuses on a different time period and relies on explicit direct transfers to indebted consumers via debt relief, rather than indirect increases in the prices of the products that they sell. Our results are complementary in that we also find that redistribution towards indebted consumers can have large aggregate effects during a recession.

Finally, our paper builds on the local fiscal multipliers literature that has convincingly shown that, while cross-state comparisons allow one to use plausibly exogenous variation to draw conclusions about the effects of shocks or policies on regional economies, a general equilibrium model is needed to draw conclusions about the aggregate effect of these shocks or these policies (e.g., Nakamura and Steinsson 2014; Farhi and Werning 2016a; Suárez Serrato and Wingender 2016; ChodorowReich Forthcoming; Martin and Philippon 2017; House, Proebsting and Tesar 2017; Dupor et al. 2019; Corbi, Papaioannou and Surico Forthcoming). The typical approach in this literature is to calculate a relative multiplier from cross-sectional variation, and then use a structural model to discuss the relationship to the aggregate multiplier. We build on this literature by applying these concepts to the case of debt relief, by showing formally why the relative and aggregate effects differ by the magnitude of the spillover effect in the control region, and by making use of both tradable and non-tradable employment outcomes as "identified moments."

The remainder of the paper is structured as follows. Section I provides a brief overview of the consumer bankruptcy system and describes our data and empirical strategy. Section II presents our difference-in-differences estimates of the effect of bankruptcy protections on employment and credit outcomes during the financial crisis. Section III establishes the relationship between relative multipliers and aggregate multipliers, and calculates relative debt relief multipliers in our context. Section IV develops our general equilibrium model and performs counterfactuals. Section V concludes. 


\section{Background, Data, and Empirical Design}

This section summarizes the most relevant information regarding our institutional setting and data, describes our empirical strategy, and provides support for the baseline assumptions required for our difference-in-differences estimator.

\section{A. Background}

Under the U.S. bankruptcy code, eligible households can discharge most unsecured debts by filing for Chapter 7 bankruptcy, after relinquishing assets above state-specific exemption limits. The U.S. bankruptcy system allows most households to choose between Chapter 7 bankruptcy, which requires households to forfeit all assets above their state's exemption limits in exchange for a discharge of debt and protection from collection efforts, and Chapter 13 bankruptcy, which adds the protection of most assets in exchange for the partial repayment of debt. Chapter 13 filers are required to repay at least as much as creditors would have received under Chapter 7, meaning that the state-specific Chapter 7 exemption limits also directly impact the generosity of Chapter 13 in each state. Chapter 7 is also chosen by approximately 75 percent of bankruptcy filers in the United States, as most filers have relatively low levels of non-exempt wealth. For these reasons, we focus on the Chapter 7 bankruptcy exemption limits for the remainder of the paper. ${ }^{5}$

Bankruptcy exemptions also provide a natural threat point in settlements with creditors, thereby providing a form of informal debt relief even when households do not formally file for bankruptcy. In our context, these settlements are most likely to occur after borrowers become delinquent on a debt, but before they formally file for bankruptcy protection. These settlements can be the result of borrowers contacting the creditor directly, but can also be arranged by non-profit credit counselors or for-profit debt settlement companies working on behalf of the borrowers, particularly when borrowers are delinquent on several debts simultaneously (Wilshusen 2011). The bankruptcy system provides a natural threat point in these settlements, as households can always threaten to file for Chapter 7 protection as an outside option. Consistent with this idea, Mahoney (2015) shows that uninsured households with a greater financial cost of bankruptcy make higher out-of-pocket medical payments, conditional on the amount of care received.

\footnotetext{
${ }^{5}$ The 2005 Bankruptcy Abuse Prevention and Consumer Protection Act (BAPCPA) changed several relevant features of the U.S. bankruptcy code. First, BAPCPA increased filing fees and imposed mandatory credit counseling for both chapters. Second, BAPCPA reduced the generosity of the bankruptcy code by restricting Chapter 7 to households that passed an income or repayment test, making it more difficult for high-income households to shield their home equity in through the bankruptcy system. These changes should not influence our results, however, as they were applied uniformly across states prior to the onset of the financial crisis.
} 
The formal and informal debt relief provided by the consumer bankruptcy system during economic downturns is economically large, both in absolute terms and compared to other social insurance programs. The average Chapter 7 bankruptcy filer between 2008 and 2010 discharged more than $\$ 94,000$ in unsecured debt, with more than 2.8 million households filing for Chapter 7 over this time period (U.S. Courts 2017, see also Figure 1). In other words, Chapter 7 helped bankruptcy filers formally discharge more than $\$ 263$ billion in unsecured debt during the Great Recession. The informal debt relief provided by the bankruptcy system, as well as the secured debt discharges through Chapter 7 and both the unsecured and secured debt discharges through Chapter 13, only add to this total. By comparison, UI payouts totaled $\$ 319.1$ billion over this time period (Whittaker and Isaacs 2016), while the payouts made by the Home Affordable Modification Program (HAMP) and two other debt relief programs under the umbrella of the Troubled Asset Relief Program (TARP) totaled \$106 billion (U.S. Treasury 2018).

Our empirical strategy exploits the considerable variation in the generosity of the bankruptcy exemptions across states. Appendix Table A1 shows Chapter 7 exemptions by state and category in 2007, just prior to the onset of the financial crisis. The variation is particularly large for the home equity exemptions, the largest and most important exemption category. Seven states allow households to protect an unlimited amount of home equity in bankruptcy, for example, while three states do not allow households to protect any home equity. There is also variation in the other exemption categories, albeit at much lower levels, with vehicle exemptions ranging from $\$ 0$ in 12 states to at least $\$ 10,000$ in three states, savings exemptions ranging from $\$ 0$ in 39 states to at least $\$ 1,000$ in seven states, and wildcard exemptions, which can be applied to any asset, ranging from $\$ 0$ in 20 states to at least $\$ 10,000$ in three states.

The variation in homestead exemptions has also been remarkably stable over time, with the initial variation in homestead exemption amounts largely emerging as states formalized their state-level approaches to bankruptcy in the late nineteenth century, in ways that are likely unrelated to current state characteristics (Goodman 1993; Skeel 2001). The population-weighted correlation between the 2007 and 1991 homestead exemption ranks, for example, is 0.88, while the correlation between the 2007 and 1920 homestead exemption ranks is 0.60 among the 38 states with exemptions in both time periods (see Appendix Figure A1). Consistent with this idea, we show below that most state characteristics are uncorrelated with state bankruptcy protections in the years just prior to the financial crisis. 


\section{B. Data and Summary Statistics}

Our empirical analysis uses information from county-level employment and inflation data, and individuallevel credit data aggregated to the county level.

County Employment Data. We measure employment outcomes between 2001 and 2013 using countylevel data from the Quarterly Census of Employment and Wages (QCEW). The data are derived from individual-level Unemployment Insurance (UI) tax files submitted by each state to the Bureau of Labor Statistics (BLS). The BLS uses these individual-level files to calculate quarterly employment by county and industry. ${ }^{6}$

There are two important challenges in constructing consistent employment measures over our sample period using the QCEW data. The first is that the industry codes in the QCEW data change from NAICS 2002 to NAICS 2007, and then to NAICS 2012 over this time period. We address this issue using the publicly-available NAICS code crosswalks and the Mian and Sufi (2014b) industry definitions to create a consistent time series of employment in each county and industry. ${ }^{7}$ The second challenge is that the QCEW employment data are suppressed in certain county-industry-year-quarter bins for confidentiality reasons. Following Mian and Sufi (2014b), we address this issue by imputing employment in suppressed county-industry-year-quarter bins using information from the County Business Patterns (CBP) data. ${ }^{8}$

We use the cleaned and harmonized QCEW employment data to construct a panel dataset for non-tradable employment, tradable and other employment, and total employment. We follow the industry groupings defined in Mian and Sufi (2014b), where non-tradable employment is defined as the retail and restaurant sectors, tradable employment is defined as industries with sufficiently large imports and exports from the rest of the United States, and other employment is defined as all other industries excluding the construction sector. In our analysis, we combine tradable and other employment into a single category, which we refer to as "tradable employment" for simplicity. We normalize all employment measures by the number of working-age adults in each county to account

\footnotetext{
${ }^{6}$ See www.bls.gov for additional information on the underlying data.

${ }^{7}$ The publicly-available NAICS crosswalks lack an exact one-to-one mapping of NAICS codes across all years. To address this issue, we first construct the Mian and Sufi (2014b) industry definitions of non-tradable, tradable, and other industries in each set of three-digit NAICS codes. We then assign the definitions to 2002 NAICS and 2012 NAICS for all industries where the definitions perfectly align. Then, when the mappings disagree (e.g., a tradable and non-tradable industry are both mapped to the same case), we manually choose an industry definition in cases when the definitions disagree. Our NAICS crosswalk is available upon request.

${ }^{8}$ Payroll data is also available from the QCEW and CBP. However, there is no way to impute suppressed cells in the payroll data, and, as a result, there is substantial measurement error in these data that varies by employment density.
} 
for any secular population trends over the years we examine. Information on population totals comes from the U.S. Census.

Credit Bureau Data. We measure credit outcomes between 2001 and 2013 using records from the Equifax / New York Fed Consumer Credit Panel (CCP), a representative five percent random sample of all individuals in the U.S. with credit files. ${ }^{9}$ Like other credit report data, the CCP data are derived from public records, collection agencies, and trade lines data from lending institutions. The data include a comprehensive set of consumer credit outcomes, including information on credit scores, unsecured credit lines, auto loans, and mortgages. The data also include year of birth and geographic location at the ZIP-code level. We identify homeowners as any individuals who currently have mortgage or home equity debt outstanding, or those individuals who have had mortgage debt in the eight years prior to 2007. ${ }^{10}$ No other demographic information is available at the individual level. We aggregate these data to the county level unless otherwise mentioned. See Avery et al. (2003) and Lee and Van der Klaauw (2010) for additional details on the underlying credit report data.

House Price Data. County-level house price indices between 2001 and 2013 come from CoreLogic. We use quarterly data from 1240 counties over the sample period. We also use zipcode-level house price estimates from Zillow.com when calculating home equity values.

Inflation Data. Price index data comes from the BLS Consumer Price Index (CPI), measured at the Metropolitan Statistical Area (MSA) level for 26 MSAs at the half-year frequency. Following Mian, Sufi and Verner (2017), we use these price indices to construct annualized inflation measures from 2001 to 2013 in three categories: overall, non-tradable, and tradable inflation. We use the All Items index for overall inflation, the Services index to measure non-tradable inflation, and Commodities to measure tradable inflation. We then use an MSA-to-county crosswalk to map these measures to our dataset.

\footnotetext{
${ }^{9}$ The credit bureau data do not include the approximately 22 million adults (nine percent of adults) in the United States without credit files, or information on non-traditional forms of credit such as payday lending, pawn shops, and borrowing from relatives. The data are therefore likely to be less representative on the behaviors and outcomes of very poor populations.

${ }^{10}$ Our measure of homeownership will not include individuals whose homes are fully owned. In our data, 48 percent of individuals are defined as homeowners, compared to around 68 percent in the Survey of Consumer Finances (SCF). Tai (2017) shows that the majority of this discrepancy in homeownership comes from individuals who are 55 and older.
} 
Summary Statistics. Table 1 provides descriptive statistics for key outcomes before, during, and after the financial crisis. We report the average percentage change in employment and credit outcomes for $2001 q 1$ to $2007 q 4,2007 q 4$ to $2010 q 4$, and $2010 q 4$ to $2013 q 4$, as well as the change in consumer price and house price indices over the same time periods. Total employment, scaled by working-age population, declined slightly prior to the financial crisis, falling by 2.57 percent from 2001q1 to 2007q4. Employment then fell sharply during the crisis, dropping by 7.41 percent from 2007q4 to 2010q4, before recovering by 4.06 percent from $2010 \mathrm{q} 4$ to $2013 \mathrm{q} 4$. Non-tradable and tradable employment both followed similar trends as overall employment, although non-tradable employment increased prior to the crisis.

Debt charge-offs were approximately unchanged from 2001q1 to 2007q4, before increasing sharply by $\$ 124.78$ per person from $2007 q 4$ to $2010 q 4$. Charge-offs then declined by $\$ 241.67$ per person from $2010 \mathrm{q} 4$ to $2013 \mathrm{q} 4$, reflecting both the tighter credit markets and improved economic conditions during this time period. Formal bankruptcy and foreclosure rates increased by 0.158 and 0.145 percentage points, respectively, before the financial crisis, with much larger increases for foreclosures from 2007q4 to 2010q4. Bankruptcy rates then fell by 0.91 percentage points from $2010 q 4$ to $2013 q 4$, with foreclosure rates increasing by 0.057 percentage points. Credit card limits grew from 2001q1 to 2007q4 by almost $\$ 3,000$ per person, but substantially declined by nearly the same amount from 2007q4 to 2010q4, followed by a recovery of $\$ 955$ per person from 2010q4-2013q4. Credit card debt also increased slightly from 2001q1 to 2007q4, but fell both during and after the financial crisis. Consistent with the results in Foote, Loewenstein and Willen (2016) and Adelino, Schoar and Severino (2018), mortgage credit increased sharply prior to the financial crisis, with a change of more than $\$ 26,000$ per person from 2001q1 to 2007q4. Mortgage credit increased by another $\$ 1,839$ per person from 2007q4 to 2010q4, before falling by $\$ 3,977$ per person from $2010 q 4$ to $2013 q 4$.

In contrast to the economically large changes in employment and credit outcomes, consumer prices were relatively stable over this time period. Prices on all consumer goods, for example, increased by 21.8 percent from 2001q1 to 2007q4 (an annualized rate of 2.4 percent), 5.0 percent from $2007 q 4$ to $2010 q 4$ (an annualized rate of 1.4 percent), and 6.4 percent from 2010q4 to 2013q4 (an annualized rate of 2.1 percent). Non-tradable and tradable prices follow a similar trend, although nontradable prices increased less from 2001q1 to 2007q4 compared to tradable prices. House prices, however, increased by over 40 percent from 2001q1 to 2007q4, before falling by roughly 22 percent from $2007 q 4$ to $2010 q 4$. House prices then partially recovered after the crisis, increasing by 11 percent from 
$2010 q 4$ to $2013 q 4$.

\section{Empirical Design}

We estimate the relative impact of ex-post debt forgiveness across states using a difference-in-differences design that compares outcomes in states with more generous bankruptcy exemptions (the "treated" states) to states with less generous exemptions (the "control" states). Our difference-in-differences design explicitly controls for any pre-existing differences between states with more and less generous exemptions, such as any time-invariant effects of bankruptcy protections on credit demand and credit supply (Gropp, Scholz and White 1997; Severino and Brown 2017). We also explicitly control for any common time effects of the financial crisis, such as the large negative aggregate demand shock for both tradable and non-tradable goods. The key identifying assumption for our difference-in-differences specification is that, in the absence of any variation in bankruptcy exemptions, outcomes in states with more and less generous exemptions would have evolved in parallel during the Great Recession. This "parallel trends" assumption allows us to interpret the difference between states with more and less generous bankruptcy exemptions during the financial crisis as the causal effect of more generous bankruptcy exemptions in the presence of a large aggregate shock, an assumption we provide extensive support for below.

Bankruptcy Protection Measure Calculation. We measure the generosity of bankruptcy protections in each state prior to the Great Recession using the average cost of filing for Chapter 7 bankruptcy in each state, $s$, using the pre-crisis bankruptcy asset exemptions in state $s$ and the balance sheets of individuals in all other states, $-s$. By using the pre-crisis bankruptcy exemptions in each state, our bankruptcy protection measure removes any endogenous changes to the exemptions made during the financial crisis. By using balance sheets of individuals in all other states, our protection measure also removes any potential effects of the bankruptcy exemptions on household characteristics such as asset holdings or income. Our bankruptcy protection measure therefore isolates the generosity of each state's bankruptcy exemptions, purged of any variation due to the characteristics of states' actual residents and any changes to the exemption laws that states made in response to the crisis. ${ }^{11}$

\footnotetext{
${ }^{11}$ Our bankruptcy protection measure is closely related to the "simulated instrument" measure developed by Currie and Gruber (1996) to isolate exogenous variation in Medicaid eligibility across states, and adapted by Mahoney (2015) to isolate exogenous variation in the generosity of bankruptcy exemptions across states. Our measure is also closely related to the financial cost of bankruptcy measure developed by Fay, Hurst and White (2002). Our measure differs from the bankruptcy protection measures used in Fay, Hurst and White (2002) and Mahoney (2015) in two ways. First, we are able to directly measure balance sheet values for some assets, rather than relying on assets and liabilities from surveys as in Fay, Hurst and White (2002) and Mahoney (2015). Second, Mahoney (2015) also exploits within-state variation based on average differences
} 
We calculate our bankruptcy protection measure in three steps. First, we calculate the financial cost of filing Chapter 7 bankruptcy, $B_{i}^{s}$, for individual $i$ in state $s$ using individual-level data on both asset values and unsecured debts. Following Fay, Hurst and White (2002) and Mahoney (2015), we define the financial cost of bankruptcy for individual $i$ in state $s$ as the value of $i$ 's assets that can be seized under Chapter 7 bankruptcy in state $s$ minus the value of any debts that can be discharged under Chapter 7 and plus a common filing fee:

$$
B_{i}^{s}=\text { Seizable Assets }_{i s}-\text { Dischargeable Debt }_{i}+\text { Filing Cost }
$$

where an individual's seizable assets Seizable Assets $_{i s}$ is the sum of individual $i$ 's seizable home equity, vehicle equity, retirement savings, financial assets, and other assets:

$$
\begin{aligned}
\text { Seizable Assets }_{i s} & =\max \left(\text { Home Equity }_{i}-\text { Homestead Exemption }_{s^{\prime}} 0\right) \\
& +\max \left(\text { Auto Equity }_{i}-\text { Auto Exemption }_{s^{\prime}} 0\right) \\
& +\max \left(\text { Retirement Assets }_{i}-\text { Retirement Exemption }_{s^{\prime}} 0\right) \\
& +\max \left(\text { Financial Assets }_{i}-\text { Financial Assets Exemption }_{s^{\prime}} 0\right) \\
& +\max \left(\text { Other Assets }_{i}-\text { Wildcard Exemption }_{s^{\prime}} 0\right)
\end{aligned}
$$

We measure dischargeable debt using the level of unsecured debt from credit cards in the CCP credit bureau data described above; home equity using mortgage balances from the CCP credit bureau data and zipcode-level housing values from Zillow; and vehicle equity, retirement assets, and other financial assets using the 2005 and 2007 PSID Wealth Files datasets, excluding households with at least one individual who is enrolled in public insurance or is over the age of 65 in the survey year. We use state bankruptcy exemption laws from 2007 for all asset categories to remove any endogenous changes to the exemptions made during the financial crisis. ${ }^{12}$

Second, we calculate the average cost of filing for bankruptcy in state $s, \bar{B}_{s}$, using the household

in asset holdings across different age, race, and education cells. We ignore this within-state heterogeneity, both because we are interested in the aggregate effect of the bankruptcy laws, and because are unable to measure across-group heterogeneity in asset holdings using our data.

${ }^{12}$ In robustness checks below, we show that we obtain similar estimates when using state exemption laws in 1991, the earliest year for which information on exemption laws is available for all 50 states, and well before either the financial crisis or the pre-crisis increase in house prices and employment. 
characteristics of individuals in all other states $-s$ :

$$
\bar{B}_{s}=\left|I_{-s}\right|^{-1} \sum_{j \in I_{-s}} B_{j}^{s}
$$

where $I_{-s}$ is the entire sample of individuals in all states excluding state $s$, and $B_{j}^{s}$ is the financial cost of bankruptcy measure for individual $j$ if they were subject to the laws of state $s$. By using household characteristics of individuals in all other states, $-s$, we make sure that the variation in $\bar{B}_{s}$ is only driven by the differences in exemption laws across states, and therefore remove any potential effects of the bankruptcy exemptions on household characteristics such as asset holdings or income.

Finally, we rescale our bankruptcy protection measure to have a mean of zero and standard deviation of one for simplicity in all our regression specifications. We also multiply our rescaled measure, $\hat{B}_{s}$, by negative one so that we can interpret positive numbers as a higher level of bankruptcy protection:

$$
\hat{B}_{s}=-\frac{\bar{B}_{s}-\mathbb{E}_{s}\left[\bar{B}_{s}\right]}{\sqrt{\operatorname{Var}_{s}\left(\bar{B}_{s}\right)}}
$$

Bankruptcy Protection Variation. Appendix Figure A2 plots the financial cost of bankruptcy by state $\bar{B}_{s}$, or our bankruptcy protection measure before we multiply by negative one and rescale to have a mean of zero and a standard deviation of one. There is considerable geographic variation in the average financial cost of bankruptcy across states, with a population-weighted standard deviation of $\$ 60,000$ on a base of $\$ 254,000$. The state with the lowest financial cost of bankruptcy is Kansas, at $\$ 154,000$, and the highest is Virginia, at $\$ 337,000$. The difference between the 10th and 90th percentile of the state-level distribution is similarly large, at $\$ 163,000$. Moreover, high- and low-cost regions are not exclusively located in any area of the United States.

Appendix Figure A3 plots the financial cost of bankruptcy in each state against the relative generosity of the homestead, vehicle, savings, and wildcard exemptions in each state. We also plot the line of best fit weighted by state population. The variation in the financial cost of bankruptcy across states is almost entirely explained by the state homestead exemptions laws, with a correlation of -0.94 between the overall financial cost of bankruptcy, and homestead exemption ranks. In contrast, the correlation between the financial cost of bankruptcy and vehicle exemptions is only -0.10 , while the correlations with savings and wildcard exemptions are only -0.07 and 0.04 , respectively.

We observe a similar pattern in Appendix Table A1, which lists the financial cost of bankruptcy separately for seizable home equity and other seizable financial assets for each state. The variation in 
the financial cost of bankruptcy for home equity is approximately ten times larger than the variation in the financial costs for any other asset, with a population-weighted standard deviation of $\$ 58,999$ on a base of $\$ 97,388$ for seizable home equity, but only $\$ 6,473$ on a base of $\$ 159,841$ for other seizable financial assets. The difference between the 10th and 90th percentile of the state-level distribution is similarly large for seizable home equity at $\$ 160,172$, compared to only $\$ 11,149$ for other seizable financial assets. ${ }^{13}$

Empirical Specification and Identifying Assumptions. For a given outcome, $Y$, our difference-indifferences regression specification takes the form:

$$
Y_{i t}=\alpha_{i}+\lambda_{t}+\sum_{\substack{u=2001 \\ u \neq 2007}}^{2013} \beta_{u} 1\left(\text { Year }_{t}=u\right) \hat{B}_{s(i)}+\sum_{\substack{u=2001 \\ u \neq 2007}}^{2013} \gamma_{u} 1\left(\text { Year }_{t}=u\right) X_{i}+\epsilon_{i t}
$$

where $\alpha_{i}$ are county fixed effects, $\lambda_{t}$ are year-quarter fixed effects, $\hat{B}_{s(i)}$ is our normalized measure of the generosity of bankruptcy protections for county $i$ in state $s$, and $X_{i}$ are potential time-invariant characteristics of county $i$ such as the housing supply elasticity measure from Saiz (2010). The estimated effects of $\hat{B}_{s(i)}$ and $X_{i}$ are allowed to be time-varying, with $\beta_{u}$ denoting the year-by-year impact of the bankruptcy protections each year, and $\gamma_{u}$ denoting the potential time-varying impact of other variables that might confound our estimates of the effects of the bankruptcy protections. ${ }^{14}$

In this specification, the $\beta_{u}$ coefficients can be interpreted as the relative impact of the bankruptcy protections in each year. We omit $2007, \beta_{2007}$, so that the other $\beta_{u}$ 's can be interpreted as relative to this pre-crisis baseline period. Our estimates of $\beta_{u}$ from 2008 to 2010 will therefore capture the relative short-run impact of the bankruptcy protections during the Great Recession, while the estimates of $\beta_{u}$ from 2011 to 2013 will capture the relative long-run impact of the protections during the recovery. As discussed in greater detail below, our estimates do not necessarily measure the aggregate impact of the bankruptcy protections during the crisis and recovery periods, as they difference out general equilibrium effects.

The identifying assumption for our difference-in-differences specification is that, in the absence of the Great Recession, the outcomes in states with more and less generous protections would have

\footnotetext{
${ }^{13}$ Retirement savings and financial assets (e.g., stock holdings) make up the vast majority of the other financial assets category. The median level of vehicle equity, for example, is less than $\$ 10,000$ in most states.

${ }^{14}$ We estimate Equation (1) using county-level data, not state-level data, as this allows us to use county-level controls that improve the precision of our estimates. We use state population weights in all regressions, however, meaning that our county-level estimates are approximately equal to the state-level estimates, but with lower residual variance.
} 
evolved in parallel. This parallel trends assumption implies that there are no other reasons why the Great Recession would impact more and less generous states differently.

To better understand what our identification assumption entails, Appendix Table A2 examines the state-level correlation between our bankruptcy protection measure and other variables that may have caused differential employment responses during the Great Recession. Panel A reports results for baseline employment outcomes, Panel B for baseline credit outcomes, and Panel C for baseline state characteristics, including Democratic vote shares, maximum unemployment benefits, demographics, sensitivity to the business cycle, per capita incomes, house prices, homeownership rates, housing supply elasticities, non-recourse laws, and predicted exposure to the financial crisis. Column 1 reports results using variables measured in 2001, the first year in our sample period. Column 2 reports results using variables measured in 2007, the year just before the onset of the financial crisis. In each panel and column, we report estimates from OLS regressions of the listed variable on our bankruptcy protection measure, weighted by state population, with robust standard errors. Statistically or economically significant estimates from these regressions do not necessarily imply a violation of our identifying assumption, as the county fixed effects $\alpha_{i}$ in our main specification will control for any time-invariant differences across geographic areas. What is critical is that any characteristics that differ across more and less generous states do not have a confounding time-varying effect on states' outcomes during the Great Recession. For example, our identifying assumption would be violated if states with more generous bankruptcy protections also had more generous UI benefits, and those more generous UI benefits had an independent impact on employment during the financial crisis.

Appendix Table A2 reveals no statistically or economically significant differences in the level of employment between areas with more and less generous bankruptcy protections. There are also no significant differences in credit outcomes between areas with more and less generous protections, with the exception of 2007 bankruptcy filings, which are 0.04 percentage points lower in areas with more generous bankruptcy protections. We also find remarkably few differences in the state-level characteristics in more and less generous areas. There are, for example, no differences in Democratic vote shares or the generosity of unemployment insurance between more and less generous areas, characteristics that partially capture states that are more likely to have responded to the Great Recession through automatic stabilizers or debt forgiveness (e.g., Di Maggio and Kermani 2017; Hsu, Matsa and Melzer 2018). We similarly observe no income or demographic differences between more and less generous areas, as well as no difference in the sensitivity of a states' employment with the national 
employment cycle. ${ }^{15}$ However, we do find a positive correlation between our bankruptcy measure and predicted exposure to local employment shocks during the Great Recession, measured using a shift-share approach at the three-digit NAICS industry level (e.g., Yagan 2017). ${ }^{16}$ We also find that areas with more generous protections have lower homeownership rates, although we find no differences in house prices, the housing supply elasticities discussed in Saiz (2010), or the non-recourse mortgage laws discussed in Ghent and Kudlyak (2011).

Based on these correlations, we can identify two potential confounding factors that may have led to differential employment responses during the Great Recession. First, areas with more generous bankruptcy protections were potentially less exposed to local unemployment shocks during the financial crisis, at least as measured by our shift-share measure. Second, areas with more generous bankruptcy protections had fewer homeowners, exactly the types of individuals who suffered the largest wealth shock during the crisis.

We partially test our identifying assumptions to assess whether the above factors (or others) are potential sources of bias. We do so in two complementary ways. First, we examine whether employment and credit outcomes evolve in parallel in states with more and less generous bankruptcy protections before the financial crisis. As discussed below, our non-parametric specifications show that outcomes for states with more and less generous bankruptcy protections move in close parallel during the pre-crisis period. These results give us confidence that our "control group" of less generous states is valid and that provides us with an accurate counterfactual for what would have happened to the "treatment group" of more generous states, despite the differences documented above.

Second, we examine whether our coefficient estimates change when we add controls for potential confounding variables interacted with time fixed effects. The added control variables interacted with time effects estimate the direct impact of these alternative economic channels during the Great Recession. If our point estimates remain consistent across specifications, then we are more confident that these potential confounding variables are not driving our main estimates. We present these robustness results in three complementary ways. First, we add controls for the supply elasticity of housing interacted with time fixed effects, and the pre-crisis share of homeowners in a county interacted with time

\footnotetext{
${ }^{15}$ We calculate the sensitivity of a states' employment with the national employment cycle, or "market beta," using the time series correlation between each state's employment growth and national employment growth from 1961 to 2001 and 1961 to 2007.

${ }^{16}$ Following Yagan (2017), we calculate exposure to local employment shocks using a shift-share approach and County Business Patterns data. Each area's shift-share shock is equal to the predicted 2006-2010 percentage change in that area's employment based on a combination of local industry composition and leave-one-out nationwide changes in employment by three-digit NAICS industry categories.
} 
fixed effects. This first set of controls tests for the potential confounding effect of the boom-bust cycle, as well as the differences in homeownership rates found in Appendix Table A2. ${ }^{17}$ Second, we add controls for demographic characteristics of the state as measured in 2007 interacted with year-quarter fixed effects, and the predicted exposure to local unemployment shocks during the Great Recession interacted with year-quarter fixed effects. This second set of controls tests whether the correlation between our bankruptcy protection measure and the predicted exposure to local unemployment shocks during the Great Recession in Appendix Table A2 is biasing our results. Finally, we rerun this last specification excluding the "sand states," or Arizona, California, Nevada and New Mexico. These states were particularly affected by the housing crisis and subsequent economic collapse, and hence we want to ensure that our results are not driven by this particular subset of states.

\section{Results}

In this section, we examine the relative short- and long-run effects of consumer bankruptcy protections across states using our difference-in-differences research design. We first analyze the relative effects of bankruptcy protections on employment, before turning to its relative effects on debt write-downs. We conclude by discussing the relative effects of bankruptcy protections on other credit outcomes and presenting additional robustness checks.

\section{A. Employment}

Panel A of Table 2 reports estimates of the impact of bankruptcy protections on employment from our parametric difference-in-differences specification that pools the effect of a one standard deviation increase in the generosity of bankruptcy protections for 2007q4-2010q4. Column 1 reports the crosscounty average and standard deviation of the change in the dependent variable from 2007q4-2010q4, the short-run crisis period, or 2010q4-2013q4, the long-run recovery period. Columns 2-5 report coefficients on the reduced form effect of a one standard deviation decrease in the log financial cost of filing for bankruptcy protection from 2007q4-2010q4. Column 2 reports estimates with only county and year-quarter fixed effects. Column 3 adds controls for the Saiz supply elasticity and share of the population who own a home for each county, both interacted with year-quarter fixed effects. Column 4 adds controls for the share of Democratic voters in 2004, the maximum unemployment insurance benefit, the share of college-educated individuals in a county, the share of the population that is under

\footnotetext{
${ }^{17}$ Controlling for an intermediate variable such as house price growth may create selection bias, as areas that do economically better due to bankruptcy debt relief may recover faster, and experience differential house price appreciation.
} 
the age of 45, the average debt-to-income ratio for the state in 2007, and the predicted exposure to local unemployment shocks during the Great Recession, all interacted with year-quarter fixed effects. Column 5 repeats the same specification excluding the "sand states" of Arizona, California, Nevada, and New Mexico. All regressions are weighted by county population as of 2007 and the standard errors are clustered at the state level to account for within-state correlation between the treatment variable and unobservable shocks (Bertrand, Duflo and Mullainathan 2004; Abadie et al. 2017).

We find that states with more generous bankruptcy protections had significantly smaller declines in local non-tradable employment during the financial crisis compared to states with less generous protections. Controlling for only county and year-quarter fixed effects, we find that a one standard deviation increase in our bankruptcy protection measure increases non-tradable employment by 0.499 percentage points, or 9.6 percent of the overall decline in non-tradable employment during this period (column 2). In our preferred specification that includes time-invariant housing controls interacted with year-quarter fixed effects, we find that a one standard deviation increase in our bankruptcy protection measure increases non-tradable employment by 0.399 percentage points, or 7.7 percent of the overall decline in non-tradable employment (column 3). The point estimates remain large and statistically significant when we add controls for state demographics and policies (column 4) or exclude the "sand states" (column 5). All of the results suggest that the more generous bankruptcy protections had an economically and statistically significant impact on non-tradable employment during the Great Recession, consistent with the consumer bankruptcy system acting as an automatic stabilizer.

In sharp contrast, we find an economically and statistically insignificant effect of the more generous bankruptcy protections on tradable employment. In our preferred specification that includes time-invariant housing controls interacted with year-quarter fixed effects, we find that a one standard deviation increase in bankruptcy protections increases tradable employment by only 0.086 percentage points from 2008q1-2010q4, or 1.0 percent of the overall decline in tradable employment during this period (column 3). We find similar results adding controls for state demographics and policies (column 4) or excluding the "sand states" (column 5), with none of the estimates suggesting economically significant effects of the bankruptcy system on tradable employment. We also find an economically and statistically insignificant effect on total employment during the crisis, as non-tradable employment makes up only about 23 percent of overall employment.

Figure 2 plots the estimated effect of the more generous bankruptcy protections from the nonparametric difference-in-differences shown in Equation (1) with log non-tradable employment, log 
tradable employment, and log total employment as dependent variables. We include time-invariant housing controls interacted with year-quarter fixed effects and cluster standard errors at the state level. The plots show no systematic relationship between the more generous bankruptcy protections and employment outcomes before the financial crisis, providing support for our parallel trends identifying assumption, and more generally corroborating our results on the timing and size of the effect.

Figure 2 also allows us to examine the relative long-run impact of the protections during the recovery. The effects on non-tradable employment are persistent throughout the recovery period, with a roughly 0.85 percent difference between the more and less generous states in 2011, 2012, and 2013. Non-tradable employment increased by an average of 5.3 percentage points over this time period, meaning that effects in percentage terms are similar in both the crisis and recovery periods. Panel B of Table 2 reports parametric difference-in-differences estimates for the recovery period, revealing that a one standard deviation increase in bankruptcy generosity increases non-tradable employment by 0.842 percentage points from 2011 to 2013, or 15.9 percent of the overall increase in non-tradable employment during this period (column 3). These persistent effects are difficult to justify in standard models of aggregate demand, which imply that the effect of transitory demand shocks should die out over time. We return to this issue in Section IV.G. ${ }^{18}$

Both Figure 2 and Table 2 suggest little impact of the bankruptcy protections on tradable employment during the recovery period, consistent with our findings for the short run. In our preferred specification that includes time-invariant housing controls interacted with year-quarter fixed effects, we find that, over this recovery period, a one standard deviation increase in the bankruptcy protection measure actually decreases tradable employment by 0.075 percentage points, or 2.0 percent of the overall change in tradable employment during this period (column 3). We also find an economically and statistically insignificant effect on total employment during this time period, again because of the small share of non-tradable employment.

\section{B. Debt Write-Downs}

We measure debt write-downs using the charge-offs that occur when seriously derogatory debts are removed from individuals' credit reports. Charge-offs do not include medical debt held by hospitals (e.g., Mahoney 2015), mortgage debt on second homes with negative equity (e.g., Ganong and Noel 2018), and payday loans (e.g., Dobbie and Skiba 2013), meaning that we will understate the impact

\footnotetext{
${ }^{18}$ The long-lasting effects of the bankruptcy protections on non-tradable employment throughout the recovery period are broadly consistent Verner and Gyongyosi (2018), who find persistent effects of foreign currency debt exposure on employment in Hungary.
} 
of bankruptcy protections to the extent that these debts are also written off due to the more generous protections. We return to this issue below when calculating the relative debt relief multiplier.

Table 3 reports estimates of the impact of bankruptcy protections on annual debt write-downs from our parametric difference-in-differences specification that pools the effect of a one standard deviation increase in the generosity of bankruptcy protections for 2007q4-2010q4 and 2010q4-2013q4. Figure 3 plots the estimated effect of the more generous bankruptcy protections from the non-parametric difference-in-differences shown in Equation (1).

Consistent with the employment results in Table 2, states with more generous bankruptcy protections had significantly larger increases in debt write-downs during the financial crisis compared to states with less generous bankruptcy protections. In our preferred specification that includes timeinvariant housing controls interacted with year-quarter fixed effects, we find that a one standard deviation increase in our bankruptcy protection measure increases annual debt write-downs from 2008q1$2010 q 4$ by $\$ 54.50$, or 43.7 percent of the overall increase in debt write-downs during this time period (column 3). The point estimates remain large and statistically significant when we add controls for state demographics and policies (column 4) or exclude the "sand states" (column 5), with all of the results suggesting that the more generous bankruptcy protections had an economically and statistically significant impact on debt write-downs during the Great Recession. We also find much larger effects for homeowners, at $\$ 80.46$, compared to renters, at $\$ 22.58$, consistent with the idea that the homestead exemptions were a particularly important source of debt forgiveness during the financial crisis and the most important source of variation in our bankruptcy protection measure (see Appendix Figure $\mathrm{A} 3)$.

Figure 3 shows no pre-trends in debt write-downs before the financial crisis, with a sharp increase in debt write-downs in 2008, consistent with the employment results. The effect of the bankruptcy protections on write-downs declines during the recovery period, however, with an estimated effect of only $\$ 33.69$ for the full sample during this time period. These results are consistent with the bankruptcy system providing significant debt forgiveness to borrowers during the financial crisis, with a much more limited impact during the recovery period.

\section{Additional Credit Outcomes and Robustness Checks}

Additional Credit Outcomes. Appendix Table A3 reports estimates of the impact of bankruptcy protections on other credit market outcomes in both the short- and long-run. There are no clear theoretical 
predictions for other credit outcomes, including bankruptcy filing rates, due to the offsetting effects of the greater availability of debt forgiveness and the improved local economic conditions documented above. In fact, we find little impact of the more generous bankruptcy protections on bankruptcy filing rates in either the crisis or recovery period. There is also no discernible impact on credit card limits in either time period, with insignificant effects on credit card debt during the crisis and modest negative effects during the recovery period. We also find a modest impact of more generous bankruptcy protections on mortgage debt in some, but not all, specifications in both time periods. Taken together, these results suggest there may have been a minor contraction in borrowing limits due to the increase in debt write-downs, but that any contraction was small compared to the nationwide fall in borrowing observed during the financial crisis.

The only credit outcome significantly impacted by the more generous bankruptcy protections during the financial crisis is foreclosure rates, which increase by 0.257 percentage points from 2008q12010q4 and 0.401 percentage points from 2011q1-2013q4 in our preferred specification that includes time-invariant housing controls interacted with year-quarter fixed effects. The increase in foreclosure rates may be due to strategic incentives to enter foreclosure on one's secondary home because of the benefit of preserving one's primary assets against creditors. ${ }^{19}$

Additional Robustness Checks. Appendix Tables A5 and A6 present results using state homestead exemptions in 1991, the earliest year for which information on exemption laws is available for all 50 states and well before either the financial crisis or the pre-crisis increase in house prices and employment. We find consistently positive results for non-tradable employment across all specifications, but the estimates are smaller in magnitude and statistically insignificant in some specifications, likely because the additional noise in our bankruptcy protection measure attenuates the estimates downward. We also find positive and statistically significant results for debt write-downs, although the estimates are again smaller than our main results. We interpret these results as supporting our conclusion that more generous bankruptcy protections increase non-tradable employment and debt writedowns, even when using noisier historical proxies of bankruptcy protection.

\footnotetext{
${ }^{19}$ It is also possible that the increase in foreclosure rates is driven by a confounding variable, such as a differential change in house prices in more and less generous areas. We explore this possibility in Appendix Table A4, where we report estimates of the impact of bankruptcy protections on log house prices. We find that areas with more generous bankruptcy protections experienced a larger fall in house prices in both the crisis period, and in the recovery, but this fall is only statistically significant once we control for state-level policies and the shift-share shock (columns 4 and 5). These declines in house prices in the presence of higher employment numbers are potentially a consequence of the foreclosure effects documented above, and are likely due to the strategic incentive to enter foreclosure on one's second home.
} 


\section{Recovering Aggregate Effects from Reduced-Form Estimates}

We interpret the differences-in-differences estimates in the previous section as the relative effect of an increase in ex-post debt relief across states, holding fixed any common general equilibrium effects. In this section, we develop a simple general equilibrium framework to relate these differences-indifferences estimates to the macroeconomic causal effect of interest, the aggregate effect of ex-post debt relief on employment. We then calculate "regional debt relief multipliers" in our context using the ratio of our difference-in-differences estimates for employment and debt write-downs, as suggested by our framework.

\section{A. Macro Treatments and Difference-in-Differences Estimates}

Consider a general equilibrium model with two symmetric regions $i \in\{H, F\}$, Home and Foreign. Suppose that the model is approximately linear in aggregate variables such as debt relief and total factor productivity (TFP). ${ }^{20}$ Consider a macroeconomic treatment $\Delta_{i, t}$ applied to region $i$ at time $t$. In our application, $\Delta_{i, t}$ will be debt relief, but $\Delta_{i, t}$ could also refer to local government spending as in the local fiscal multipliers literature, for example. Assume that this treatment affects macroeconomic variables only contemporaneously. That is, assume that the treatment features no aggregate anticipation or persistence. ${ }^{21}$ With this structure, a given outcome (such as log employment) $Y_{i, t}$ in region $i$ at time $t$ can be represented, to a first-order approximation, as:

$$
Y_{i, t}=\alpha_{i}+\lambda_{t}+\mathcal{M}_{H} \Delta_{i, t}+\mathcal{M}_{F} \Delta_{-i, t}
$$

where $\Delta_{i, t}$ denotes treatment in region $i$ per person in region $i$. Equation (2) expresses the outcome $Y_{i, t}$ as the sum of a region fixed effect $\alpha_{i}$ representing the time-invariant steady state level of the outcome, a time fixed effect $\lambda_{t}$ representing any common shocks such as nationwide variation in preferences or TFP, and the causal aggregate effect of the treatment on region $i$, which is the response to the treatment in both the home and foreign region $\mathcal{M}_{H} \Delta_{i, t}+\mathcal{M}_{F} \Delta_{-i, t}$. The home multiplier $\mathcal{M}_{H}$ represents the causal effect of home treatment $\Delta_{i, t}$ on home outcome $Y_{i, t}$, including any general equilibrium effects. Similarly, the foreign multiplier $\mathcal{M}_{F}$ represents the causal effect of foreign treatment $\Delta_{-i, t}$ on home out-

\footnotetext{
${ }^{20}$ Most solution methods log-linearize the model to first order and therefore assume this explicitly.

${ }^{21}$ This is true of government spending changes in standard Neoclassical models, and will be approximately true of debt relief in our model below. The general first-order equation for potential outcomes, taking into account anticipation and persistence, is $Y_{i, t}=\gamma_{i}+\lambda_{t}+\sum_{s=-\infty}^{\infty} \mathcal{M}_{H, s} \Delta_{i, t+s}+\sum_{s=-\infty}^{\infty} \mathcal{M}_{F, s} \Delta_{-i, t+s}$. Limited anticipation and persistence allow us to simplify this equation using $\mathcal{M}_{H, s}=\mathcal{M}_{F, s}=0$ for $s \neq 0$. This hypothesis is not necessary for our results, but allows us to simplify the discussion by focusing on the impact effect of the debt relief shock and focusing on the two contemporaneous multipliers $\mathcal{M}_{H}$ and $\mathcal{M}_{F}$.
} 
come $Y_{i, t}$. The model's symmetry between regions implies that $\mathcal{M}_{H}$ and $\mathcal{M}_{F}$ do not depend on $i .^{22}$ As we now show, the spillover term $\mathcal{M}_{F} \Delta_{-i, t}$ leads to the disconnect between cross-sectional estimates provided by a difference-in-differences design and the causal effect of interest from a macroeconomic perspective.

Since the regions are symmetric, aggregate treatment per person is equal to $\Delta_{t} \equiv \frac{1}{2} \sum_{i} \Delta_{i, t}$. We can therefore rewrite Equation (2) as:

$$
Y_{i, t}=\alpha_{i}+\underbrace{\lambda_{t}+2 \mathcal{M}_{F} \Delta_{t}}_{\tilde{\lambda}_{t}}+\left(\mathcal{M}_{H}-\mathcal{M}_{F}\right) \Delta_{i, t}
$$

Equation (3) implies that, given exogenous variation in treatment across states, a regression of outcome $Y_{i, t}$ on region fixed effect, time fixed effect and regional treatment $\Delta_{i, t}$ recovers a regression coefficient:

$$
\beta_{\Delta_{i, t} \rightarrow Y_{i, t}}=\mathcal{M}_{r e l}=\mathcal{M}_{H}-\mathcal{M}_{F}
$$

Another option to recover $\mathcal{M}_{\text {rel }}$ is to take the ratio of two difference-in-differences estimates. Specifically, let $t=0$ be a base period. Equation (2) shows that:

$$
\frac{\left(Y_{H, t}-Y_{H, 0}\right)-\left(Y_{F, t}-Y_{F, 0}\right)}{\left(\Delta_{H, t}-\Delta_{H, 0}\right)-\left(\Delta_{F, t}-\Delta_{F, 0}\right)}=\mathcal{M}_{r e l}=\mathcal{M}_{H}-\mathcal{M}_{F}
$$

Equations (4) and (5) show that these two common empirical specifications recover the difference between two causal effects $\mathcal{M}_{H}$ and $\mathcal{M}_{F}$. The reason is as follows. In an integrated economy, local macroeconomic changes such as treatment at home $\Delta_{H, t}$ simultaneously "treats" all regions. However, Equation (4) shows that a cross-sectional regression differences out the effect $\mathcal{M}_{F}$ of the treatment in the "control" (foreign) region. When $\mathcal{M}_{F}>0$, the relative multiplier $\mathcal{M}_{\text {rel }}$ understates the effect of the treatment on the local region $\mathcal{M}_{H}$, because the local treatment also increases the other region's outcome. When $\mathcal{M}_{F}<0$, the regional multiplier $\mathcal{M}_{\text {rel }}$ instead overstates the causal effect of interest because the treatment lowers outcomes in the other region. For our application to debt relief in the model below, $\mathcal{M}_{F}$ will take on either sign depending on parameter values.

While the relative multipliers $\mathcal{M}_{H}$ and $\mathcal{M}_{F}$ may be of interest for regional policy evaluation, the macroeconomic effect of interest is typically the aggregate multiplier, or the causal effect of the aggregate

\footnotetext{
${ }^{22}$ Symmetry also implies that $\alpha_{i}$ does not depend on $i$.
} 
treatment on the aggregate outcome. This aggregate multiplier is simply equal to:

$$
\mathcal{M}_{\text {agg }}=\frac{\frac{1}{2} \sum_{i}\left(\mathcal{M}_{H} \Delta_{i, t}+\mathcal{M}_{F} \Delta_{-i, t}\right)}{\Delta_{t}}=\mathcal{M}_{H}+\mathcal{M}_{F}
$$

Any macroeconomic treatment $\Delta_{t}$ tends to affect all regions, even if it affects some regions more than others. Equation (6) shows that the average effect across regions reflects the sum of its local and its spillover effect. This point is general and does not depend on our assumption that there are only two regions. ${ }^{23}$ Except in the special case of no spillovers $\mathcal{M}_{F}=0$, the aggregate multiplier $\mathcal{M}_{\text {agg }}$ is different from the relative multiplier $\mathcal{M}_{r e l}$ in Equation (5). Nevertheless, $\mathcal{M}_{r e l}$ is useful because it contains information about $\mathcal{M}_{H}$ that is in turn relevant for $\mathcal{M}_{\text {agg }}$.

For empirical papers interested in aggregate macroeconomic outcomes, the results above provide caution in interpreting cross-regional elasticities. Cases where $\mathcal{M}_{\text {rel }}$ is positive may reflect a situation where the overall aggregate effect is small, or negative, and vice versa. Traditional backof-the-envelope calculations that identify $\mathcal{M}_{\text {agg }}$ with $\mathcal{M}_{\text {rel }}$ are implicitly assuming $\mathcal{M}_{F}=0$, that is, zero general equilibrium spillovers. This may be appropriate in particular situations. For example, in our structural model below, we will find that $\mathcal{M}_{F}=0$ for non-tradable employment under a particular specification of monetary policy, while we will always find $\mathcal{M}_{F}>0$ for tradable employment (see Figure A4). This suggests that regional tradable employment elasticities tend to be an underestimate of aggregate tradable employment elasticities because the spillovers are stronger for tradable employment.

Motivated by these results, we proceed as follows. We first calculate the relative multiplier $\mathcal{M}_{\text {rel }}$ implicit in our difference-in-differences estimates for both tradable and non-tradable employment. We then develop a model of the causal effect of debt relief and show that it verifies approximately the equation for potential outcomes in Equation (2). Next, we calibrate our model and validate this calibration by comparing the relative debt relief multipliers $\mathcal{M}_{N T \text {,rel }}$ and $\mathcal{M}_{T, \text { rel }}$ in the theory and the data. Finally, we use the aggregate multiplier $\mathcal{M}_{\text {agg }}$ from our calibrated model to recover the aggregate effect of debt relief during the Great Recession.

We are not the first to point out the disconnect between regional and aggregate elasticities. Our

\footnotetext{
${ }^{23}$ In the more general case with $n$ symmetric regions, the potential outcomes Equation (2) is replaced with $Y_{i t}=\alpha_{i}+\lambda_{t}+$ $\mathcal{M}_{H} \Delta_{i t}+\mathcal{M}_{F} \frac{1}{n-1} \sum_{j \neq i} \Delta_{j t}$. Equation (4) is replaced by $\mathcal{M}_{\text {rel }}=\mathcal{M}_{H}-\frac{1}{n-1} \mathcal{M}_{F}$, and Equation (6) is still $\mathcal{M}_{\text {agg }}=\mathcal{M}_{H}+\mathcal{M}_{F}$. In the limit as $n \rightarrow \infty$, as in Galí and Monacelli (2005) and Farhi and Werning (2016a) for example, the relative multiplier $\mathcal{M}_{\text {rel }}$ is equal to $\mathcal{M}_{H}$, as any given region is too small to affect any one other, but the aggregate multiplier differs from $\mathcal{M}_{\text {rel }}$ by $\mathcal{M}_{F}$, the effect of simultaneously treating all regions on any given region.
} 
approach builds most closely on recent work on local fiscal multipliers by Nakamura and Steinsson (2014) and the large literature that followed (see Chodorow-Reich Forthcoming and Nakamura and Steinsson 2018 for summaries of recent work). The typical approach in this literature is to calculate a relative multiplier from cross-sectional variation, and then use a structural model to discuss the relationship to the aggregate multiplier. We build on this literature by applying these concepts to the case of debt relief, by showing formally why the relative and aggregate effects differ by the spillover effect in the control region $\mathcal{M}_{F}$, and by making use of both tradable and non-tradable employment outcomes as "identified moments."

The issue of aggregation from regional to aggregate elasticities has been taken up in other work, including Adao, Arkolakis and Esposito (2019), Beraja, Hurst and Ospina (2016), Guren et al. (2018), and Sarto (2018). The typical approach in these papers is to impose more structure than we do. One advantage of our approach is its transparency, as we can directly compute $\mathcal{M}_{H}, \mathcal{M}_{F}$, $\mathcal{M}_{\text {rel }}$, and $\mathcal{M}_{\text {agg }}$ in any given calibration and then compare these numbers to our empirical specification.

\section{B. Calculating the Relative Debt Relief Multiplier}

We can now use our difference-in-differences estimates to calculate the relative debt relief multipliers $\mathcal{M}_{\text {rel }}$ for both non-tradable and tradable employment. As defined above, the relative debt relief multipliers identify the percentage increase in employment from each percentage point increase in debt write-downs. We measure the debt write-downs as a share of aggregate consumption in order to give our multipliers more easily interpretable units. Equation (5) suggests that these relative debt relief multipliers can be estimated as the simple ratio of our difference-in-differences estimates for each employment sector and debt write-downs, scaled by consumption. ${ }^{24}$

There are two potential problems with simply taking the ratio of our difference-in-differences estimates, however. The first is that this simple approach assumes that all of the debt forgiveness created by the consumer bankruptcy system is captured by our debt write-down measure. Yet, there are many important types of debt forgiveness that are not included in our debt write-down measure, including medical debt charged off by hospitals (e.g., Mahoney 2015), the debt on second homes with negative equity charged off by mortgage lenders (e.g., Ganong and Noel 2018), and the debt charged off by most payday lenders (e.g., Dobbie and Skiba 2013). We therefore inflate our difference-in-differences estimate for debt write-downs to account for the incomplete nature of our write-down measure. We

\footnotetext{
${ }^{24}$ In the model below, we assume that debt write-downs are a one-time transfer to borrowers. In practice, however, the economic benefits of debt write-downs may occur over multiple time periods. We therefore calculate the multipliers over a three-year time horizon, rather than a shorter time horizon such as only one year.
} 
calculate the fraction of forgiven debt included in our debt write-down measure using a sample of Chapter 7 bankruptcy filings, where we find that our write-down measure captures approximately 77.5 percent of the debt forgiven in the typical Chapter 7 filing. ${ }^{25}$

The second potential problem with simply taking the ratio of our difference-in-differences estimates is that this assumes that the effect of bankruptcy protections acts solely through the channel of debt relief, and not through some alternative channel. Our debt relief multiplier will therefore be biased if, for example, bankruptcy protections have an independent effect on employment by increasing the incentive to work by eliminating or reducing wage garnishment orders (e.g., Dobbie and Song 2015; Donaldson, Piacentino and Thakor Forthcoming). We are unable to estimate the magnitude of these independent effects using our data, and, as a result, unable to account for this issue when calculating our debt relief multiplier.

Formally, we define the relative debt relief multiplier, following Equation (5), as:

$$
\mathcal{M}_{s, \text { rel }}=\frac{\Delta \log \left(\text { Employment }_{s}\right)}{\text { Write-Downs/Consumption }}, \quad s \in\{\mathrm{T}, \mathrm{NT}\}
$$

where $\Delta \log (\text { Employment })_{s}$ is the change in employment for sector $s$ over a given period of time, and Write-Downs is economy-wide change in debt scaled by aggregate consumption for the same time period. The relative debt relief employment multiplier $\mathcal{M}_{s}$ therefore measures the percentage increase in employment from each percentage point increase in debt write-downs in consumption units.

We calculate the cross-state debt relief multipliers using our preferred specification from column 3 of Tables 2 and 3. Following the adjustment for the fraction of forgiven debt included in our debt write-down measure discussed above, we find:

$$
\mathcal{M}_{N T, \text { rel }}=1.81, \quad \mathcal{M}_{T, \text { rel }}=0.39
$$

These cross-state debt relief multipliers suggest economically significant relative effects of debt write-downs on employment in non-tradable sectors, but economically small relative effects on employment in tradable sectors. We now turn to our a general equilibrium model of debt relief that will

\footnotetext{
${ }^{25}$ We estimate the fraction of forgiven debt included in our debt write-down using the random sample of Chapter 7 bankruptcy filings described in Dobbie, Goldsmith-Pinkham and Yang (2015). To do this, we first identify the composition of different debts that were discharged in Chapter 7. We then calculate the share of that total debt that is accounted for by credit card and auto debt: 77.5 percent.
} 
allow us to map these relative debt relief multipliers into aggregate multipliers. ${ }^{26}$

\section{Model}

Our model combines elements from recent New Keynesian models of currency unions with incomplete markets that have been used to study fiscal and transfer multipliers (see for example Farhi and Werning 2016a, Nakamura and Steinsson 2014, and Chodorow-Reich Forthcoming). We expand upon this standard framework in two natural directions given our context. First, our model includes heterogeneity in the marginal propensity to consume out of liquid wealth for savers and borrowers, which allows ex-post debt relief to have real effects. Second, our model includes both traded and non-traded goods, which allows us to examine the causal effect of debt relief on traded and non-traded employment separately, facilitating the mapping between our empirical difference-in-differences estimates and the model.

\section{A. Model Setup}

Our model is a two-agent, two-region, two-good ("TANK ${ }^{3 \prime}$ ) currency union model. The model features a home $H$ and foreign $F$ region, each producing traded $T$ and non-traded $N T$ goods, and each inhabited by a representative borrower $B$ and a representative saver $S$. To ensure symmetry, we assume that the home region and the foreign region are of equal size, or $\frac{1}{2}$ each. In each region, borrowers make up the fraction $\varphi^{B}$ of the population, and savers the faction $\varphi^{S}=1-\varphi^{B}$. Households $h \in\{B, S\}$ share the same utility function over consumption and hours worked (up to a factor that normalizes their total hours), but differ in their discount factor $\beta^{h}$, with $\beta^{B}<\beta^{S}$. They also face an exogenous credit constraint, which is binding for borrowers in steady state. Goods are produced under monopolistic competition. We index goods by type $\{T, N T\}$, production location $i \in\{H, F\}$, producer $j$, and time $t$.

Households. All households within a region consume traded and non-traded goods, receive employment and dividend income, and can borrow and save in nominal risk-free bonds. Households maximize utility:

$$
\mathbb{E}\left[\sum_{t=0}^{\infty}\left(\beta^{h}\right)^{t} u^{h}\left(C_{i, t}^{h}, N_{i, t}^{h}\right)\right]
$$

\footnotetext{
${ }^{26}$ We can also construct cross-state debt relief multipliers using an instrumental variables (IV) approach, where we instrument for debt write-downs using our measure of bankruptcy protections. However, this instrumental variables approach assumes that all of the debt forgiveness created by the consumer bankruptcy system is captured by our debt write-down measure, an assumption we believe to be invalid in this setting. We therefore prefer our simple scaling approach to a formal IV.
} 
where $\beta^{h}$ is the discount factor of household type $h \in\{B, S\}, C_{i, t}^{h}$ is aggregate consumption of household type $h$ living in region $i$ at time $t$, and $N_{i, t}^{h}$ is that household's labor supply. For our baseline specification, we assume standard separable preferences of the form $u^{h}(C, N)=\frac{C^{1-\sigma}}{1-\sigma}-\chi^{h} \frac{N^{1+\psi}}{1+\psi}$, where $\psi$ is the inverse Frisch elasticity of labor supply and $\sigma$ the inverse elasticity of intertemporal substitution in consumption. Consumption $C$ is itself an aggregate of the consumption of traded and non-traded goods:

$$
C\left(C_{T}, C_{N T}\right)=\left[\alpha^{\frac{1}{\eta}}\left(C_{T}\right)^{\frac{\eta-1}{\eta}}+(1-\alpha)^{\frac{1}{\eta}}\left(C_{N T}\right)^{\frac{\eta-1}{\eta}}\right]^{\frac{\eta}{\eta-1}}
$$

where $\alpha$ represents the expenditure share on traded goods at a unit relative price and $\eta$ is the elasticity of substitution between tradable and non-tradable goods. In turn, traded and non-traded goods are made up of an aggregate of intermediate goods:

$$
C_{T, i}^{h}=\left(\int_{0}^{1}\left(C_{T, i, j}^{h}\right)^{\frac{\epsilon-1}{\epsilon}} d j\right)^{\frac{\epsilon}{\epsilon-1}} \quad C_{N T, i}^{h}=\left(\int_{0}^{1}\left(C_{N T, i, j}^{h}\right)^{\frac{\epsilon-1}{\epsilon}} d j\right)^{\frac{\epsilon}{\epsilon-1}}
$$

where $C_{T, i, j}^{h}$ is household $h^{\prime}$ s demand for the traded good produced in location $i$ by firm $j$ (similarly for $\left.C_{N T, i, j}^{h}\right)$, and $\epsilon$ is the elasticity of substitution between goods.

We assume that non-traded goods are all produced locally, but traded goods can be imported from the other region. Tradable goods $j \in\left[0, \frac{1}{2}\right]$ are produced in the home region, and goods $j \in\left(\frac{1}{2}, 1\right]$ are produced in the foreign region. Since the home region also has size $\frac{1}{2}$, there is no home bias in tradable spending.

There is free trade across the two regions, so the price of traded goods is the same in both locations. We write $P_{T, j}$ for the common price of tradable intermediate good $j$, and $P_{N T, i, j}$ for the price of intermediate good $j$ in region $i$. The nominal price indices for tradable and non-tradable goods are defined as:

$$
P_{T}=\left(\int_{0}^{1}\left(P_{T, j}\right)^{1-\epsilon} d j\right)^{\frac{1}{1-\epsilon}} \quad P_{N T, i}=\left(\int_{0}^{1}\left(P_{N T, i, j}\right)^{1-\epsilon} d j\right)^{\frac{1}{1-\epsilon}}
$$

and the consumer price index in region $i$ is given by:

$$
P_{i}=\left[\alpha P_{T}^{1-\eta}+(1-\alpha)\left(P_{N T, i}\right)^{1-\eta}\right]^{\frac{1}{1-\eta}}
$$

Workers are immobile, so the nominal hourly wage may differ in the two regions. We write $W_{i}$ for the nominal wage in region $i^{27}$

\footnotetext{
${ }^{27}$ Appendix Table A7 validates this assumption by showing that the in-migration response across states with different
} 
The budget constraint of consumer $h$, in region $i$ at time $t$ is given by:

$$
P_{i, t} C_{i, t}^{h}+B_{i, t-1}^{h}-\Delta_{i, t}^{h}=\frac{B_{i, t}^{h}}{1+I_{t}}+W_{i, t} N_{i, t}^{h}+D_{i, t}
$$

where $C_{i, t}^{h}=C\left(C_{T, i, t}^{h} C_{N T, i, t}^{h}\right)$ is aggregate consumption for consumer $h$ in region $i$ at time $t, B_{i, t}^{h}$ is her nominal debt level, $I_{t}$ the nation-wide nominal interest rate, and $D_{i, t}$ are total nominal profits of firms in region $i$. The government does not impose any taxes or transfers, except for those needed to impose the consumer debt write-downs $\Delta_{i, t}^{h}$, as detailed below. Consumers face a borrowing constraint, such that their real debt (in units of the traded good price index) is constrained to stay below a constant level $\bar{b}$ at all times:

$$
B_{i, t}^{h} \leq \bar{b} P_{T, t} \quad \forall h, i
$$

Firms. Firms produce goods under monopolistic competition using local labor as their only input. Firm $j$ produces tradable good $j$ using the production function:

$$
Y_{T, j, t}=A_{T, t}\left(N_{T, j, t}\right)^{\gamma}
$$

where $A_{T}$ denotes productivity in the traded good sector- which is common across firms and regionsand $\gamma$ denotes the extent of diminishing returns to production. Similarly, non-tradable firms in both the home and foreign regions produce non-tradable goods using the production function:

$$
Y_{N T, i, j, t}=A_{N T, t}\left(N_{N T, i, j, t}\right)^{\gamma} \quad i \in\{H, F\}
$$

where $A_{N T}$ denotes the common productivity in the non-traded good sector.

Prices for both traded and non-traded goods are set in a Calvo fashion, with each firm getting a chance to reset their price with a probability $1-\theta$ that is iid across firms and over time. When $\theta=0$, prices are fully flexible. The degree of price rigidity $\theta$ is the same for both traded and non-traded goods.

Monetary Policy. For our baseline specification, we assume that monetary policy is such that there is a constant nominal interest rate of $I_{t}$ :

$$
I_{t}=\bar{I}
$$

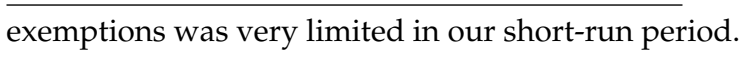


where $\bar{I}$ is the steady-state nominal interest rate in our model. Since our focus will be on the effects of debt relief shocks, this baseline specification implies that monetary policy is unresponsive to the effect of these shocks, mimicking a situation where debt relief takes place at the zero lower bound. ${ }^{28}$ We refer to this policy as ZLB policy.

We will also consider the effect of debt relief in a non-crisis period. In this non-crisis period, we assume that the monetary authority responds to consumer price inflation in both regions with an equal weight $\phi_{\pi}$. In this Taylor rule policy scenario, the central bank sets the nominal interest rate such that:

$$
1+I_{t}=(1+\bar{I})\left(\frac{P_{H, t}}{P_{H, t-1}}\right)^{\phi_{\pi}}\left(\frac{P_{F, t}}{P_{F, t-1}}\right)^{\phi_{\pi}}
$$

where $\frac{P_{H, t}}{P_{H, t-1}}$ is home consumer price inflation at time $t, \frac{P_{F, t}}{P_{F, t-1}}$ is foreign CPI inflation, and $\phi_{\pi}$ is the degree of responsiveness of monetary policy to inflation.

To ensure the determinacy of outcomes in response to transitory debt relief shocks, both in the ZLB policy case given by Equation (9), and in the Taylor rule policy case given by Equation (10) when $\phi_{\pi}$ is sufficiently low, we assume that the central bank ensures that the economy returns to steady state at a time $T$ that is far enough in the future that the effects of these debt relief shocks have died out.

Equilibrium. Equilibrium in our model is defined in a standard way. ${ }^{29}$ Market clearing requires that, at any point in time, the labor market clears locally, so that aggregate employment in region $i$ is both equal to aggregate supply by all agents and to aggregate demand by all local firms (the sum of traded goods employment $N_{T, i}$ and non-traded goods employment $N_{N T, i}$,

$$
N_{i, t} \equiv \varphi^{B} N_{i, t}^{B}+\varphi^{S} N_{i, t}^{S}=N_{T, i, t}+N_{N T, i, t} \quad i \in\{H, F\}
$$

The non-traded goods market must clear locally, so that: $C_{N T, i, j, t}=Y_{N T, i, j, t}$ in each region $i$ and for each non-traded firm $j$, and the traded goods and the asset market must clear nationwide. This implies

\footnotetext{
${ }^{28}$ While the steady-state nominal interest rate $\bar{I}$ is always strictly positive in our model, it is easy to conceive of "Great Recession" shocks, such as shocks to productivity or discount factors, that would push the economy to $I_{t}=0$. Since the model is approximately linear, these shocks would not interact with the effects of debt relief conditional on ZLB policy. Our assumption helps us isolate the effect of debt relief at the ZLB without explicitly modeling these Great Recession shocks.

${ }^{29}$ See Appendix B for the full set of equations describing the equilibrium solution, as well as a description of our solution method.
} 
in particular that all borrowers' debts are also savers' assets:

$$
\frac{\varphi^{B}}{2}\left(B_{H, t}^{B}+B_{F, t}^{B}\right)+\frac{\varphi^{S}}{2}\left(B_{H, t}^{S}+B_{F, t}^{S}\right)=0 .
$$

In the zero-inflation steady state of our model, borrowers in both regions are at their credit constraint:

$$
B_{i}^{B}=\bar{b} P_{T} \quad \forall i
$$

and the nominal and real interest rate are both equal to $\bar{I}=\left(\beta^{S}\right)^{-1}-1$.

Debt Relief. We model the debt relief shock as follows. At time 0, it is unexpectedly announced that home borrowers will receive a sequence of transfers $\Delta_{H, t}^{B}$ and that foreign borrowers will receive a sequence of transfers $\Delta_{F, t}^{B}$. The home borrowers can use these transfers to pay down their debts, and, since they are constrained, they will do so fully in equilibrium, provided that the transfers are small enough. This sequence of transfers captures the ex-post nature of the debt relief shock that we are modeling, in that it reduces borrowers' debts without affecting borrowing rates or ex-ante credit supply.

Each period, total transfers $\Delta_{t} \equiv \frac{\varphi^{B}}{2}\left(\Delta_{H, t}^{B}+\Delta_{F, t}^{B}\right)$ are paid for by a lump-sum tax on savers in one or both regions, such that:

$$
\frac{\varphi^{S}}{2} \Delta_{H, t}^{S}=-f \Delta_{t} \quad \frac{\varphi^{S}}{2} \Delta_{F, t}^{S}=-(1-f) \Delta_{t}
$$

The parameter $f \in[0,1]$ in (11) indexes the regional incidence of payment for the debt relief in our model. Consider, for example, the case where $\Delta_{F, t}^{B}=0$, so that debt relief only takes place in the home region $H$. Then, if $f=1$, savers at home pay entirely for local debt relief, generating the largest domestic offset. In that case, the aggregate demand effect of debt relief comes entirely from the difference in marginal propensities to consume between borrowers and savers in the home region. If $f<1$, debt relief also implies regional redistribution, or a net asset transfer from the foreign region to the home region. The case $f=\frac{1}{2}$ implies that the burden of debt relief in the home region is borne equally by savers in both regions.

\section{B. Model Calibration}

In line with our objective of maintaining a transparent mapping between model and data, our baseline calibration uses standard parameter values from the literature. In later sections, we discuss the 
robustness of our results to other parameter values.

Table 4 summarizes our baseline calibration, with all parameters at the quarterly frequency. We set the fraction of borrowers in each region to 0.5 , reflecting the approximate share of households carrying a positive credit card balance in our data.

We set $\beta^{S}=0.983$ so that the steady-state annual real interest rate is 7 percent per year, corresponding to the average interest rate paid by households in 2007Q4 according to national account estimates. ${ }^{30}$ For borrowers, we consider a baseline of $\beta^{B}=0.92$. Provided that $\beta^{B}<\beta^{S}$, our model produces identical outcomes for small shocks. $\left(\beta^{B}\right.$ becomes relevant when we study large shocks, as we discuss in Section IV.F.) In our baseline of separable preferences, $u^{h}(C, N)=\frac{C^{1-\sigma}}{1-\sigma}-\chi_{h} \frac{N^{1+\psi}}{1+\psi}$, we assume that the long-run income and substitution effects on labor supply cancel out, so $\sigma=1$, and set the Frisch elasticity of labor supply to a standard macroeconomic value of $\psi^{-1}=1$.

We set $1-\alpha=0.236$, since our measure of non-tradable sectors, following Mian and Sufi (2014b), represents 23.6 percent of employment. We follow the standard practice of setting an elasticity of substitution within tradable and non-tradable goods equal to 10 to match a steady-state level of markups of 11 percent, and set the elasticity of substitution between T and NT to a relatively high value of 2 . We set $\gamma=0.66$ to match a steady-state labor share of $\frac{\epsilon}{\epsilon-1} \gamma=0.6$, as in NIPA data for the period.

We consider two assumptions for price rigidity. In our baseline, prices are sticky and $\theta=0.8$, implying an average price duration of 5 quarters. This level of price stickiness is on the high end of the empirical estimates, but we show in Section IV.C that only a high degree of price rigidity can rationalize our empirical relative multiplier estimates. We also consider an alternative calibration with fully flexible prices $(\theta=0)$. We will argue that our empirical relative multipliers soundly reject this specification.

We set $\bar{b} / C=1$ so that aggregate credit card debt equals 12.5 percent of annual PCE, its U.S. value in 2008. ${ }^{31}$ We normalize the steady-state hours of borrowers and savers to 1, implying that borrowers and savers have the same income before interest payments. In the steady state equilibrium, borrowers are at their borrowing limits and spend 1.7 percent of their income on interest payments. We set average PCE at $C=\$ 32,000$, its U.S. value in 2007Q4. We solve for a symmetric steady state

\footnotetext{
${ }^{30}$ According to the BEA, mortgage interest payments were $\$ 682 \mathrm{bn}$ and other consumer credit payments were $\$ 265 \mathrm{bn}$ at an annualized rate in 2007Q3. According to the Flow of Funds, in that quarter there was $\$ 10.5$ trn outstanding in mortgage credit and $\$ 2.5$ trn in consumer credit. The average annual interest rate paid by households was therefore 6.9 percent in that quarter.

${ }^{31}$ In our data, the average credit card balance is $\$ 4000$ per person. This implies a balance of $\frac{\$ 4000}{\varphi^{B}}=\$ 8000$ per borrower, which is 100 percent of quarterly PCE.
} 
in which all relative prices are 1 . We obtain the values of $A_{T}, A_{N T}, \chi^{S}$ and $\chi^{B}$ that achieve these steady-state targets, as described in Appendix B.B.

C. Impulse Responses and the Degree of Price Rigidity

We first study impulse responses to debt relief shocks. Recall from Section III that we are interested in recovering $\mathcal{M}_{H}$ and $\mathcal{M}_{F}$ for both the tradable and non-tradable sectors. To do so, we assume that the only shock that hits the model is a home debt relief shock of $\Delta_{H}=1$ percent of home PCE, with $\Delta_{F}=0$. This shock corresponds to a one-time reduction of the level of debt of every borrower in the home region by 2 percent, or $\$ 160$. By definition, the percentage point impact to this shock in the home and foreign region correspond to our multipliers of interest, $\mathcal{M}_{H}$ and $\mathcal{M}_{F}$, respectively.

Figure 4 presents the impulse response of the model to this one-time debt relief shock in the home region. The effects of the debt relief shock are not very persistent, with very limited impact on aggregate outcomes beyond the first quarter. This lack of persistence validates our focus on "the" debt relief multiplier, and shows why our model fits the assumptions used to derive Equation (2) in Section III. See Auclert, Rognlie and Straub (2018) for additional discussion on why TANK models generate limited endogenous persistence.

In our baseline calibration, non-tradable employment rises by more than one percent in the home region in the short run, but only slightly increases in the foreign region over the same time period:

$$
\mathcal{M}_{N T, H}=1.56, \quad \mathcal{M}_{N T, F}=0.33, \quad \mathcal{M}_{N T, \text { rel }}=1.23
$$

In contrast, tradable employment increases by around one percent in both the home and foreign regions in the short run in our baseline calibration:

$$
\mathcal{M}_{T, H}=0.89, \quad \mathcal{M}_{T, F}=0.99, \quad \mathcal{M}_{T, r e l}=-0.10
$$

These relative debt relief multipliers are close to, but slightly below, our empirical debt relief multipliers reported in Equation (8).

Our model's success in matching the empirical debt relief multipliers of both tradable and nontradable employment relies on the interaction between its three main features: heterogeneity in marginal propensities to consume between borrowers and savers, nominal rigidities, and trade linkages across regions. First, debt relief redistributes wealth from savers in both the home and foreign regions, who 
have low MPCs, to borrowers in the home region, who have high MPCs. This redistribution from savers to borrowers stimulates consumption in the home region, increasing aggregate demand for both non-tradable goods locally and for tradable goods in both regions. Second, given relatively sticky prices, this additional spending stimulates production and therefore incomes at home, leading to additional spending on both traded and non-traded goods in the home region (i.e., positive $\mathcal{M}_{N T, H}$ and $\left.\mathcal{M}_{T, H}\right)$. Finally, given trade linkages, the rise in labor demand from traded goods firms raises tradable employment in the foreign region as well (i.e., a positive $\mathcal{M}_{T, F}$ ). Interestingly, the positive $\mathcal{M}_{T, F}$ also increases incomes and therefore overall spending in the foreign region, leading to an increase in non-tradable employment in the foreign region as well (i.e., a positive $\mathcal{M}_{N T, F}$ ). ${ }^{32}$

An important lesson from Equation (13) is that even though the observed relative tradable employment multiplier $\mathcal{M}_{T, \text { rel }}$ is close to zero, this relative multiplier masks a large and positive response of tradable employment in both regions. In our model, $\mathcal{M}_{T, \text { rel }}$ is slightly negative because the increase in home wages makes goods produced in the home region relatively more expensive. These "terms of trade" effects induce some substitution of consumers away from home goods towards foreign goods, so that foreign traded employment increases by more than home traded employment. However, these effects are relatively muted given our assumed degree of price stickiness, and the economy largely adjusts to debt relief via an increase in income in both regions.

Our ability to match both the tradable and non-tradable employment multipliers is, in fact, specific to our calibration of high price rigidity. Appendix Figure A5 shows the impulse responses under flexible prices, $\theta=0$. In this calibration, aggregate home employment goes down in the shortrun. Upon receiving debt relief, borrowers increase consumption but also immediately reduce hours worked (a wealth effect, large under standard separable preferences). ${ }^{33}$ Since non-traded goods can only be produced locally while traded goods can be imported, the overall effect is a moderate rise in local non-tradable employment and a large increase in imports, intermediated by an increase in the price of home tradable goods. Overall, under flexible prices, $\mathcal{M}_{N T, \text { rel }}$ is close to 0 while $\mathcal{M}_{\text {T,rel }}$ is very negative (i.e., less than -0.6$)$.

In this sense, the non-tradable and the tradable relative employment multipliers are both useful moments to identify the degree of macroeconomic price stickiness. Figure 5 illustrates this point by

\footnotetext{
${ }^{32}$ See Chodorow-Reich Forthcoming, House, Proebsting and Tesar (2017), Dupor et al. (2019), Chodorow-Reich et al. (2018) and Chodorow-Reich, Nenov and Simsek (2019) for other currency union models in which tradable demand spillovers are important determinants of the aggregate multiplier. These papers also find that $\mathcal{M}_{F}$ tends to be positive at the zero lower bound, i.e. that the relative multiplier tends to be a lower bound for the aggregate multiplier.

${ }^{33}$ The wealth effect from debt relief is also visible in our sticky price calibration when comparing employment rates of borrowers and savers. Hours rise mostly for savers, with hours for borrowers remaining relatively flat.
} 
plotting the relative multipliers for both non-tradable and tradable employment as a function of the degree of price rigidity $\theta$. Both $\mathcal{M}_{N T \text {,rel }}$ and $\mathcal{M}_{T, \text { rel }}$ increase with $\theta$, and get closer to their empirical counterparts as $\theta$ grows larger. If anything, our empirical estimates would lead us to infer completely fixed prices for this period, $\theta=1$ (see Mian and Sufi $2014 b$ for a related argument.) ${ }^{34}$

We conclude this subsection by considering what models could achieve an even better fit to our empirical relative debt relief multipliers. While our baseline model does a reasonable job, there are two versions of our model that are able to hit the empirical relative non-tradable multiplier exactly right, though both have drawbacks in other dimensions. ${ }^{35}$ The first version increases the aggregate degree of home bias by reducing the tradable share of consumption $\alpha$. Appendix Figure A6 shows that, as $\alpha$ is reduced, the home multiplier rises and the foreign multiplier falls, increasing $\mathcal{M}_{N T, r e l}$. More home bias reduces the amount of foreign demand "leakage," increasing the local multiplier. Holding the other parameters constant, we obtain $\mathcal{M}_{N T, \text { rel }}=1.81$ for $\alpha=0.09$, an implausible degree of home bias for the United States, leading us to prefer our baseline to this alternative for policy evaluation.

The second version of our model that more closely fits the relative non-tradable multiplier in the data replaces our baseline specification of preferences with GHH preferences (Greenwood, Hercowitz and Huffman 1988), with period utility function $u^{h}(C, N)=\log \left(C-\chi_{h} N^{2}\right)$. In Appendix Figure A7, we repeat Figure 5 with this alternative specification. When $\theta=0.67$, we are able to exactly match the relative non-tradable employment multiplier of $\mathcal{M}_{N T, \text { rel }}=1.81$. However, in this parametrization, the implied home and foreign multipliers are very large for both non-tradable and tradable goods. That is, at the zero lower bound, $\mathcal{M}_{N T, H}=6.94$ and $\mathcal{M}_{N T, F}=5.12$, while $\mathcal{M}_{T} \simeq 6$ for both. As discussed in Auclert and Rognlie (2017), these large aggregate multipliers are due to the interaction between nominal price rigidities and the strong complementarity between consumption and labor supply that GHH preferences generate. These effects seem implausibly strong, again leading us to prefer our baseline to this alternative for policy evaluation.

\footnotetext{
${ }^{34}$ Another way of validating our assumption of high price rigidity is to directly look at inflation as an outcome in our empirical research design. Appendix Table A8 does this using inflation measures come from the Bureau of Labor Statistics (BLS) and shows that the response of both non-tradable and tradable CPI to the bankruptcy exemptions was small and insignificant.

${ }^{35}$ We focus on the relative non-tradable employment multiplier. The relative tradable employment multiplier is always slightly negative in our model because we do not have any home bias in tradable spending and relative price movements always reduce home competitiveness in producing tradable goods. To generate a positive relative tradable multiplier our model would need to feature enough home bias in tradable consumption, in addition to the home bias in non-tradable consumption.
} 


\section{Using the Model to Recover the Aggregate Effect}

We can now use our model to recover an estimate of the aggregate effect of debt relief during the Great Recession, $\mathcal{M}_{\text {agg. }}$. Observe from Equations (12) and (13) that, in our model, the aggregate multiplier is the same for tradable and non-tradable employment, and it is equal to $\mathcal{M}_{\text {agg }}=\mathcal{M}_{T, a g g}=\mathcal{M}_{N T, a g g}=$ 1.88. Therefore, to obtain an estimate of the employment effect of debt relief, we need an estimate of the aggregate unsecured debt relief that took place over the Great Recession. Multiplying this number by $\mathcal{M}_{\text {agg }}$ then delivers our average counterfactual employment effect for both tradable and non-tradable employment.

We construct an estimate of the aggregate level of debt relief over time from our credit report data. Debt write-downs varied with the business cycle in the period prior to the Great Recession, with an average of slightly above 1.9 percent of 2007 PCE between 2001Q1-2007Q4. ${ }^{36}$ Debt write-downs then increased dramatically to reach 2.7 percent of 2007 PCE at their peak in 2009Q3. As in Section II.7, we then scale this number by $1 / 0.77$ to reflect our best estimate of the aggregate debt relief that took place over this period.

Clearly, some debt relief takes place even in normal times. For our counterfactual, we are interested in the contribution of the excess debt relief that took place during the recession. We estimate excess debt relief by subtracting the 2007Q4 level of debt write-downs from the levels observed after that date. This procedure delivers the green line in Panel A of Figure 6. We then feed in this path of excess debt relief into the model, assuming that, as in our model, these are expected transfers from savers to borrowers that do not distort credit market interest rates. Through the model, we recover our aggregate employment counterfactual for non-tradable employment (Panel B, green line) and tradable employment (Panel C, green line). At the peak in 2009Q3, this exercise delivers an aggregate employment effect of $1 \times 1.88=1.88$ percent, or roughly 2.6 million jobs.

Figure 6 also reports the outcomes in two representative high-exemption ("home") and lowexemption ("foreign") regions. We assume that the average debt relief across the high- and the lowexemption regions is equal to the average debt relief in the data (the green line), and that the difference between the high- and the low-exemption region is equal to our estimated effect from a one-standard deviation change in our exemption measure from Figure 3. This exercise makes clear that our empirical variation picks up the difference between two large numbers. Comparing the relative outcome in

\footnotetext{
${ }^{36}$ Recall that our charge-off measure from the credit report data does not include recoveries, and hence will be higher than the net charge-off rate.
} 
the model (solid black line) vs the data (dashed black line) gives a sense of our model's success.

\section{E. The Role of Monetary Policy}

Our counterfactuals so far have been based on our assumption of zero lower bound policy. As a comparison between our baseline impulse responses (Figure 4) and our flexible-price impulse responses (Figure A5) shows, the response of monetary policy is critical when estimating the aggregate effect of debt relief. Absent a change in prices or monetary policy, debt relief induces an aggregate wealth effect. Under the zero lower bound, monetary policy does not respond to the increase in inflation from the pressure of aggregate demand. By contrast, under flexible prices, monetary policy increases nominal interest rates by almost 40 basis points, prompting savers in both regions to dramatically reduce their consumption and offset the rise in borrower consumption at home.

While such a tightening of monetary policy is implausible in crisis times like the Great Recession, it may not be implausible in non-crisis times, during which we would expect the central bank to counter any inflationary shock such as a debt relief shock. Appendix Figure A4 evaluates the effect of alternative degrees of monetary tightening, indexed by the degree of responsiveness of the central bank to inflation (the Taylor rule coefficient $\phi_{\pi}$ ), in our baseline calibration. The case $\phi_{\pi}=0$ corresponds to our baseline of the zero lower bound. As Nakamura and Steinsson (2014) have pointed out, the relative multiplier differences out the effect of monetary policy across the two regions. Hence, no matter how much monetary policy tightens, the relative multipliers $\mathcal{M}_{T, \text { rel }}$ and $\mathcal{M}_{N T \text {, rel }}$ remain unchanged. ${ }^{37}$ However, the larger the response of monetary policy, the lower the effect on non-tradable and tradable employment in both regions. But our insight that there are positive spillover effects on the foreign region, so that $\mathcal{M}_{N T, F}>0$ and $\mathcal{M}_{T, F}>0$, remains valid under many plausible values of $\phi_{\pi}$. Zero spillovers for non-tradable employment, $\mathcal{M}_{N T, F}=0$, is only reached for $\phi_{\pi}=6.5$, corresponding to a relatively large monetary tightening of 15 basis points. This particular parameterization of the model is interesting because it exhibits a case where $\mathcal{M}_{\text {rel }}=\mathcal{M}_{\text {agg }}$ for non-tradable employment, or, in other words, a case where it is correct to extrapolate directly from relative to aggregate multipliers. Even in this special case, $\mathcal{M}_{F}$ is still very positive for tradable employment, so that $\mathcal{M}_{\text {rel }} \ll \mathcal{M}_{\text {agg }}$ for the tradable sector. Intuitively, tradable employment comes with much larger spillover effects across regions, so while it may be possible to extrapolate from relative non-tradable employment multipliers to the aggregate, the same is generally not possible for tradable employment.

\footnotetext{
${ }^{37}$ Since this is a currency union model where relative prices across regions also matter, the limit with the Taylor rule coefficient $\phi_{\pi} \rightarrow \infty$ does not correspond to the flexible price limit, where relative multipliers are different, as Figure 5 shows.
} 


\section{F. Additional Counterfactuals}

We use the model to conduct two additional counterfactuals. The first is the extent to which our results change with the size of the debt relief provided to borrowers. For example, would the employment effects have been twice as large if the amount of debt relief during the Great Recession had also been twice as large? Figure 7 plots the debt relief multipliers, both absolute and relative, as a fraction of the size of the debt relief shock. The impact multiplier is largest when the shock $\Delta$ is small relative to PCE. This is because small transfers are spent immediately by constrained consumers. When the transfer gets sufficiently large, borrowers save a fraction of it, lowering the impact multiplier and spreading the aggregate effect of debt relief over multiple periods. The lower their discount factor $\beta^{B}$, the larger the transfer needs to be before this happens. In our baseline calibration with an annual $\beta^{B}=0.92$, this nonlinearity takes place once transfers reach 3 percent of PCE. ${ }^{38}$ This exercise provides an important cautionary tale for debt relief programs as aggregate demand management, since they show that those programs are most effective at boosting current demand when they are relatively small in magnitude.

The final counterfactual we consider is the how our results change with depending on who finances the debt relief. If the agents that are financing the debt relief are themselves highly constrained, for example, the aggregate effect of debt relief may be smaller or even contractionary. We address this question in two ways. First, within our model, we assess what happens as we vary the burden of debt relief financing $f$ between home and foreign savers. If home savers pay for home debt relief, aggregate effectiveness might be more limited than if foreign savers paid for it. Appendix Figure A8 shows that while this is qualitatively right, lowering $f$ towards zero does not significantly reduce either the relative or the home multiplier significantly. The intuition is that saver MPCs are always low, so the amount of regional offset is low no matter where savers are located. Second, we can speculate on what would happen in an alternative model in which savers also had high MPCs but were located in the foreign region. Such a model would generate positive relative multipliers but a zero aggregate multiplier (see for example Hausman, Rhode and Wieland 2019). A model along these lines would generate much smaller relative multipliers, and be inconsistent with our empirical results. We conclude that, while the MPCs of agents financing debt relief are important for the aggregate effectiveness of debt relief policy, our results are only consistent with low MPCs for savers over the period.

\footnotetext{
${ }^{38}$ This result can be understood by considering the shape of the consumption of borrowers, which we derive explicitly for a continuous-time version of the model in Appendix B. As in Achdou et al. (2017), the consumption function of borrowers behaves likes a square-root function of debt relief when debt relief is sufficiently small. This concave consumption function translates into a concave aggregate employment effect as a function of debt relief size, or a diminishing multiplier.
} 


\section{G. Persistence}

We conclude this section by considering the issue of persistence. Figure 2 shows that the non-tradable employment effects are highly persistent in the data, and, in fact, increase over time. These results are consistent with the highly persistent responses to local unemployment shocks documented in Yagan (2017), but imply that the long-run debt relief multipliers are even larger than the short-run multipliers. Simple models in which debt relief constitutes a transitory demand shock, including our model, are unable to generate these kinds of highly persistent responses. Neoclassical adjustment mechanisms, such as a change in relative prices or movements of capital and labor across regions, tend to make these transitory demand effects disappear in the medium-run, also contrasting with our empirical findings. In principle, mechanisms relying on an endogenous response of innovation to demand shocks (Benigno and Fornaro 2018), or on a slow human capital decay following aggregate unemployment (Jarosch 2015) may be able to quantitatively explain our findings, however. We leave this question to future research.

\section{Conclusion}

We use cross-state variation in bankruptcy exemptions and a general equilibrium model to show that the ex-post debt forgiveness provided by the consumer bankruptcy system stabilized macroeconomic activity during the Great Recession. We find that states with more generous bankruptcy exemptions had larger consumer debt write-downs and smaller declines in local non-tradable employment compared to less generous states during this time period. In contrast, we estimate a small and statistically insignificant effect of more generous bankruptcy exemptions on local tradable employment during the Great Recession, and all outcomes prior to the Great Recession. The implied relative debt relief multiplier from our estimates suggest that each additional percent of PCE spent on reducing local borrowers' debt results in a 1.81 percent relative increase in non-tradable employment and a 0.39 percent relative increase in tradable employment. However, we show that these relative multipliers are insufficient to identify the overall level effect of debt relief during this period.

To recover an aggregate debt relief multiplier, we develop a general equilibrium currency union model of consumer debt forgiveness featuring non-tradable and tradable goods. We find that substantial nominal rigidities are required to rationalize our reduced form estimates. With monetary policy at the zero lower bound, spillovers through traded good demand imply a large causal effect of debt relief on employment in both high and low debt relief locations. Our model implies an aggregate debt 
relief multiplier of 1.88, suggesting that the debt forgiveness provided during the Great Recession increased aggregate employment by almost two percent at the end of 2009. Our multiplier is large in part because debt relief is sufficiently small that consumers spend all of it immediately.

The findings from this paper can help inform ongoing efforts to evaluate the welfare impact of the consumer bankruptcy system. These evaluations typically use quantitative models to weigh the trade-off between the ex-post consumption smoothing benefits provided by bankruptcy protection at the individual level (e.g., Dobbie and Song 2015), with the ex-ante increased borrowing costs suggested by economic theory (e.g., Athreya 2002, Li and Sarte 2006, Livshits, MacGee and Tertilt 2007, Chatterjee and Gordon 2012) and documented empirically by Severino and Brown (2017). Our results suggest that aggregate demand effects are important to evaluate the macroeconomic benefits of the consumer bankruptcy system, so that the overall benefit may be broader than previously realized. We therefore view the incorporation of our empirical estimates into a general equilibrium model of the credit market incorporating ex-ante effects as an important area for future research. 


\section{References}

Abadie, Alberto, Susan Athey, Guido W. Imbens, and Jeffrey Wooldridge. 2017. "When Should You Adjust Standard Errors for Clustering?" National Bureau of Economic Research Working Paper 24003.

Achdou, Yves, Jiequn Han, Jean-Michel Lasry, Pierre-Louis Lions, and Benjamin Moll. 2017. "Income and Wealth Distribution in Macroeconomics: A Continuous-Time Approach." National Bureau of Economic Research Working Paper 23732.

Adao, Rodrigo, Costas Arkolakis, and Federico Esposito. 2019. "Spatial Linkages, Global Shocks, and Local Labor Markets: Theory and Evidence." National Bureau of Economic Research Working Paper 25544.

Adelino, Manuel, Antoinette Schoar, and Felipe Severino. 2018. "Dynamics of Housing Debt in the Recent Boom and Great Recession." NBER Macroeconomics Annual, 32(1): 265-311.

Agarwal, Sumit, Gene Amromin, Itzhak Ben-David, Souphala Chomsisengphet, Tomasz Piskorski, and Amit Seru. 2017. "Policy Intervention in Debt Renegotiation: Evidence from the Home Affordable Modification Program." Journal of Political Economy, 125(3): 654-712.

Athreya, Kartik B. 2002. "Welfare Implications of the Bankruptcy Reform Act of 1999." Journal of Monetary Economics, 49(8): 1567-1595.

Auclert, Adrien, and Kurt Mitman. 2018. “Consumer Bankruptcy as Aggregate Demand Management." Manuscript.

Auclert, Adrien, and Matthew Rognlie. 2017. "A Note on Multipliers in NK Models with GHH Preferences." Manuscript.

Auclert, Adrien, Matthew Rognlie, and Ludwig Straub. 2018. “The Intertemporal Keynesian Cross." National Bureau of Economic Research Working Paper 25020.

Avery, Robert B, Paul S Calem, Glenn B Canner, and Raphael W Bostic. 2003. "An Overview of Consumer Data and Credit Reporting." Federal Reserve Bulletin, 89: 47.

Benigno, Gianluca, and Luca Fornaro. 2018. "Stagnation Traps." Review of Economic Studies, 85(3): 1425-1470.

Beraja, Martin, Erik Hurst, and Juan Ospina. 2016. “The Aggregate Implications of Regional Business Cycles." National Bureau of Economic Research Working Paper 21956.

Bertrand, Marianne, Esther Duflo, and Sendhil Mullainathan. 2004. "How Much Should We Trust Differences-In-Differences Estimates?" Quarterly Journal of Economics, 119(1): 249-275.

Board of Governors. 2018a. "Charge-Off and Delinquency Rates on Loans and Leases at Commercial Banks." Board of Governors of the Federal Reserve System. https: / /www. federalreserve. gov/releases/chargeoff/chgallsa.htm. 
Board of Governors. 2018b. "Households and nonprofit organizations; consumer credit; liability, Level." Board of Governors of the Federal Reserve System. Retrieved from FRED, Federal Reserve Bank of St. Louis. https: / / fred.stlouisfed.org/series/HNOCCIQ027.S.

Chatterjee, Satyajit, and Grey Gordon. 2012. "Dealing with Consumer Default: Bankruptcy vs Garnishment." Journal of Monetary Economics, 59: S1-S16.

Chodorow-Reich, Gabriel. Forthcoming. "Geographic Cross-Sectional Fiscal Multipliers: What Have We Learned?" American Economic Journal: Economic Policy.

Chodorow-Reich, Gabriel, Gita Gopinath, Prachi Mishra, and Abhinav Narayanan. 2018. "Cash and the Economy: Evidence from India's Demonetization." National Bureau of Economic Research Working Paper 25370.

Chodorow-Reich, Gabriel, Plamen T. Nenov, and Alp Simsek. 2019. "Stock Market Wealth and the Real Economy: A Local Labor Market Approach." Manuscript.

Corbi, Raphael B., Elias Papaioannou, and Paolo Surico. Forthcoming. "Regional Transfer Multipliers." Review of Economic Studies.

Currie, Janet, and Jonathan Gruber. 1996. "Saving Babies: The Efficacy and Cost of Recent Changes in the Medicaid Eligibility of Pregnant Women." Journal of Political Economy, 104(6): 1263-1296.

Dávila, Eduardo. 2016. “Using Elasticities to Derive Optimal Bankruptcy Exemptions.” European Systemic Risk Board Working Paper.

Department of Labor. 2018. “Unemployment Insurance Chartbook.” Department of Labor.

Di Maggio, Marco, and Amir Kermani. 2017. “Unemployment Insurance as an Automatic Stabilizer: The Financial Channel."

Dobbie, Will, and Jae Song. 2015. "Debt Relief and Debtor Outcomes: Measuring the Effects of Consumer Bankruptcy Protection." American Economic Review, 105(3): 1272-1311.

Dobbie, Will, and Paige Marta Skiba. 2013. "Information Asymmetries in Consumer Credit Markets: Evidence from Payday Lending." American Economic Journal: Applied Economics, 5(4): 256-82.

Dobbie, Will, Paul Goldsmith-Pinkham, and Crystal Yang. 2015. "Consumer Bankruptcy and Financial Health." National Bureau of Economic Research Working Paper 21032.

Donaldson, Jason Roderick, Giorgia Piacentino, and Anjan V Thakor. Forthcoming. "Household Debt and Unemployment." Journal of Finance.

Dupor, Bill, Marios Karabarbounis, Marianna Kudlyak, and M. Saif Mehkari. 2019. "Regional Consumption Responses and the Aggregate Fiscal Multiplier." Federal Reserve of San Francisco Working Paper 3131248.

Eggertsson, Gauti B., and Paul Krugman. 2012. "Debt, Deleveraging, and the Liquidity Trap: A Fisher-Minsky-Koo Approach." Quarterly Journal of Economics, 127(3): 1469-1513. 
Farhi, Emmanuel, and Iván Werning. 2016a. "Chapter 31 - Fiscal Multipliers: Liquidity Traps and Currency Unions." In Handbook of Macroeconomics. Vol. 2, , ed. Harald Uhlig and John B. Taylor, 2417-2492. Elsevier.

Farhi, Emmanuel, and Iván Werning. 2016b. "A Theory of Macroprudential Policies in the Presence of Nominal Rigidities." Econometrica, 84(5): 1645-1704.

Fay, Scott, Erik Hurst, and Michelle J White. 2002. "The Household Bankruptcy Decision." American Economic Review, 92(3): 706-718.

Foote, Christopher L, Lara Loewenstein, and Paul S Willen. 2016. "Cross-Sectional Patterns of Mortgage Debt during the Housing Boom: Evidence and Implications." National Bureau of Economic Research Working Paper 22985.

Galí, Jordi, and Tommaso Monacelli. 2005. "Monetary Policy and Exchange Rate Volatility in a Small Open Economy." Review of Economic Studies, 72(3): 707-734.

Ganong, Peter, and Pascal Noel. 2018. "Liquidity vs. Wealth in Household Debt Obligations: Evidence from Housing Policy in the Great Recession." National Bureau of Economic Research Working Paper 24964.

Ghent, Andra C, and Marianna Kudlyak. 2011. "Recourse and Residential Mortgage Default: Evidence from US States." Review of Financial Studies, 24(9): 3139-3186.

Goodman, Paul. 1993. "The Emergence of Homestead Exemption in the United States: Accommodation and Resistance to the Market Revolution, 1840-1880." Journal of American History, 80(2): 470-498.

Greenwood, Jeremy, Zvi Hercowitz, and Gregory W. Huffman. 1988. “Investment, Capacity Utilization, and the Real Business Cycle." American Economic Review, 78(3): 402-417.

Gropp, Reint, John Karl Scholz, and Michelle J White. 1997. “Personal Bankruptcy and Credit Supply and Demand." Quarterly Journal of Economics, 112(1): 217-251.

Gross, Tal, Matthew J. Notowidigdo, and Jialan Wang. 2016. “The Marginal Propensity to Consumer Over the Business Cycle." National Bureau of Economic Research Working Paper 22518.

Guerrieri, Luca, and Matteo Iacoviello. 2015. “Occbin: A Toolkit for Solving Dynamic Models with Occasionally Binding Constraints Easily." Journal of Monetary Economics, 70: 22-38.

Guerrieri, Veronica, and Guido Lorenzoni. 2017. "Credit Crises, Precautionary Savings, and the Liquidity Trap." Quarterly Journal of Economics, 132(3): 1427-1467.

Guren, Adam M., Alisdair McKay, Emi Nakamura, and Jón Steinsson. 2018. "What Do We Learn From Cross-Sectional Empirical Estimates in Macroeconomics?” Manuscript.

Hall, Robert E. 2011. “The Long Slump.” American Economic Review, 101(2): 431-469.

Hausman, Joshua K., Paul W. Rhode, and Johannes F. Wieland. 2019. "Recovery from the Great Depression: The Farm Channel in Spring 1933." American Economic Review, 109(2): 427-472. 
House, Christopher L, Christian Proebsting, and Linda L Tesar. 2017. "Austerity in the Aftermath of the Great Recession." National Bureau of Economic Research Working Paper 23147.

Hsu, Joanne W, David A Matsa, and Brian T Melzer. 2018. “Unemployment Insurance as a Housing Market Stabilizer." American Economic Review, 108(1): 49-81.

Jarosch, Gregor. 2015. "Searching for Job Security and the Consequences of Job Loss." Manuscript.

Kekre, Rohan. 2018. “Unemployment Insurance in Macroeconomic Stabilization.” Manuscript.

Korinek, Anton, and Alp Simsek. 2016. "Liquidity Trap and Excessive Leverage." American Economic Review, 106(3): 699-738.

Lee, Donghoon, and Wilbert Van der Klaauw. 2010. "An Introduction to the FRBNY Consumer Credit Panel." Federal Reserve Bank of New York Staff Report.

Livshits, Igor, James MacGee, and Michele Tertilt. 2007. "Consumer Bankruptcy: A Fresh Start." American Economic Review, 97(1): 402-418.

Li, Wenli, and Pierre-Daniel Sarte. 2006. "US Consumer Bankruptcy Choice: The Importance of General Equilibrium Effects." Journal of Monetary Economics, 53(3): 613-631.

Mahoney, Neale. 2015. "Bankruptcy as Implicit Health Insurance." American Economic Review, 105(2): 710-746.

Martin, Philippe, and Thomas Philippon. 2017. “Inspecting the Mechanism: Leverage and the Great Recession in the Eurozone." American Economic Review, 107(7): 1904-37.

McKay, Alisdair, and Ricardo Reis. 2016. “Optimal Automatic Stabilizers." National Bureau of Economic Research Working Paper 22359.

Mian, Atif, Amir Sufi, and Emil Verner. 2017. "How Do Credit Supply Shocks Affect the Real Economy? Evidence from the United States in the 1980s." National Bureau of Economic Research Working Paper 23802.

Mian, Atif, and Amir Sufi. 2014a. House of Debt: How They (and You) Caused the Great Recession, and How We Can Prevent It from Happening Again. Chicago; London: University Of Chicago Press.

Mian, Atif, and Amir Sufi. 2014b. "What Explains the 2007-2009 Drop in Employment?" Econometrica, 82(6): 2197-2223.

Mian, Atif, Kamalesh Rao, and Amir Sufi. 2013. "Household Balance Sheets, Consumption, and the Economic Slump." Quarterly Journal of Economics, 128(4): 1687-1726.

Midrigan, Virgiliu, and Thomas Philippon. 2018. "Household Leverage and the Recession." National Bureau of Economic Research Working Paper 16965.

Nakamura, Emi, and Jón Steinsson. 2014. “Fiscal Stimulus in a Monetary Union: Evidence from US Regions." American Economic Review, 104(3): 753-792. 
Nakamura, Emi, and Jón Steinsson. 2018. "Identification in Macroeconomics." Journal of Economic Perspectives, 32(3): 59-86.

Piskorski, Tomasz, and Amit Seru. 2018. "Debt Relief and Slow Recovery: A Decade after Lehman." National Bureau of Economic Research Working Paper 25403.

Saiz, Albert. 2010. “The Geographic Determinants of Housing Supply.” Quarterly Journal of Economics, 125(3): 1253-1296.

Sarto, Andres. 2018. “Recovering Macro Elasticities from Regional Data." Manuscript.

Severino, Felipe, and Meta Brown. 2017. "Personal Bankruptcy Protection and Household Debt." SSRN Working Paper 2447687.

Skeel, David A. 2001. Debt's Dominion: A History of Bankruptcy Law in America. Princeton University Press.

Suárez Serrato, Juan Carlos, and Philippe Wingender. 2016. "Estimating Local Fiscal Multipliers." National Bureau of Economic Research Working Paper 22425.

Tai, Mingzhu. 2017. "House Prices and the Allocation of Consumer Credit." Manuscript.

U.S. Courts. 2017. "Bankruptcy Abuse Prevention and Consumer Protection Act (BAPCPA) Report." http://www.uscourts.gov/statistics-reports/bapcpa-report-2017.

U.S. Treasury. 2018. "Making Home Affordable Program Performance Report - Fourth Quarter 2017." https://www.treasury.gov/initiatives/financial-stability/reports/ Documents/4Q17MHAReportFinal.pdf.

Verner, Emil, and Gyozo Gyongyosi. 2018. "Household Debt Revaluation and the Real Economy: Evidence from a Foreign Currency Debt Crisis." SSRN Working Paper 3241309.

Whittaker, Julie M., and Katelin P. Isaacs. 2016. "Unemployment Insurance: Programs and Benefits." Congressional Research Service CRS Report RL33362. https: / fas.org/sgp/crs/misc/ RL33362.pdf.

Wilshusen, Stephanie. 2011. "Meeting the Demand for Debt Relief." Payment Cards Center, Federal Reserve Bank of Philadelphia Discussion Paper 11-04.

Yagan, Danny. 2017. "Employment Hysteresis from the Great Recession." National Bureau of Economic Research Working Paper 23844. 
Table 1: Descriptive Statistics

\begin{tabular}{|c|c|c|c|}
\hline & $\begin{array}{l}\text { Avg Change from } \\
\text { 2001q1-2007q4 }\end{array}$ & $\begin{array}{l}\text { Avg Change from } \\
\text { 2007q4-2010q4 }\end{array}$ & $\begin{array}{l}\text { Avg Change from } \\
\text { 2010q4-2013q4 }\end{array}$ \\
\hline Panel A: Employment Outcomes & $(1)$ & $(2)$ & (3) \\
\hline Non-Tradable Emp. ( $\Delta$ p.p.) & 1.194 & -5.178 & 5.300 \\
\hline Tradable + Other Emp. ( $\Delta$ p.p.) & -3.376 & -7.988 & 3.740 \\
\hline Total Emp. ( $\Delta$ p.p.) & -2.570 & -7.406 & 4.056 \\
\hline \multicolumn{4}{|l|}{ Panel B: Credit Outcomes } \\
\hline Annual Charge-offs $(\Delta \$)$ & -3.918 & 124.775 & -241.672 \\
\hline Bankrupty Rate ( $\Delta$ p.p.) & 0.158 & 0.107 & -0.091 \\
\hline Foreclosure Rate ( $\Delta$ p.p.) & 0.145 & 0.906 & 0.057 \\
\hline Credit Card Limits $(\Delta \$)$ & $2,790.922$ & $-2,539.916$ & 954.736 \\
\hline Credit Card Debt $(\Delta \$)$ & 182.507 & -132.620 & -276.685 \\
\hline Mortgage Debt $(\Delta \$ 000)$ & 26.124 & 1.839 & -3.977 \\
\hline \multicolumn{4}{|l|}{ Panel C: Inflation Outcomes } \\
\hline Non-Tradable CPI ( $\Delta$ p.p.) & 21.836 & 4.985 & 6.417 \\
\hline Tradable CPI ( $\Delta$ p.p.) & 10.908 & 3.167 & 6.503 \\
\hline Total CPI ( $\Delta$ p.p.) & 17.646 & 4.292 & 6.462 \\
\hline \multicolumn{4}{|l|}{ Panel D: Housing Outcomes } \\
\hline House Price ( $\Delta$ p.p.) & 40.958 & -21.846 & 10.669 \\
\hline
\end{tabular}

Note: This table reports summary statistics. Each column reports the difference in the outcome over the period, averaged over all counties in the sample using population weights. Panel A reports the difference in log employment per working-age person, or the percent change in the share employed of the working-age population. Employment data is from the Quarterly Census of Employment and Wages. Non-tradable industries are defined as the retail and restaurant sectors following Mian and Sufi (2014b). Tradable and Other industries are also defined following Mian and Sufi (2014b). Panel B reports the average change across counties for various credit outcomes using data from Equifax. Annual charge-offs reports the average difference in dollars in the amount of derogatory debt discharged by credit card and auto lenders per person. Bankruptcy and foreclosure rates report the difference in the percent of people who file for foreclosure and bankruptcy per county. Credit card limits and debt report the difference in dollars per person and mortgage debt reports the difference in mortgage debt in thousands of dollars per person. All credit outcomes are smoothed according to a moving average which includes $t-2$ through $t+1$. Panel $C$ reports the difference in log consumer price index over the period, or the percent change in inflation. Price index data is from the BLS Consumer Price Index measured at the Metropolitan Statistical Area level matched to counties. Non-tradable CPI is based on prices for services and tradable CPI refers to commodity prices, following Mian, Sufi and Verner (2017). Panel D reports the difference in log house prices, or the percent change in house prices. House price data comes from CoreLogic. 
Table 2: Reduced Form Effects of Bankruptcy Protections on Employment

\begin{tabular}{|c|c|c|c|c|c|}
\hline \multirow[b]{2}{*}{ Panel A: 2008q1-2010q4 } & \multirow{2}{*}{$\frac{\text { Avg Change }}{(1)}$} & \multicolumn{4}{|c|}{ Effect of Bankruptcy Protections } \\
\hline & & $(2)$ & $(3)$ & $(4)$ & $(5)$ \\
\hline Log Non-Tradable Emp. & $\begin{array}{l}-5.178 \\
(6.737)\end{array}$ & $\begin{array}{l}0.499^{* * *} \\
(0.183)\end{array}$ & $\begin{array}{c}0.399^{* *} \\
(0.166)\end{array}$ & $\begin{array}{l}0.422^{* * *} \\
(0.100)\end{array}$ & $\begin{array}{l}0.435^{* * *} \\
(0.104)\end{array}$ \\
\hline Log Tradable + Other Emp. & $\begin{array}{l}-7.988 \\
(8.263)\end{array}$ & $\begin{array}{c}0.162 \\
(0.366)\end{array}$ & $\begin{array}{c}0.086 \\
(0.330)\end{array}$ & $\begin{array}{c}-0.125 \\
(0.221)\end{array}$ & $\begin{array}{c}-0.048 \\
(0.211)\end{array}$ \\
\hline Log Total Emp. & $\begin{array}{l}-7.406 \\
(6.919)\end{array}$ & $\begin{array}{c}0.231 \\
(0.311)\end{array}$ & $\begin{array}{c}0.156 \\
(0.272)\end{array}$ & $\begin{array}{r}-0.005 \\
(0.176)\end{array}$ & $\begin{array}{c}0.061 \\
(0.170)\end{array}$ \\
\hline \multicolumn{6}{|l|}{ Panel B: 2011q1-2013q4 } \\
\hline Log Non-Tradable Emp. & $\begin{array}{c}5.300 \\
(5.896)\end{array}$ & $\begin{array}{l}1.096^{* * *} \\
(0.228)\end{array}$ & $\begin{array}{l}0.842^{* * *} \\
(0.268)\end{array}$ & $\begin{array}{l}0.941^{* * *} \\
(0.241)\end{array}$ & $\begin{array}{l}0.945^{\text {*** }} \\
(0.241)\end{array}$ \\
\hline Log Tradable + Other Emp. & $\begin{array}{c}3.740 \\
(8.224)\end{array}$ & $\begin{array}{c}-0.103 \\
(0.455)\end{array}$ & $\begin{array}{c}-0.075 \\
(0.404)\end{array}$ & $\begin{array}{c}-0.249 \\
(0.275)\end{array}$ & $\begin{array}{c}-0.209 \\
(0.273)\end{array}$ \\
\hline Log Total Emp. & $\begin{array}{c}4.056 \\
(6.712)\end{array}$ & $\begin{array}{c}0.139 \\
(0.337) \\
\end{array}$ & $\begin{array}{c}0.130 \\
(0.308) \\
\end{array}$ & $\begin{array}{c}0.018 \\
(0.212) \\
\end{array}$ & $\begin{array}{c}0.054 \\
(0.211) \\
\end{array}$ \\
\hline Number of Observations & & 161,720 & 161,720 & 161,720 & 155,324 \\
\hline County F.E. & & Y & Y & Y & $\mathrm{Y}$ \\
\hline Year-Quarter F.E. & & $\mathrm{Y}$ & $\mathrm{Y}$ & $\mathrm{Y}$ & $\mathrm{Y}$ \\
\hline Housing Controls × YQ F.E. & & $\mathrm{N}$ & $\mathrm{Y}$ & $\mathrm{Y}$ & $\mathrm{Y}$ \\
\hline Additional Controls $\times$ YQ F.E. & & $\mathrm{N}$ & $\mathrm{N}$ & Y & $\mathrm{Y}$ \\
\hline Exclude Sand States & & $\mathrm{N}$ & $\mathrm{N}$ & $\mathrm{N}$ & $\mathrm{Y}$ \\
\hline
\end{tabular}

Note: This table reports estimates of the reduced form effect of cross-state bankruptcy protections on log employment outcomes scaled by working-age population (age 18-65). The first row of each panel reports results for log non-tradable employment, defined as the retail and restaurant sectors. The second row reports results for log tradable and other employment, where tradable employment is defined as industries with sufficiently large imports and exports from the United States, and other employment is defined as all other industries excluding the construction sector Mian and Sufi (2014b). The third row reports results for log total employment. Column 1 reports the cross-county average and standard deviation of the change in the dependent variable from 2007q4-2010q4 or 2010q4-2013q4. Columns 2-5 report coefficients on the average effect of a one standard deviation decrease in the log financial cost of filing for bankruptcy protection, pooled over the periods 2008q1-2010q4 in Panel A and and 2011q1-2013q4 in Panel B. All estimates should be interpreted as the relative effect compared to 2007q4. Column 2 reports estimates with county and year-quarter fixed effects. Column 3 repeats the regression, adding the Saiz supply elasticity and share of the population who own a home in 2007q4 for each county, interacted with year-quarter fixed effects. For counties without the Saiz supply elasticity measure, the measure is set to zero, and an additional dummy for missing supply elasticity is interacted with year-quarter fixed effects. Column 4 repeats the same regression, but with a set of location controls interacted with year-quarter fixed effects: the share of Democratic voters in 2004, the maximum unemployment insurance benefit, the share of college-educated individuals in a county, the share of the population that is under the age of 45 , the average debt-to-income ratio for the state in 2007, and the predicted exposure to local unemployment shocks during the Great Recession. Finally, Column 5 repeats Column 4, but excludes the "sand states," or Arizona, California, Nevada, and New Mexico. All regressions are weighted by county population as of 2007 and cluster the standard errors at the state level. Standard errors are clustered at the state level. See the text for additional details on the specification and the Table 1 notes for additional details on the outcome measures and sample. 
Table 3: Reduced Form Effects of Bankruptcy Protections on Debt Write-Downs

\begin{tabular}{|c|c|c|c|c|c|}
\hline \multirow[b]{2}{*}{ Panel A: 2008q1-2010q4 } & \multirow{2}{*}{$\frac{\text { Avg Change }}{(1)}$} & \multicolumn{4}{|c|}{ Effect of Bankruptcy Protections } \\
\hline & & $(2)$ & (3) & $(4)$ & (5) \\
\hline Charge-Offs in Full Sample & $\begin{array}{c}124.775 \\
(199.676)\end{array}$ & $\begin{array}{c}50.385 \\
(35.896)\end{array}$ & $\begin{array}{l}54.503^{* *} \\
(22.779)\end{array}$ & $\begin{array}{l}38.177^{* * *} \\
(9.016)\end{array}$ & $\begin{array}{l}33.578^{* * *} \\
(9.530)\end{array}$ \\
\hline Charge-Offs for Homeowners & $\begin{array}{c}242.352 \\
(360.046)\end{array}$ & $\begin{array}{c}77.499 \\
(61.751)\end{array}$ & $\begin{array}{c}80.459^{* *} \\
(39.185)\end{array}$ & $\begin{array}{l}55.587^{* * *} \\
(13.294)\end{array}$ & $\begin{array}{l}53.032^{* * *} \\
(16.064)\end{array}$ \\
\hline Charge-Offs for Renters & $\begin{array}{c}-11.849 \\
(104.352)\end{array}$ & $\begin{array}{c}24.626^{*} \\
(14.019)\end{array}$ & $\begin{array}{c}22.579^{* *} \\
(10.733)\end{array}$ & $\begin{array}{l}15.272^{*} \\
(8.916)\end{array}$ & $\begin{array}{l}10.799^{* * *} \\
(3.258)\end{array}$ \\
\hline Panel B: 2011q1-2013q4 & & & & & \\
\hline Charge-Offs in Full Sample & $\begin{array}{c}-241.672 \\
(174.642)\end{array}$ & $\begin{array}{c}31.714 \\
(27.598)\end{array}$ & $\begin{array}{c}33.691^{*} \\
(18.338)\end{array}$ & $\begin{array}{l}22.861^{* * *} \\
(6.916)\end{array}$ & $\begin{array}{l}22.137^{* * *} \\
(7.408)\end{array}$ \\
\hline Charge-Offs for Homeowners & $\begin{array}{l}-400.601 \\
(290.675)\end{array}$ & $\begin{array}{c}47.585 \\
(51.431)\end{array}$ & $\begin{array}{c}49.411 \\
(32.105)\end{array}$ & $\begin{array}{l}29.151^{* * *} \\
(10.418)\end{array}$ & $\begin{array}{c}29.348^{* *} \\
(11.763)\end{array}$ \\
\hline Charge-Offs for Renters & $\begin{array}{c}-91.944 \\
(139.866)\end{array}$ & $\begin{array}{c}9.889 \\
(7.273)\end{array}$ & $\begin{array}{c}9.325 \\
(6.480)\end{array}$ & $\begin{array}{c}8.088^{*} \\
(4.157)\end{array}$ & $\begin{array}{c}7.311^{*} \\
(3.896)\end{array}$ \\
\hline Number of Observations & & 161,720 & 161,720 & 161,720 & 155,324 \\
\hline County F.E. & & $\mathrm{Y}$ & Y & $\mathrm{Y}$ & $\mathrm{Y}$ \\
\hline Year-Quarter F.E. & & $\mathrm{Y}$ & Y & $\mathrm{Y}$ & Y \\
\hline Housing Controls $\times$ YQ F.E. & & $\mathrm{N}$ & $\mathrm{Y}$ & Y & Y \\
\hline Additional Controls $\times$ YQ F.E. & & $\mathrm{N}$ & $\mathrm{N}$ & Y & Y \\
\hline Exclude Sand States & & $\mathrm{N}$ & $\mathrm{N}$ & $\mathrm{N}$ & Y \\
\hline
\end{tabular}

Note: This table reports estimates of the reduced form effect of cross-state bankruptcy protections on consumer debt chargeoffs. The first row of each panel reports results for the full sample. The second row reports results for homeowners, defined as mortgage borrowers in 2007. The third row reports results for renters, defined as all non-mortgage borrowers in 2007. Column 1 reports the cross-county average and standard deviation of the change in the dependent variable from 2007q4$2010 q 4$ or 2010q4-2013q4. Columns 2-5 report coefficients on the average effect of a one standard deviation decrease in the $\log$ financial cost of filing for bankruptcy protection, pooled over the periods 2008q1-2010q4 in Panel A and and 2011q1$2013 q 4$ in Panel B. All estimates should be interpreted as the relative effect compared to 2007q4. Column 2 reports estimates with county and year-quarter fixed effects. Column 3 repeats the regression, adding the Saiz supply elasticity and share of the population who own a home in 2007q4 for each county, interacted with year-quarter fixed effects. For counties without the Saiz supply elasticity measure, the measure is set to zero, and an additional dummy for missing supply elasticity is interacted with year-quarter fixed effects. Column 4 repeats the same regression, but with a set of location controls interacted with year-quarter fixed effects: the share of Democratic voters in 2004, the maximum unemployment insurance benefit, the share of college-educated individuals in a county, the share of the population that is under the age of 45 , the average debtto-income ratio for the state in 2007, and the predicted exposure to local unemployment shocks during the Great Recession. Finally, Column 5 repeats Column 4, but excludes the "sand states," or Arizona, California, Nevada, and New Mexico. All regressions are weighted by county population as of 2007 and cluster the standard errors at the state level. Standard errors are clustered at the state level. See the text for additional details on the specification and the Table 1 notes for additional details on the outcome measures and sample. 
Table 4: Model Parameters and Baseline Calibration

\begin{tabular}{c|c|c|c}
\hline & Parameter (Quarterly Frequency) & Value & Target \\
\hline$\varphi^{B}$ & Fraction of borrowers in each region & 0.5 & Share with credit card balance \\
$\beta^{S}$ & Saver discount factor & 0.983 & $7 \%$ annual interest rate \\
$\beta^{B}$ & Borrower discount factor & 0.92 & Arbitrary level below $\beta^{S}$ \\
$u(C, N)$ & Utility function & $\log (C)-\chi_{h} N^{2}$ & Standard specification \\
$1-\alpha$ & Non-tradable share & 0.236 & Data (Mian and Sufi 2014b) \\
$\eta$ & Subst. between T and NT & 2 & Standard value \\
$\epsilon$ & Subst. within T and within NT & 10 & Standard value \\
$\gamma$ & Exponent on labor in production & 0.66 & Data (NIPA) \\
$\theta$ & Fraction of firms with fixed price & 0.8 & Duration of price rigidity $=5 \mathrm{Q}$ \\
$\bar{b} / C$ & Debt limit (\% of annual PCE) & $16.67 \%$ & Avg Debt/PCE=8.33\% \\
$f$ & Incidence of debt relief & 0.5 & Equal incidence across regions \\
\hline
\end{tabular}

Note: This table displays parameter calibration values for the model in Section IV. See the text for additional details on the definition of each parameter and the target values. 


\section{Figure 1: Employment and Debt Relief during the Great Recession}

Employment to
Population Ratio

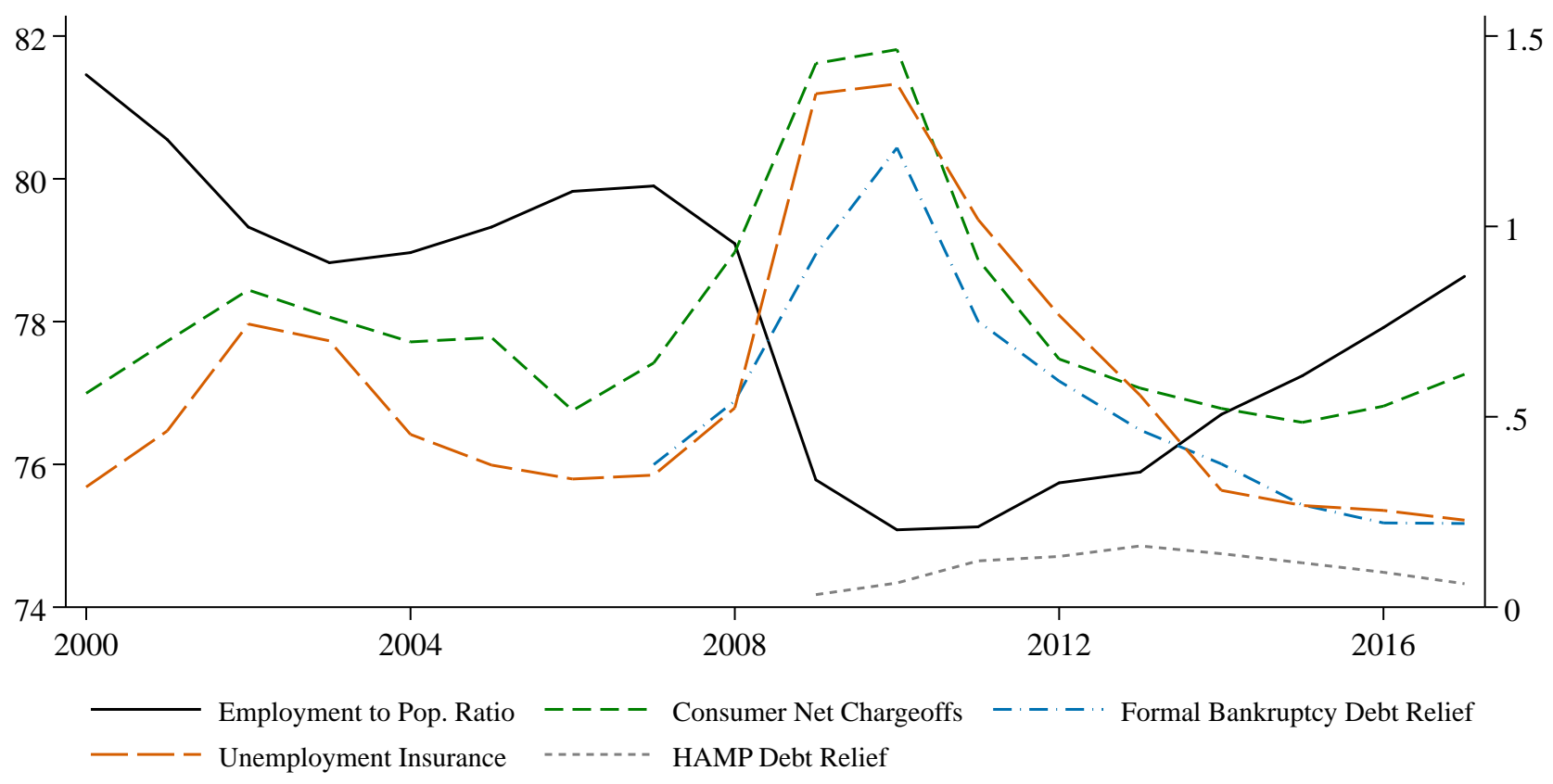

Program Payout Scaled by PCE
Note: This figure plots the employment-to-population ratio over time on the left y-axis, and payout measures as a percentage of PCE for four different debt relief programs on the right y-axis. Employment to population ratio is the 12-month average employment-to-population ratio for the working age population of individuals aged 25-54, as measured by the CPS in December of each year. Consumer net charge-offs is net consumer charge-offs on non-housing debt, as measured by the product of net charge-off rates from commercial banks on all non-real estate consumer loans (Board of Governors, 2018a) and consumer loans liabilities measured using the flow of funds (Board of Governors, 2018b). Formal bankruptcy debt relief is the annual level of unsecured debt scheduled for discharge for Chapter 7 bankruptcy filers reported in the BAPCPA reports (U.S. Courts, 2017). We report the face value of both net charge-offs and the amount of unsecured credit discharged in Chapter 7. Unemployment insurance is the annual program outlays from unemployment insurance reported by the Department of Labor (Department of Labor, 2018). HAMP debt relief combines the reported debt relief of the Home Affordable Modification Program (HAMP), the Principal Reduction Alternative (PRA) and the Home Affordable Foreclosure Alternatives (HAFA). To construct annual numbers, we take changes in the reported cumulative debt relief for each program reported in the Program Performance Reports (U.S. Treasury, 2018). For 2009-2012, where only HAMP numbers are reported, we proportionally allocate the other programs to the same share as HAMP. We thank Kurt Mitman for pointing out the time series relationship with UI payouts. 


\section{Figure 2: Reduced Form Effects of Bankruptcy Protections on Employment}

\section{Panel A: Log Non-Tradable Employment}

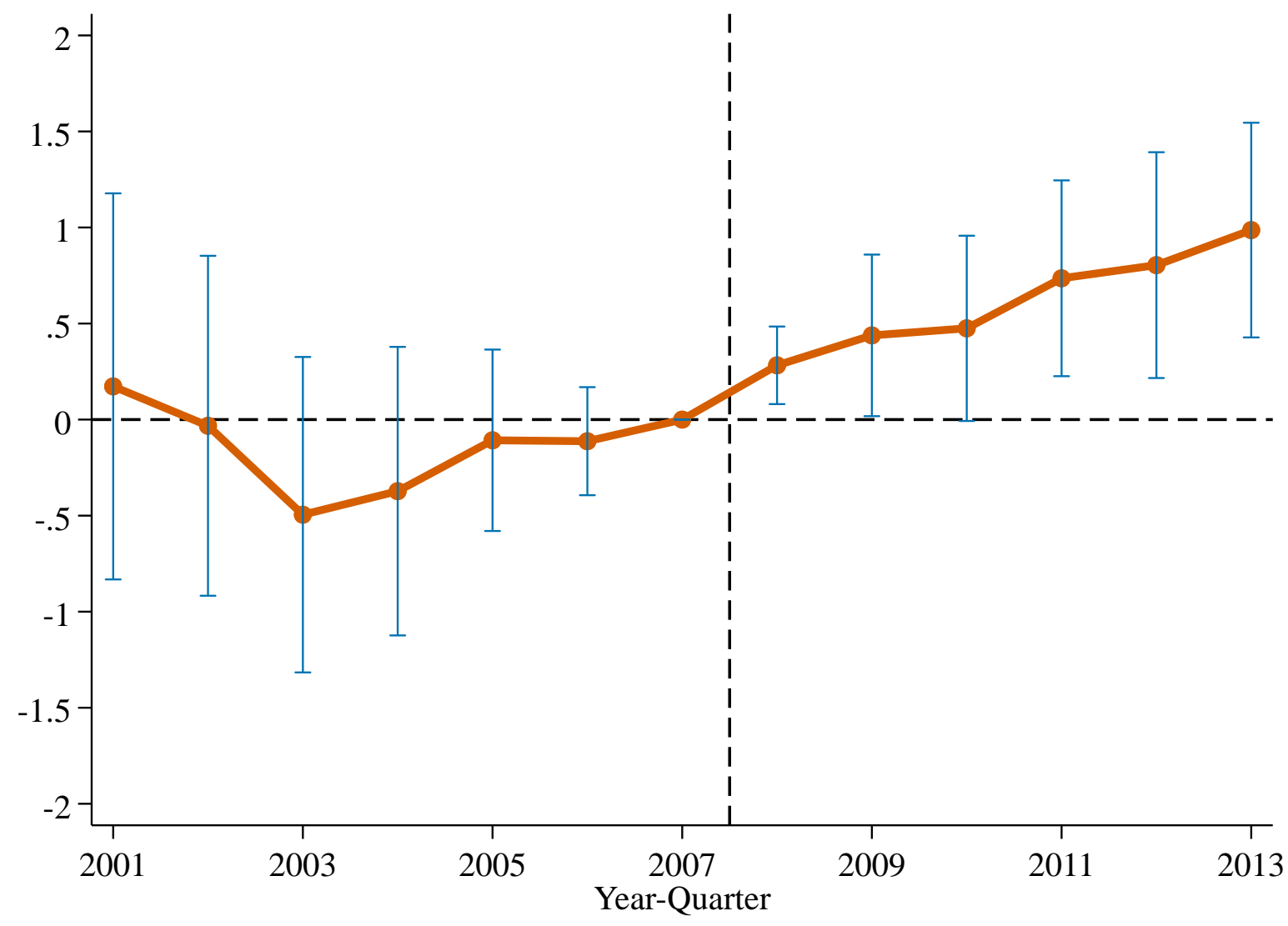

Panel B: Log Tradable and Other Employment

Panel C: Log Total Employment
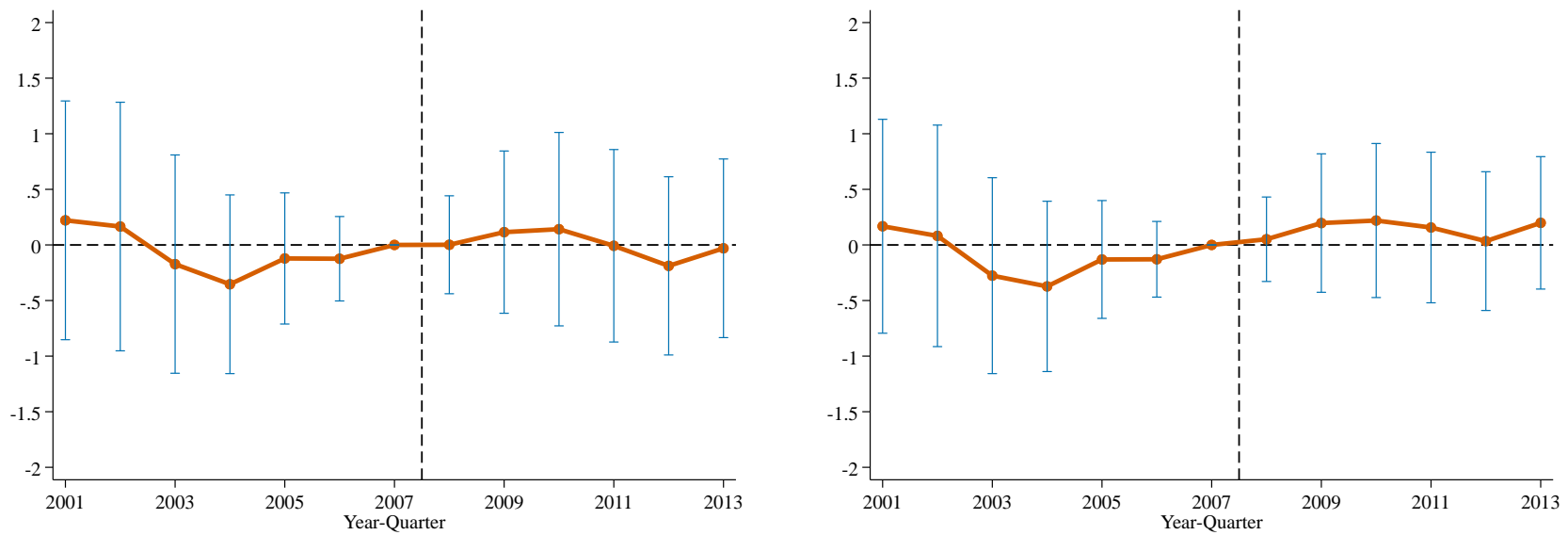

Note: This figure plots reduced form estimates of the effect of cross-state bankruptcy protections on employment outcomes. Panel A reports results for log non-tradable employment, defined as the retail and restaurant sectors. Panel B reports results for log tradable and other employment, where tradable employment is defined as industries with sufficiently large imports and exports from the United States, and other employment is defined as all other industries excluding the construction sector Mian and Sufi (2014b). Panel C reports results for log total employment. We report the coefficients from a panel regression of each log employment measure scaled by working-age population on the log financial cost of filing for bankruptcy protection interacted with year fixed effects. All specifications are weighted by county population as of 2007 and include county and year-quarter fixed effects, as well as the Saiz supply elasticity and share of the population who own a home in $2007 \mathrm{q} 1 \mathrm{for}$ each county interacted with year-quarter fixed effects. For counties without the Saiz supply elasticity measure, the measure is set to zero, and an additional dummy for missing supply elasticity is interacted with year-quarter fixed effects. The estimated effect is normalized to zero in 2007, meaning all estimates are relative to 2007. The dashed lines are 95 percent confidence intervals from standard errors clustered at the state level. See the text for additional details on the specification and the Table 1 notes for additional details on the outcome measures and sample. 


\section{Figure 3: Reduced Form Effects of Bankruptcy Protections on Per-Period Debt Write-Downs}

\section{Panel A: Charge-Offs in Full Sample}

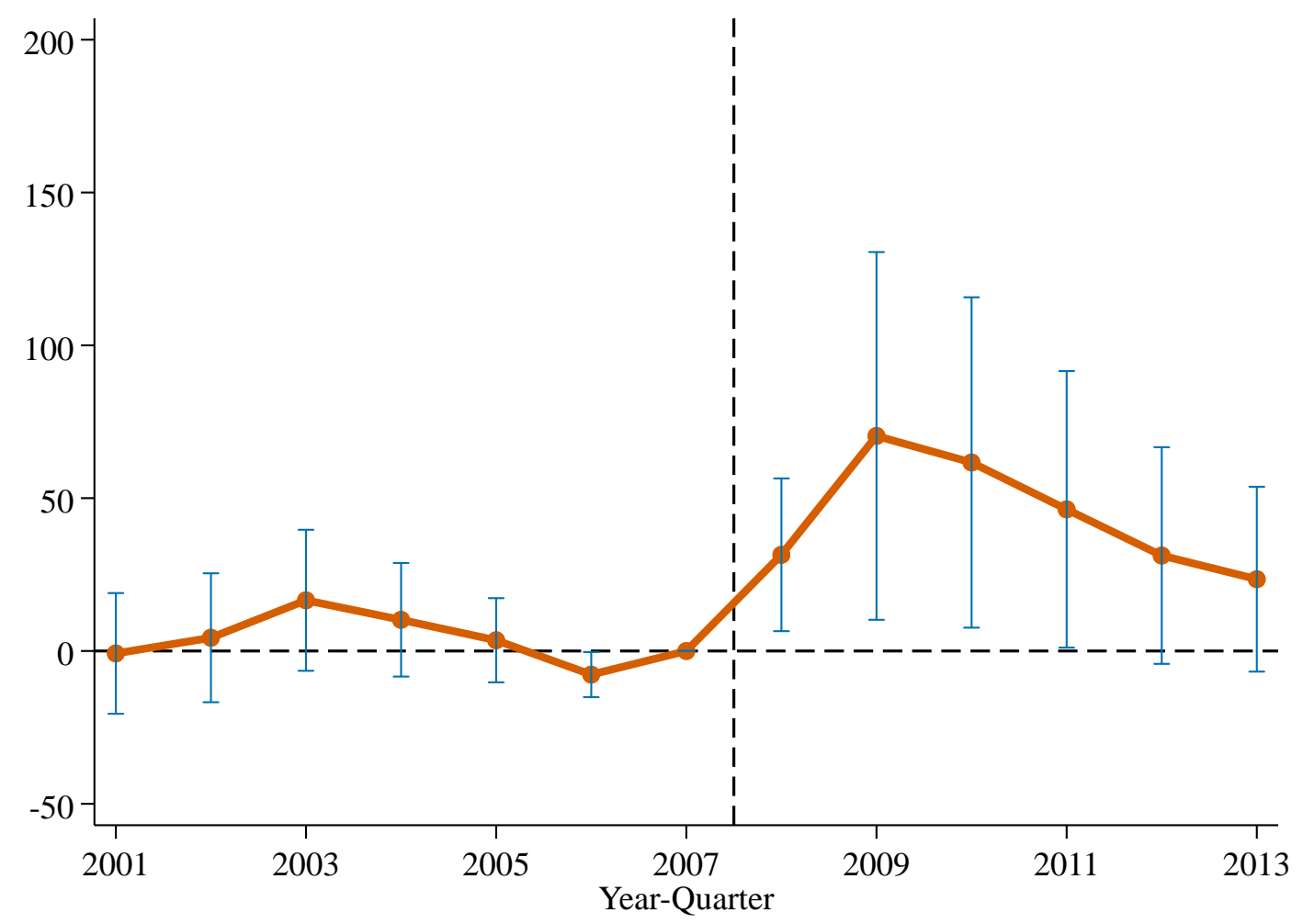

Panel B: Charge-Offs for Homeowners Only

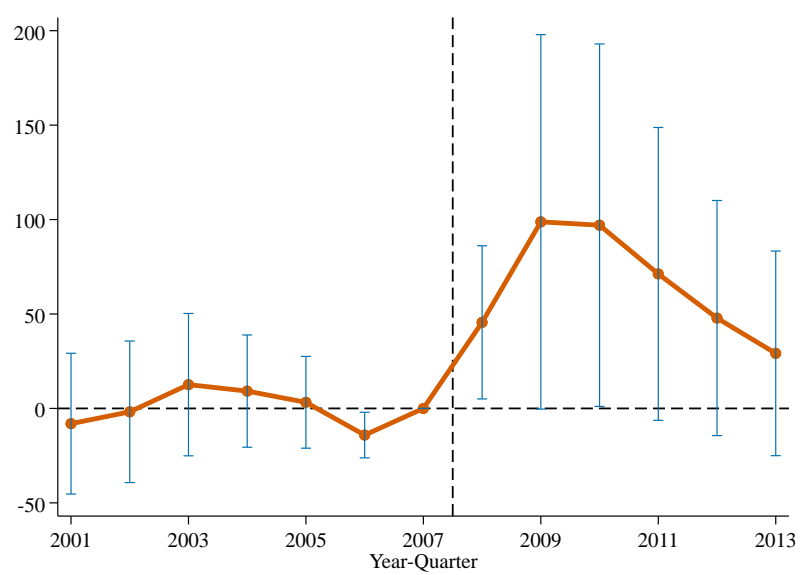

Panel C: Charge-Offs for Renters Only

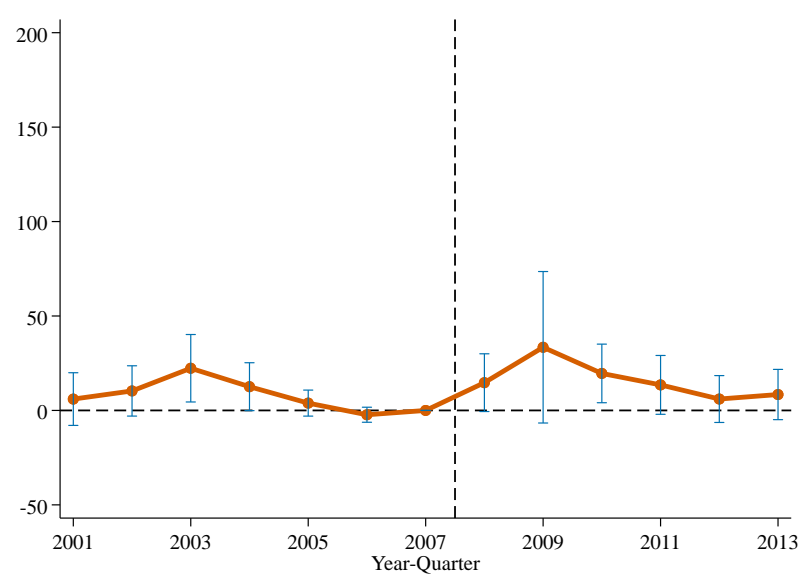

Note: This figure plots reduced form estimates of the effect of cross-state bankruptcy protections on annual charge-offs. Panel A reports results for the full sample. Panel B reports results for homeowners, defined as mortgage borrowers in 2007. Panel C reports results for renters, defined as all non-mortgage borrowers in 2007. We report the coefficients from a panel regression of charge-offs on the log financial cost of filing for bankruptcy protection interacted with year fixed effects. All specifications are weighted by county population as of 2007 and include county and year-quarter fixed effects, as well as the Saiz supply elasticity and share of the population who own a home in $2007 q 1$ for each county interacted with yearquarter fixed effects. For counties without the Saiz supply elasticity measure, the measure is set to zero, and an additional dummy for missing supply elasticity is interacted with year-quarter fixed effects. The estimated effect is normalized to zero in 2007, meaning all estimates are relative to 2007. The dashed lines are 95 percent confidence intervals from standard errors clustered at the state level. Coefficients are multiplied by four to scale average quarterly charge-off amounts to annual charge-offs. See the text for additional details on the specification and the Table 1 notes for additional details on the outcome measures and sample. 
Figure 4: Impulse Response to a Debt Relief Shock under Sticky Prices
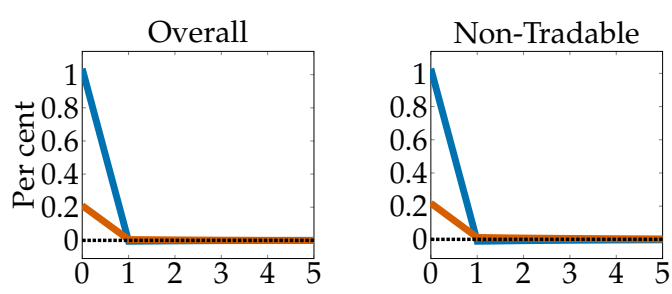

Panel A: Consumption
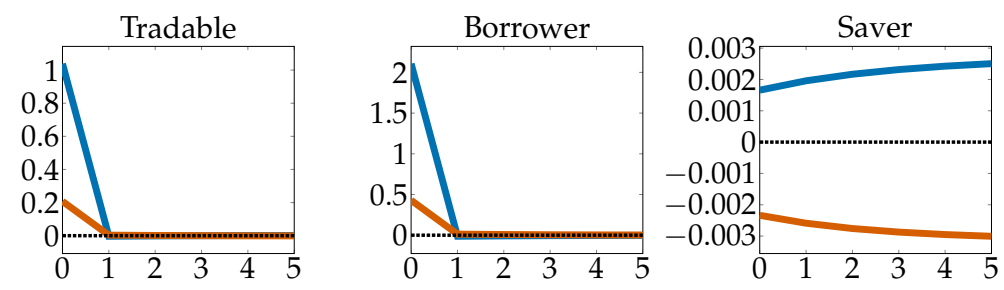

Panel B: Employment
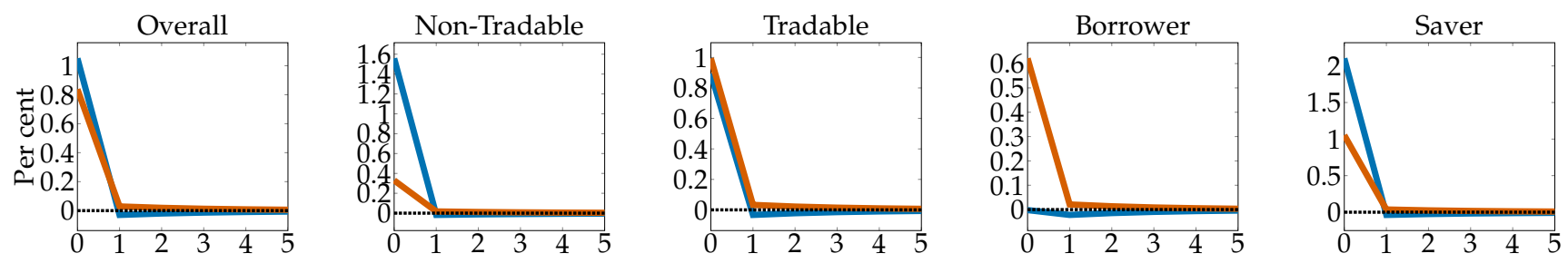

Panel C: Other Outcomes
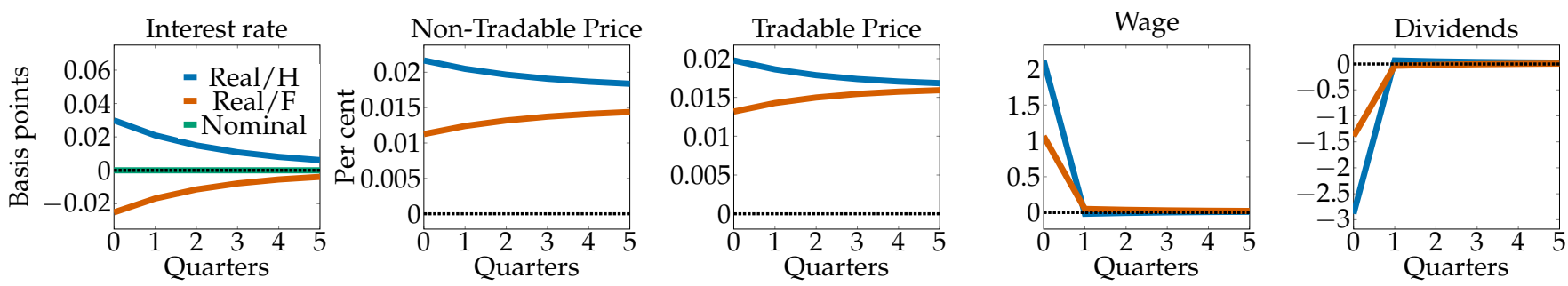

-Home - Foreign

Note: This figure plots the effect in our model of a debt relief shock that reduces borrower debts in the high exemptions regions by 1 percent of PCE on aggregate outcomes under the assumption that prices are sticky $(\theta=0.8)$. The blue line represents outcomes in the home region ("high-exemption"), and the red line is outcomes in the foreign region ("lowexemption"). Panel A plots consumption outcomes, where the first column plots aggregate consumption, the second and third columns plot non-tradable and tradable consumption, and the fourth and fifth columns plot borrower and saver consumption. Panel B plots employment outcomes, where the first column plots aggregate employment, the second and third columns plot non-tradable and tradable employment, and the fourth and fifth columns plot borrower and saver employment. Panel C plots price outcomes, where the first column plots nominal and real interest rates, the second and third columns plot non-tradable and tradable prices, the fourth column plots nominal wages, and the fifth column plots aggregate dividends from firms. 


\section{Figure 5: Debt Relief Multiplier as a Function of the Degree of Price Rigidity $\theta$}
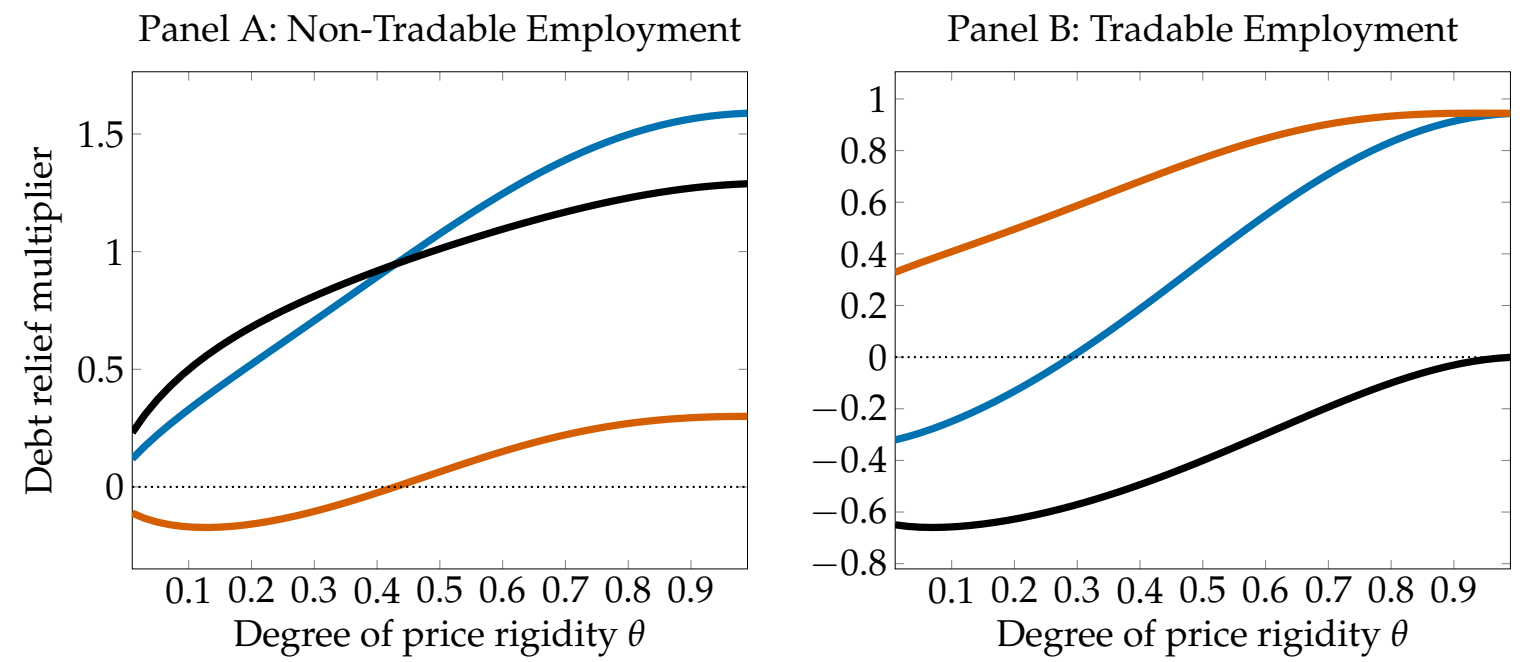

- Home multiplier $\left(\mathcal{M}_{H}\right)$ - Foreign multiplier $\left(\mathcal{M}_{F}\right)$ - Relative multiplier $\left(\mathcal{M}_{\text {rel }}\right)$

Note: This figure plots the home, foreign and relative debt relief multipliers in our model for non-tradable and tradable employment as a function of the degree of price rigidity. The blue line is the response of log employment in the home region ("high-exemption") to a reduction in home borrowers' debts of 1 percent of PCE. The red line is the response of log employment in the foreign region ("low-exemption") to the same shock. The black line is the difference between the responses in the home and the foreign region ("relative multiplier"), which corresponds to the debt relief multiplier identified by our difference-in-differences research design. To draw this figure, we assume that monetary policy follows a Taylor rule with a coefficient $\phi_{\pi}=0.8$ that is sufficient to guarantee determinacy. This lowers the home and foreign multipliers slightly for $\theta=0.8$, and ensures that the outcome converges to flexible prices as $\theta \rightarrow 0$. As we show in Section IV.E, the relative multipliers are independent of monetary policy, so they are identical to those resulting from assuming the zero lower bound throughout. 


\title{
Figure 6: Model Predictions for the Path of Employment During the Recession
}
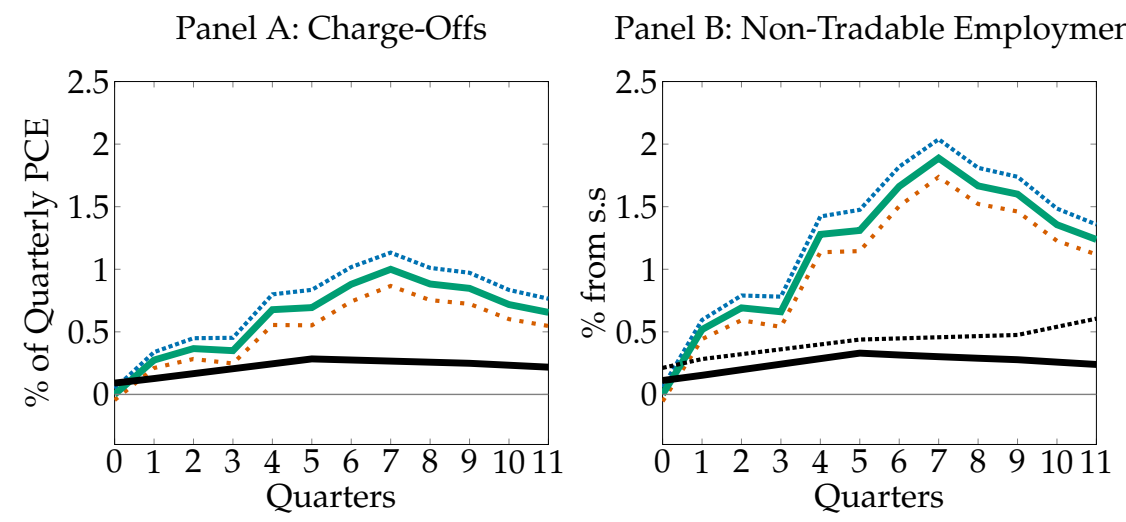

\author{
Panel C: Tradable Employment
}

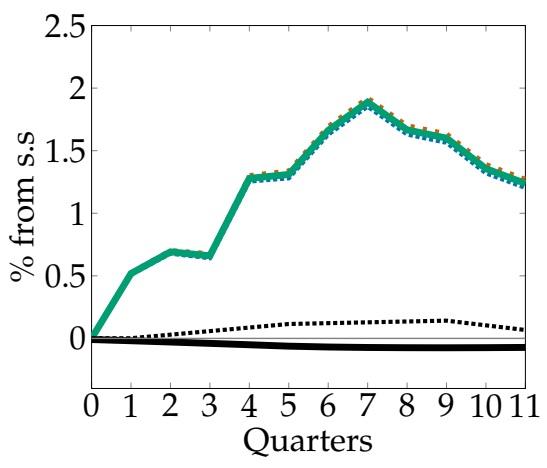

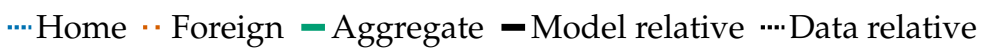

Note: This figure plots the effect of debt relief in our model on the path of non-tradable and tradable employment in highand low-exemption regions during and after the financial crisis. Panel A plots our assumptions for the path of debt relief in the home ("high-exemption") and foreign ("low-exemption") regions. We assume that average charge-offs across the home and the foreign region equal the observed path of charge-offs in the data starting in 2007q4. We also assume that charge-offs in the home region equal charge-offs in the foreign region plus the empirically estimated effect of a one standard deviation increase in bankruptcy protections in the data. Panels B and C shows the model-implied paths of non-tradable and tradable employment in both regions after 2007q4, i.e. the counterfactual effect of financial crisis chargeoffs on employment implied by our model. The solid black line represents the model-implied difference between the outcomes in the home and foreign regions, which corresponds to the model-predicted difference-in-differences effect of a one standard deviation increase in bankruptcy protections in the data. The dotted black line represents the empirically estimated difference-in-differences effect of a one standard deviation increase in bankruptcy protections in the data. 


\section{Figure 7: Debt Relief Multiplier as a Function of the Size of Debt Relief}
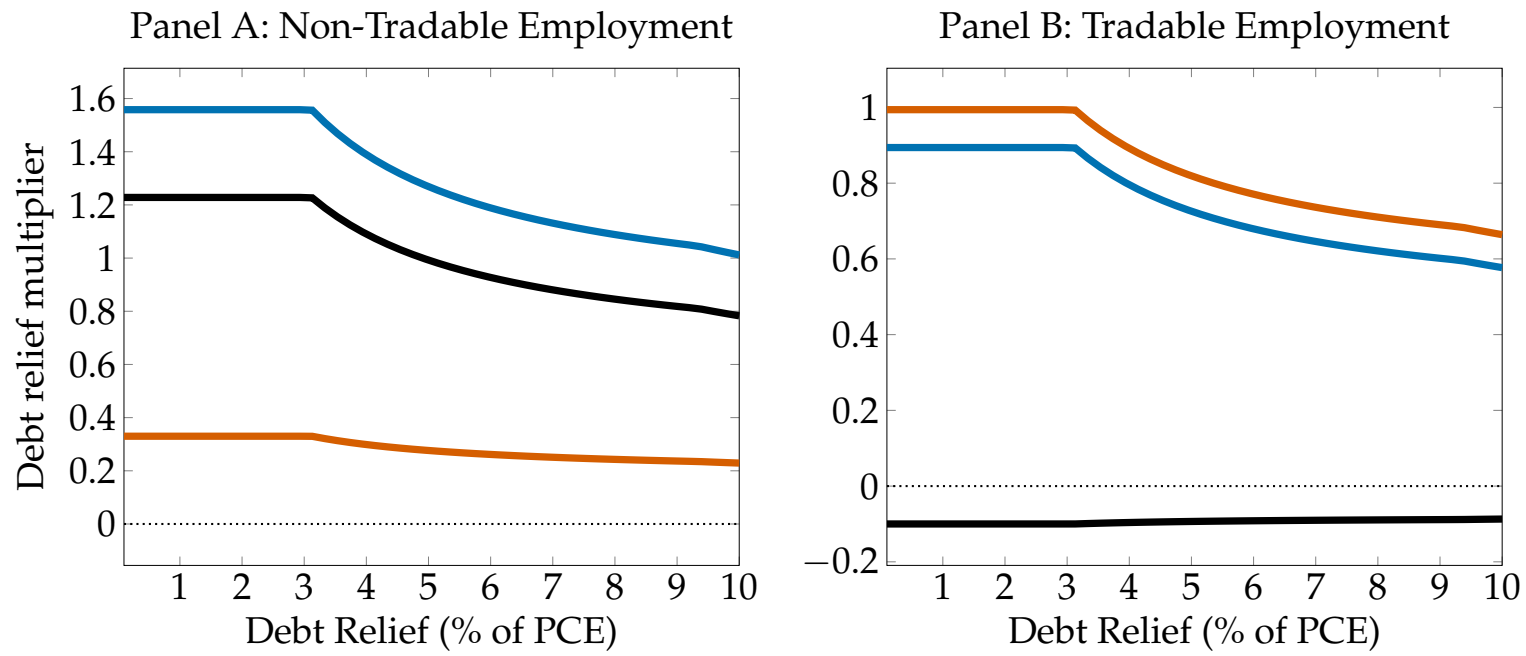

- Home multiplier $\left(\mathcal{M}_{H}\right)-$ Foreign multiplier $\left(\mathcal{M}_{F}\right)-$ Relative multiplier $\left(\mathcal{M}_{\text {rel }}\right)$

Note: This figure plots the debt relief multiplier in our model for non-tradable and tradable employment in high- and low-exemption regions as a function of the size of the debt relief shock. The blue line is the debt relief multiplier in the home region ("high-exemption"), the red line is the debt relief multiplier in the foreign region ("low-exemption"), and the black line represents the difference between the multipliers in the home and the foreign regions. The effect of debt relief on employment is linear initially, but later declines with the size of the debt relief due to borrowers becoming less constrained and spreading their spending out over additional periods. 
Appendix A. Additional Results

Appendix Table A1: Bankruptcy Exemptions by State

\begin{tabular}{|c|c|c|c|c|c|c|}
\hline \multirow[b]{2}{*}{ State } & \multicolumn{4}{|c|}{ Chapter 7 Bankruptcy Exemptions in 2007} & \multicolumn{2}{|c|}{ Financial Cost of Bankruptcy } \\
\hline & Homestead & Vehicle & Savings & Wildcard & Home Equity & Other Assets \\
\hline Alaska & 67,500 & 3,750 & 1,750 & 0 & 113,742 & 159,444 \\
\hline Alabama & 10,000 & 0 & 0 & 3,000 & 160,173 & 162,586 \\
\hline Arkansas & Unlimited & 1,200 & 0 & 500 & 0 & 182,904 \\
\hline Arizona & 150,000 & 5,000 & 150 & 0 & 66,855 & 152,309 \\
\hline California & 75,000 & 2,550 & 4,050 & 0 & 86,855 & 152,515 \\
\hline Colorado & 90,000 & 3,000 & 0 & 0 & 99,353 & 160,923 \\
\hline Connecticut & 150,000 & 1,500 & 0 & 1,000 & 66,356 & 161,572 \\
\hline Delaware & 50,000 & 0 & 0 & 500 & 126,679 & 163,453 \\
\hline Florida & Unlimited & 1,000 & 0 & 1,000 & 0 & 158,622 \\
\hline Georgia & 20,000 & 3,500 & 0 & 600 & 153,329 & 160,939 \\
\hline Hawaii & 30,000 & 2,575 & 0 & 0 & 133,183 & 161,519 \\
\hline Iowa & Unlimited & 7,000 & 0 & 100 & 0 & 157,972 \\
\hline Idaho & 50,000 & 3,000 & 0 & 800 & 126,750 & 160,401 \\
\hline Illinois & 30,000 & 2,400 & 0 & 4,000 & 143,346 & 160,583 \\
\hline Indiana & 30,000 & 0 & 300 & 8,000 & 145,012 & 161,844 \\
\hline Kansas & Unlimited & 20,000 & 0 & 0 & 0 & 153,636 \\
\hline Kentucky & 10,000 & 2,500 & 0 & 1,000 & 160,056 & 160,170 \\
\hline Louisiana & 25,000 & 0 & 0 & 0 & 147,256 & 164,026 \\
\hline Massachusetts & 500,000 & 700 & 1,200 & 0 & 4,323 & 160,463 \\
\hline Maryland & 0 & 0 & 0 & 11,000 & 166,668 & 159,593 \\
\hline Maine & 70,000 & 5,000 & 0 & 400 & 111,979 & 159,852 \\
\hline Michigan & 31,900 & 2,950 & 0 & 0 & 137,110 & 161,934 \\
\hline Minnesota & 200,000 & 3,800 & 0 & 0 & 48,263 & 159,709 \\
\hline Missouri & 15,000 & 3,000 & 0 & 1,250 & 156,118 & 160,760 \\
\hline Mississippi & 75,000 & 0 & 0 & 10,000 & 108,814 & 162,834 \\
\hline Montana & 200,000 & 2,500 & 0 & 0 & 47,869 & 161,567 \\
\hline North Carolina & 37,000 & 3,500 & 0 & 500 & 139,270 & 161,600 \\
\hline North Dakota & 80,000 & 1,200 & 0 & 5,000 & 105,199 & 170,776 \\
\hline Nebraska & 12,500 & 0 & 0 & 2,500 & 157,593 & 162,728 \\
\hline New Hampshire & 200,000 & 4,000 & 0 & 1,000 & 47,904 & 160,220 \\
\hline New Jersey & 0 & 0 & 0 & 1,000 & 131,025 & 162,298 \\
\hline New Mexico & 60,000 & 4,000 & 0 & 500 & 119,369 & 160,310 \\
\hline Nevada & 350,000 & 15,000 & 0 & 0 & 16,683 & 155,892 \\
\hline New York & 100,000 & 2,400 & 2,500 & 0 & 88,370 & 156,339 \\
\hline Ohio & 10,000 & 1,000 & 400 & 400 & 163,915 & 162,217 \\
\hline Oklahoma & Unlimited & 3,000 & 0 & 0 & 0 & 161,414 \\
\hline Oregon & 39,600 & 2,150 & 7,500 & 400 & 134,560 & 182,680 \\
\hline Pennsylvania & 0 & 0 & 0 & 300 & 136,446 & 163,664 \\
\hline Rhode Island & 300,000 & 10,000 & 0 & 0 & 24,032 & 156,892 \\
\hline South Carolina & 10,000 & 1,200 & 1,000 & 0 & 160,519 & 162,895 \\
\hline South Dakota & Unlimited & 0 & 0 & 6,000 & 0 & 165,850 \\
\hline Tennessee & 7,500 & 0 & 0 & 4,000 & 164,097 & 162,346 \\
\hline Texas & Unlimited & 0 & 0 & 30,000 & 0 & 153,806 \\
\hline Utah & 40,000 & 2,500 & 0 & 0 & 134,532 & 161,927 \\
\hline Virginia & 10,000 & 2,000 & 0 & 0 & 158,357 & 183,046 \\
\hline Vermont & 150,000 & 2,500 & 700 & 400 & 66,713 & 160,856 \\
\hline Washington & 40,000 & 2,500 & 0 & 2,000 & 132,896 & 151,869 \\
\hline Wisconsin & 40,000 & 1,200 & 1,000 & 0 & 135,426 & 162,018 \\
\hline
\end{tabular}




\begin{tabular}{lcccccc} 
West Virginia & 50,000 & 2,400 & 0 & 800 & 126,737 & 161,485 \\
Wyoming & 20,000 & 2,400 & 0 & 0 & 150,847 & 161,709 \\
\hline
\end{tabular}

Note: This table reports Chapter 7 asset exemptions and average financial cost of bankruptcy by state in 2007. The homestead and vehicle exemptions refer to the maximum equity in a residential home or vehicle exempt in bankruptcy. Savings refers to the amount of cash and bank account assets exempt, while wildcard exemptions can generally be applied to any other assets, or increase the exemption amount of other categories. The last two columns report the average financial cost of bankruptcy by state based on state-specific exemptions and a national sample of households' wealth. The first of the last two columns reports the average home equity at risk in each state, using home equity amounts from a national sample of 2007 home equity estimates from Equifax and Zillow. The second of the last two columns reports the average amount of assets at risk for all other assets except housing in each state, using 2005 and 2007 PSID surveys excluding the state at hand. Both columns exclude individuals in the random sample from that state. 


\section{Appendix Table A2: Correlates with State Bankruptcy Protection Measure}

\begin{tabular}{|c|c|c|}
\hline & $\begin{array}{l}\text { Levels in } \\
2001\end{array}$ & $\begin{array}{l}\text { Levels in } \\
2007\end{array}$ \\
\hline Panel A: Employment Outcomes & (1) & (2) \\
\hline Log Non-Tradable Employment & $\begin{array}{c}0.014 \\
(0.012)\end{array}$ & $\begin{array}{c}0.013 \\
(0.009)\end{array}$ \\
\hline Log Tradable + Other Employment & $\begin{array}{r}-0.006 \\
(0.019)\end{array}$ & $\begin{array}{r}-0.010 \\
(0.020)\end{array}$ \\
\hline Log Total Employment & $\begin{array}{r}-0.002 \\
(0.016)\end{array}$ & $\begin{array}{r}-0.005 \\
(0.016)\end{array}$ \\
\hline Panel B: Credit Outcomes & & \\
\hline Bankrupty Rate (p.p.) & $\begin{array}{r}-0.020 \\
(0.016)\end{array}$ & $\begin{array}{c}-0.041^{* *} \\
(0.016)\end{array}$ \\
\hline Foreclosure Rate (p.p.) & $\begin{array}{c}0.033 \\
(0.039)\end{array}$ & $\begin{array}{r}-0.075 \\
(0.060)\end{array}$ \\
\hline Credit Card Limits $(\$)$ & $\begin{array}{c}-2.281 \\
(351.177)\end{array}$ & $\begin{array}{l}-82.992 \\
(489.225)\end{array}$ \\
\hline Credit Card Debt $(\$)$ & $\begin{array}{c}52.226 \\
(49.649)\end{array}$ & $\begin{array}{c}49.320 \\
(45.253)\end{array}$ \\
\hline Mortgage Debt $(\$ 000)$ & $\begin{array}{r}-0.891 \\
(1.774)\end{array}$ & $\begin{array}{c}0.130 \\
(4.141)\end{array}$ \\
\hline Debt-to-Income Ratio & $\begin{array}{c}0.005 \\
(0.049)\end{array}$ & $\begin{array}{c}0.058 \\
(0.138)\end{array}$ \\
\hline Panel C: State Characteristics & & \\
\hline Democratic Vote Share (p.p.) & $\begin{array}{r}-0.638 \\
(1.522)\end{array}$ & $\begin{array}{r}-0.694 \\
(1.944)\end{array}$ \\
\hline Max. Unemp. Benefit (\$) & $\begin{array}{c}219.405 \\
(501.763)\end{array}$ & $\begin{array}{c}133.546 \\
(727.673)\end{array}$ \\
\hline Population $<45$ (p.p.) & $\begin{array}{c}0.102 \\
(0.890)\end{array}$ & $\begin{array}{c}0.386 \\
(0.887)\end{array}$ \\
\hline College Educated (p.p.) & $\begin{array}{c}0.271 \\
(0.625)\end{array}$ & $\begin{array}{c}0.124 \\
(0.701)\end{array}$ \\
\hline Employment Sensitivity to Business Cycle & $\begin{array}{r}-0.055 \\
(0.046)\end{array}$ & $\begin{array}{r}-0.033 \\
(0.042)\end{array}$ \\
\hline Annual Income per Capita (\$) & $\begin{array}{c}221.372 \\
(635.750)\end{array}$ & $\begin{array}{c}576.162 \\
(887.380)\end{array}$ \\
\hline Log Average House Price & $\begin{array}{c}1.258 \\
(0.948)\end{array}$ & $\begin{array}{c}4.943 \\
(4.973)\end{array}$ \\
\hline Homeownership Share & $\begin{array}{c}-1.283^{* *} \\
(0.556)\end{array}$ & $\begin{array}{c}-1.410^{* *} \\
(0.584)\end{array}$ \\
\hline Elasticity of Housing Supply & \multicolumn{2}{|c|}{$\begin{array}{c}0.042 \\
(0.140)\end{array}$} \\
\hline Recourse Indicator & \multicolumn{2}{|c|}{$\begin{array}{c}0.029 \\
(0.063)\end{array}$} \\
\hline Predicted Employment Shock & \multicolumn{2}{|c|}{$\begin{array}{c}0.628^{* * *} \\
(0.211)\end{array}$} \\
\hline
\end{tabular}

Note: This table reports results of OLS regressions of various outcomes on cross-state bankruptcy protections, $\hat{B}_{s}$. All county-level outcomes are aggregated to the state level using population weights. Each row and column refer to a separate regression. Outcomes in Panel A and B are described in the notes of Table 1 and Section I. The remaining variables are pulled from additional sources. Debt-to-Income Ratio is from Mian and Sufi (2014b), and measures the county-level total debt divided by income. Democratic Vote Share is the presidential vote counts in 2000 and US House of Representatives vote counts by state in 2006, excluding special elections. Maximum Unemployment Benefit is the maximum UI benefit in 2001 and 2007 by state, as measured in Hsu, Matsa and Melzer (2018). Population < 45 measures the population share below the age of 45 in 2007 and College Educated measure to the percent of population over 25 with a bachelors degree or higher in 2007. Both measures come from the ACS. The Employment Sensitivity to Business Cycle is the coefficient relating national employment growth to state employment growth from 1961-2001 and 1961-2007. Annual Income per Capita measures the average state-level income per capita and is from the CPS in 2007. Log Average House Price is the log of the Corelogic House Price index. Homeownership Share is the share of individuals in an area that are measured as homeowners, using the Equifax data. We mark mortgage holders are homeowners. Elasticity of Housing Supply is time-invariant and comes from Saiz (2010). The Recourse Indicator, from Ghent and Kudlyak (2011), refers to whether or not state law allows for lenders to seek recourse in the case of defaulted underwater mortgages and is treated as time invariant in the sample. Predicted Employment Shock is the predicted exposure to local unemployment shocks during the Great Recession from Yagan (2017). All regressions are run at the state-level using robust standard errors, and weighted by state population as of 2007. See the text for additional details on the specification and the Table 1 notes for additional details on the outcome measures and sample. 


\section{Appendix Table A3: Effects of Bankruptcy Protections on Other Consumer Debt Outcomes}

\begin{tabular}{|c|c|c|c|c|c|}
\hline \multirow[b]{2}{*}{ Panel A: 2008q1-2010q4 } & \multirow{2}{*}{$\frac{\text { Avg Change }}{(1)}$} & \multicolumn{4}{|c|}{ Effect of Bankruptcy Protections } \\
\hline & & $(2)$ & (3) & $(4)$ & (5) \\
\hline Bankrupty Rate (p.p.) & $\begin{array}{c}0.107 \\
(0.118)\end{array}$ & $\begin{array}{c}-0.005 \\
(0.009)\end{array}$ & $\begin{array}{c}-0.002 \\
(0.007)\end{array}$ & $\begin{array}{c}-0.001 \\
(0.005)\end{array}$ & $\begin{array}{c}-0.003 \\
(0.004)\end{array}$ \\
\hline Credit Card Limits (\$) & $\begin{array}{c}-2,539.916 \\
(958.845)\end{array}$ & $\begin{array}{c}-16.026 \\
(36.031)\end{array}$ & $\begin{array}{c}-38.402 \\
(33.407)\end{array}$ & $\begin{array}{c}-26.223 \\
(20.852)\end{array}$ & $\begin{array}{c}-23.311 \\
(17.796)\end{array}$ \\
\hline Credit Card Debt $(\$)$ & $\begin{array}{l}-132.620 \\
(270.095)\end{array}$ & $\begin{array}{c}30.515 \\
(39.938)\end{array}$ & $\begin{array}{c}31.516 \\
(22.202)\end{array}$ & $\begin{array}{c}10.059 \\
(11.120)\end{array}$ & $\begin{array}{c}8.360 \\
(12.754)\end{array}$ \\
\hline Mortgage Debt $(\$ 000)$ & $\begin{array}{c}1.839 \\
(5.044)\end{array}$ & $\begin{array}{c}-0.034 \\
(0.285)\end{array}$ & $\begin{array}{r}-0.051 \\
(0.265)\end{array}$ & $\begin{array}{c}-0.363^{* *} \\
(0.179)\end{array}$ & $\begin{array}{r}-0.356^{*} \\
(0.200)\end{array}$ \\
\hline Foreclosure Rate (p.p.) & $\begin{array}{c}0.906 \\
(1.080)\end{array}$ & $\begin{array}{c}0.249^{*} \\
(0.145)\end{array}$ & $\begin{array}{l}0.257^{* * *} \\
(0.095)\end{array}$ & $\begin{array}{l}0.223^{* * *} \\
(0.031)\end{array}$ & $\begin{array}{l}0.216^{* * *} \\
(0.039)\end{array}$ \\
\hline \multicolumn{6}{|l|}{ Panel B: 2011q1-2013q4 } \\
\hline Bankrupty Rate (p.p.) & $\begin{array}{l}-0.091 \\
(0.094)\end{array}$ & $\begin{array}{c}0.001 \\
(0.015)\end{array}$ & $\begin{array}{c}0.004 \\
(0.008)\end{array}$ & $\begin{array}{c}0.005 \\
(0.006)\end{array}$ & $\begin{array}{c}0.003 \\
(0.006)\end{array}$ \\
\hline Credit Card Limits $(\$)$ & $\begin{array}{c}954.736 \\
(1,007.336)\end{array}$ & $\begin{array}{l}-30.221 \\
(159.535)\end{array}$ & $\begin{array}{c}-105.276 \\
(124.984)\end{array}$ & $\begin{array}{r}-68.180 \\
(42.363)\end{array}$ & $\begin{array}{r}-46.853 \\
(43.125)\end{array}$ \\
\hline Credit Card Debt $(\$)$ & $\begin{array}{l}-276.685 \\
(303.066)\end{array}$ & $\begin{array}{c}-21.966 \\
(23.782)\end{array}$ & $\begin{array}{r}-32.189^{*} \\
(17.003)\end{array}$ & $\begin{array}{c}-52.191^{* * *} \\
(12.374)\end{array}$ & $\begin{array}{c}-48.584^{* * *} \\
(12.030)\end{array}$ \\
\hline Mortgage Debt (\$000) & $\begin{array}{l}-3.977 \\
(5.331)\end{array}$ & $\begin{array}{c}-0.918 \\
(0.970)\end{array}$ & $\begin{array}{r}-1.164 \\
(0.759)\end{array}$ & $\begin{array}{c}-1.193^{* * *} \\
(0.444)\end{array}$ & $\begin{array}{c}-1.103^{* *} \\
(0.485)\end{array}$ \\
\hline Foreclosure Rate (p.p.) & $\begin{array}{c}0.057 \\
(0.318)\end{array}$ & $\begin{array}{c}0.379 \\
(0.243)\end{array}$ & $\begin{array}{c}0.401^{* *} \\
(0.159)\end{array}$ & $\begin{array}{l}0.337^{* * *} \\
(0.055)\end{array}$ & $\begin{array}{l}0.316^{* * *} \\
(0.064)\end{array}$ \\
\hline Number of Observations & & 161,720 & 161,720 & 161,720 & 155,324 \\
\hline County F.E. & & Y & Y & $\mathrm{Y}$ & Y \\
\hline Year-Quarter F.E. & & $\mathrm{Y}$ & $\mathrm{Y}$ & $\mathrm{Y}$ & $\mathrm{Y}$ \\
\hline Housing Controls $\times$ YQ F & & $\mathrm{N}$ & $\mathrm{Y}$ & $\mathrm{Y}$ & $\mathrm{Y}$ \\
\hline Additional Controls $\times Y Q$ & & $\mathrm{~N}$ & $\mathrm{~N}$ & Y & Y \\
\hline Exclude Sand States & & $\mathrm{N}$ & $\mathrm{N}$ & $\mathrm{N}$ & $\mathrm{Y}$ \\
\hline
\end{tabular}

Note: This table reports estimates of the effect of cross-state bankruptcy protections on consumer debt outcomes. Column 1 reports the cross-county average and standard deviation of the change in the dependent variable from 2007q4-2010q4 or 2010q4-2013q4. Columns 2-5 report coefficients on the average effect of a one standard deviation decrease in the log financial cost of filing for bankruptcy protection, pooled over the periods 2008q1-2010q4 in Panel A and and 2011q1-2013q4 in Panel B. All estimates should be interpreted as the relative effect compared to $2007 q 4$. Column 2 reports estimates with county and year-quarter fixed effects. Column 3 repeats the regression, adding the Saiz supply elasticity and share of the population who own a home in 2007q4 for each county, interacted with year-quarter fixed effects. For counties without the Saiz supply elasticity measure, the measure is set to zero, and an additional dummy for missing supply elasticity is interacted with yearquarter fixed effects. Column 4 repeats the same regression, but with a set of location controls interacted with year-quarter fixed effects: the share of Democratic voters in 2004, the maximum unemployment insurance benefit, the share of collegeeducated individuals in a county, the share of the population that is under the age of 45 , the average debt-to-income ratio for the state in 2007, and the predicted exposure to local unemployment shocks during the Great Recession. Finally, Column 5 repeats Column 4, but excludes the "sand states," or Arizona, California, Nevada, and New Mexico. All regressions are weighted by county population as of 2007 and cluster the standard errors at the state level. Standard errors are clustered at the state level. See the text for additional details on the specification and the Table 1 notes for additional details on the sample. 


\section{Appendix Table A4: Effects of Bankruptcy Protections on Log House Price Index}

\begin{tabular}{|c|c|c|c|c|c|}
\hline \multirow[b]{2}{*}{ Panel A: 2008q1-2010q4 } & \multirow{2}{*}{$\frac{\text { Avg Change }}{(1)}$} & \multicolumn{4}{|c|}{ Effect of Bankruptcy Protections } \\
\hline & & $(2)$ & (3) & $(4)$ & (5) \\
\hline Log House Price & $\begin{array}{l}-21.846 \\
(14.963)\end{array}$ & $\begin{array}{r}-3.147 \\
(3.003)\end{array}$ & $\begin{array}{r}-3.114 \\
(2.224)\end{array}$ & $\begin{array}{c}-3.184^{* * *} \\
(0.854)\end{array}$ & $\begin{array}{c}-2.968^{* * *} \\
(0.898)\end{array}$ \\
\hline \multicolumn{6}{|l|}{ Panel B: 2011q1-2013q4 } \\
\hline Log House Price & $\begin{array}{c}10.669 \\
(12.554)\end{array}$ & $\begin{array}{r}-1.357 \\
(3.990)\end{array}$ & $\begin{array}{r}-1.310 \\
(3.096)\end{array}$ & $\begin{array}{r}-1.962 \\
(1.341)\end{array}$ & $\begin{array}{r}-1.547 \\
(1.339)\end{array}$ \\
\hline \multicolumn{2}{|l|}{ Number of Observations } & 122,736 & 122,736 & 122,736 & 114,544 \\
\hline \multicolumn{2}{|l|}{ County F.E. } & Y & $\mathrm{Y}$ & $\mathrm{Y}$ & $\mathrm{Y}$ \\
\hline \multicolumn{2}{|c|}{ Year-Quarter F.E. } & Y & Y & Y & Y \\
\hline \multicolumn{2}{|c|}{ Housing Controls × YQ F.E. } & $\mathrm{N}$ & Y & $\mathrm{Y}$ & Y \\
\hline \multicolumn{2}{|c|}{ Additional Controls $\times$ YQ F.E. } & $\mathrm{N}$ & $\mathrm{N}$ & $\mathrm{Y}$ & Y \\
\hline \multicolumn{2}{|c|}{ Exclude Sand States } & $\mathrm{N}$ & $\mathrm{N}$ & $\mathrm{N}$ & Y \\
\hline
\end{tabular}

Note: This table reports estimates of the effect of cross-state bankruptcy protections on log house prices from CoreLogic. Column 1 reports the cross-county average and standard deviation of the change in the dependent variable from 2007q42010q4 or 2010q4-2013q4. Columns 2-5 report coefficients on the average effect of a one standard deviation decrease in the $\log$ financial cost of filing for bankruptcy protection, pooled over the periods 2008q1-2010q4 in Panel A and and 2011q1$2013 q 4$ in Panel B. All estimates should be interpreted as the relative effect compared to 2007q4. Column 2 reports estimates with county and year-quarter fixed effects. Column 3 repeats the regression, adding the Saiz supply elasticity and share of the population who own a home in 2007q4 for each county, interacted with year-quarter fixed effects. For counties without the Saiz supply elasticity measure, the measure is set to zero, and an additional dummy for missing supply elasticity is interacted with year-quarter fixed effects. Column 4 repeats the same regression, but with a set of location controls interacted with year-quarter fixed effects: the share of Democratic voters in 2004, the maximum unemployment insurance benefit, the share of college-educated individuals in a county, the share of the population that is under the age of 45 , the average debtto-income ratio for the state in 2007, and the predicted exposure to local unemployment shocks during the Great Recession. Finally, Column 5 repeats Column 4, but excludes the "sand states," or Arizona, California, Nevada, and New Mexico. All regressions are weighted by county population as of 2007 and cluster the standard errors at the state level. Standard errors are clustered at the state level. See the text for additional details on the specification and the Table 1 notes for additional details on the outcome measures and sample. 


\section{Appendix Table A5: Effects of 1991 Homestead Exemption on Employment}

\begin{tabular}{|c|c|c|c|c|c|}
\hline \multirow[b]{2}{*}{ Panel A: 2008q1-2010q4 } & \multirow{2}{*}{$\frac{\text { Avg Change }}{(1)}$} & \multicolumn{4}{|c|}{ Effect of Bankruptcy Protections } \\
\hline & & (2) & (3) & $(4)$ & $(5)$ \\
\hline Log Non-Tradable Emp. & $\begin{array}{l}-5.178 \\
(6.737)\end{array}$ & $\begin{array}{c}0.111 \\
(0.164)\end{array}$ & $\begin{array}{c}0.077 \\
(0.151)\end{array}$ & $\begin{array}{c}0.230^{*} \\
(0.118)\end{array}$ & $\begin{array}{c}0.245^{*} \\
(0.123)\end{array}$ \\
\hline Log Tradable + Other Emp. & $\begin{array}{l}-7.988 \\
(8.263)\end{array}$ & $\begin{array}{c}-0.207 \\
(0.168)\end{array}$ & $\begin{array}{c}-0.251 \\
(0.157)\end{array}$ & $\begin{array}{r}-0.244^{*} \\
(0.144)\end{array}$ & $\begin{array}{r}-0.243^{*} \\
(0.144)\end{array}$ \\
\hline Log Total Emp. & $\begin{array}{l}-7.406 \\
(6.919)\end{array}$ & $\begin{array}{c}-0.147 \\
(0.150)\end{array}$ & $\begin{array}{c}-0.188 \\
(0.139)\end{array}$ & $\begin{array}{c}-0.156 \\
(0.118)\end{array}$ & $\begin{array}{c}-0.152 \\
(0.119)\end{array}$ \\
\hline \multicolumn{6}{|l|}{ Panel B: 2011q1-2013q4 } \\
\hline Log Non-Tradable Emp. & $\begin{array}{c}5.300 \\
(5.896)\end{array}$ & $\begin{array}{c}0.247 \\
(0.227)\end{array}$ & $\begin{array}{c}0.167 \\
(0.232)\end{array}$ & $\begin{array}{l}0.477^{* * *} \\
(0.134)\end{array}$ & $\begin{array}{l}0.506^{* * *} \\
(0.138)\end{array}$ \\
\hline Log Tradable + Other Emp. & $\begin{array}{c}3.740 \\
(8.224)\end{array}$ & $\begin{array}{c}-0.223 \\
(0.196)\end{array}$ & $\begin{array}{c}-0.237 \\
(0.186)\end{array}$ & $\begin{array}{c}-0.180 \\
(0.148)\end{array}$ & $\begin{array}{c}-0.161 \\
(0.141)\end{array}$ \\
\hline Log Total Emp. & $\begin{array}{c}4.056 \\
(6.712)\end{array}$ & $\begin{array}{c}-0.131 \\
(0.166)\end{array}$ & $\begin{array}{c}-0.152 \\
(0.167)\end{array}$ & $\begin{array}{c}-0.052 \\
(0.120)\end{array}$ & $\begin{array}{c}-0.031 \\
(0.115)\end{array}$ \\
\hline Number of Observations & & 161,720 & 161,720 & 161,720 & 155,324 \\
\hline County F.E. & & Y & Y & $\mathrm{Y}$ & Y \\
\hline Year-Quarter F.E. & & Y & $\mathrm{Y}$ & $\mathrm{Y}$ & $\mathrm{Y}$ \\
\hline Housing Controls × YQ F.E. & & $\mathrm{N}$ & $\mathrm{Y}$ & Y & Y \\
\hline Additional Controls $\times$ YQ F.E. & & $\mathrm{N}$ & $\mathrm{N}$ & Y & Y \\
\hline Exclude Sand States & & $\mathrm{N}$ & $\mathrm{N}$ & $\mathrm{N}$ & Y \\
\hline
\end{tabular}

Note: This table reports estimates of the effect of historical homestead protections on log employment outcomes scaled by working-age population (age 18-65). See Appendix Table A1 for details on the historical exemptions. The first row of each panel reports results for log non-tradable employment, defined as the retail and restaurant sectors. The second row reports results for log tradable and other employment, where tradable employment is defined as industries with sufficiently large imports and exports from the United States, and other employment is defined as all other industries excluding the construction sector Mian and Sufi (2014b). The third row reports results for log total employment. Column 1 reports the cross-county average and standard deviation of the change in the dependent variable from 2007q4-2010q4 or 2010q4-2013q4. Columns 2-5 report coefficients on the average effect of a one standard deviation decrease in the log financial cost of filing for bankruptcy protection, pooled over the periods 2008q1-2010q4 in Panel A and and 2011q1-2013q4 in Panel B. All estimates should be interpreted as the relative effect compared to 2007q4. Column 2 reports estimates with county and year-quarter fixed effects. Column 3 repeats the regression, adding the Saiz supply elasticity and share of the population who own a home in 2007q4 for each county, interacted with year-quarter fixed effects. For counties without the Saiz supply elasticity measure, the measure is set to zero, and an additional dummy for missing supply elasticity is interacted with year-quarter fixed effects. Column 4 repeats the same regression, but with a set of location controls interacted with year-quarter fixed effects: the share of Democratic voters in 2004, the maximum unemployment insurance benefit, the share of college-educated individuals in a county, the share of the population that is under the age of 45 , the average debt-to-income ratio for the state in 2007, and the predicted exposure to local unemployment shocks during the Great Recession. Finally, Column 5 repeats Column 4, but excludes the "sand states," or Arizona, California, Nevada, and New Mexico. All regressions are weighted by county population as of 2007 and cluster the standard errors at the state level. Standard errors are clustered at the state level. See the text for additional details on the specification and the Table 1 notes for additional details on the outcome measures and sample. 
Appendix Table A6: Effects of 1991 Homestead Exemption on Debt Write-Downs

\begin{tabular}{|c|c|c|c|c|c|}
\hline \multirow[b]{2}{*}{ Panel A: 2008q1-2010q4 } & \multirow{2}{*}{$\frac{\text { Avg Change }}{(1)}$} & \multicolumn{4}{|c|}{ Effect of Bankruptcy Protections } \\
\hline & & $(2)$ & (3) & $(4)$ & (5) \\
\hline Charge-Offs in Full Sample & $\begin{array}{c}124.775 \\
(199.676)\end{array}$ & $\begin{array}{c}10.422 \\
(12.015)\end{array}$ & $\begin{array}{l}12.940 \\
(8.363)\end{array}$ & $\begin{array}{l}12.459^{* * *} \\
(3.528)\end{array}$ & $\begin{array}{c}9.892^{* *} \\
(3.794)\end{array}$ \\
\hline Charge-Offs for Homeowners & $\begin{array}{c}242.352 \\
(360.046)\end{array}$ & $\begin{array}{c}15.561 \\
(20.788)\end{array}$ & $\begin{array}{c}18.856 \\
(14.499)\end{array}$ & $\begin{array}{l}18.932^{* * *} \\
(5.138)\end{array}$ & $\begin{array}{l}16.427^{* *} \\
(6.287)\end{array}$ \\
\hline Charge-Offs for Renters & $\begin{array}{c}-11.849 \\
(104.352)\end{array}$ & $\begin{array}{c}5.371 \\
(3.959)\end{array}$ & $\begin{array}{r}5.105^{*} \\
(2.871)\end{array}$ & $\begin{array}{c}3.889 \\
(3.129)\end{array}$ & $\begin{array}{c}2.118 \\
(1.833)\end{array}$ \\
\hline \multicolumn{6}{|l|}{ Panel B: 2011q1-2013q4 } \\
\hline Charge-Offs in Full Sample & $\begin{array}{l}-241.672 \\
(174.642)\end{array}$ & $\begin{array}{c}4.248 \\
(9.428)\end{array}$ & $\begin{array}{c}5.559 \\
(7.130)\end{array}$ & $\begin{array}{c}6.562^{* *} \\
(3.175)\end{array}$ & $\begin{array}{c}6.025^{*} \\
(3.000)\end{array}$ \\
\hline Charge-Offs for Homeowners & $\begin{array}{l}-400.601 \\
(290.675)\end{array}$ & $\begin{array}{c}4.421 \\
(16.756)\end{array}$ & $\begin{array}{c}6.928 \\
(11.474)\end{array}$ & $\begin{array}{l}10.465^{* *} \\
(4.432)\end{array}$ & $\begin{array}{c}9.386^{* *} \\
(4.350)\end{array}$ \\
\hline Charge-Offs for Renters & $\begin{array}{c}-91.944 \\
(139.866)\end{array}$ & $\begin{array}{c}1.426 \\
(2.728)\end{array}$ & $\begin{array}{c}1.207 \\
(2.547)\end{array}$ & $\begin{array}{c}0.268 \\
(2.049)\end{array}$ & $\begin{array}{c}0.428 \\
(1.729)\end{array}$ \\
\hline Number of Observations & & 161,720 & 161,720 & 161,720 & 155,324 \\
\hline County F.E. & & Y & Y & Y & $\mathrm{Y}$ \\
\hline Year-Quarter F.E. & & $\mathrm{Y}$ & $\mathrm{Y}$ & $\mathrm{Y}$ & $\mathrm{Y}$ \\
\hline Housing Controls × YQ F.E. & & $\mathrm{N}$ & $\mathrm{Y}$ & $\mathrm{Y}$ & $\mathrm{Y}$ \\
\hline Additional Controls $\times$ YQ F.E. & & $\mathrm{N}$ & $\mathrm{N}$ & $\mathrm{Y}$ & $\mathrm{Y}$ \\
\hline Exclude Sand States & & $\mathrm{N}$ & $\mathrm{N}$ & $\mathrm{N}$ & $\mathrm{Y}$ \\
\hline
\end{tabular}

Note: This table reports estimates of the effect of historical homestead protections on annual charge-offs. See Appendix Table A1 for details on the historical exemptions. Column 1 reports the cross-county average and standard deviation of the change in the dependent variable from 2007q4-2010q4 or 2010q4-2013q4. Columns 2-5 report coefficients on the average effect of a one standard deviation decrease in the log financial cost of filing for bankruptcy protection, pooled over the periods 2008q1-2010q4 in Panel A and and 2011q1-2013q4 in Panel B. All estimates should be interpreted as the relative effect compared to 2007q4. Column 2 reports estimates with county and year-quarter fixed effects. Column 3 repeats the regression, adding the Saiz supply elasticity and share of the population who own a home in 2007q4 for each county, interacted with year-quarter fixed effects. For counties without the Saiz supply elasticity measure, the measure is set to zero, and an additional dummy for missing supply elasticity is interacted with year-quarter fixed effects. Column 4 repeats the same regression, but with a set of location controls interacted with year-quarter fixed effects: the share of Democratic voters in 2004, the maximum unemployment insurance benefit, the share of college-educated individuals in a county, the share of the population that is under the age of 45 , the average debt-to-income ratio for the state in 2007, and the predicted exposure to local unemployment shocks during the Great Recession. Finally, Column 5 repeats Column 4, but excludes the "sand states," or Arizona, California, Nevada, and New Mexico. All regressions are weighted by county population as of 2007 and cluster the standard errors at the state level. Standard errors are clustered at the state level. See the text for additional details on the specification and the Table 1 notes for additional details on the outcome measures and sample. 


\section{Appendix Table A7: Effects of Bankruptcy Protections on Log In-Migration}

\begin{tabular}{|c|c|c|c|c|c|}
\hline \multirow[b]{2}{*}{ Panel A: 2008q1-2010q4 } & \multirow{2}{*}{$\frac{\text { Avg Change }}{(1)}$} & \multicolumn{4}{|c|}{ Effect of Bankruptcy Protections } \\
\hline & & $(2)$ & (3) & $(4)$ & (5) \\
\hline Log In-Migration & $\begin{array}{c}-11.134 \\
(9.390)\end{array}$ & $\begin{array}{l}1.453 \\
(1.053)\end{array}$ & $\begin{array}{c}1.495 \\
(0.991)\end{array}$ & $\begin{array}{c}2.273^{* *} \\
(0.866)\end{array}$ & $\begin{array}{l}2.465^{\text {*** }} \\
(0.886)\end{array}$ \\
\hline \multicolumn{6}{|l|}{ Panel B: 2011q1-2013q4 } \\
\hline Log In-Migration & $\begin{array}{c}4.941 \\
(7.230)\end{array}$ & $\begin{array}{c}1.334 \\
(1.649) \\
\end{array}$ & $\begin{array}{c}1.437 \\
(1.355) \\
\end{array}$ & $\begin{array}{l}2.489^{* *} \\
(1.219) \\
\end{array}$ & $\begin{array}{l}2.623^{* *} \\
(1.212)\end{array}$ \\
\hline \multicolumn{2}{|l|}{ Number of Observations } & 111,960 & 111,960 & 111,960 & 107,532 \\
\hline \multicolumn{2}{|l|}{ County F.E. } & Y & Y & Y & Y \\
\hline \multicolumn{2}{|c|}{ Year-Quarter F.E. } & $\mathrm{Y}$ & Y & $\mathrm{Y}$ & Y \\
\hline \multicolumn{2}{|c|}{ Housing Controls $\times$ YQ F.E. } & $\mathrm{N}$ & $\mathrm{Y}$ & $\mathrm{Y}$ & $\mathrm{Y}$ \\
\hline \multicolumn{2}{|c|}{ Additional Controls $\times$ YQ F.E. } & $\mathrm{N}$ & $\mathrm{N}$ & $\mathrm{Y}$ & Y \\
\hline \multicolumn{2}{|c|}{ Exclude Sand States } & $\mathrm{N}$ & $\mathrm{N}$ & $\mathrm{N}$ & $\mathrm{Y}$ \\
\hline
\end{tabular}

Note: This table reports estimates of the effect of cross-state bankruptcy protections on the log of the share of state population who moved from outside the state in the last year. Migration data comes from the American Community Survey (ACS). In-migration is defined as the share of current state residents who lived in a different state or country one year ago. We use data from 2004-2013 due to availability constraints. Column 1 reports the cross-county average and standard deviation of the change in the dependent variable from 2007q4-2010q4 or 2010q4-2013q4. Columns 2-5 report coefficients on the average effect of a one standard deviation decrease in the log financial cost of filing for bankruptcy protection, pooled over the periods 2008q1-2010q4 in Panel A and and 2011q1-2013q4 in Panel B. All estimates should be interpreted as the relative effect compared to 2007q4. Column 2 reports estimates with county and year-quarter fixed effects. Column 3 repeats the regression, adding the Saiz supply elasticity and share of the population who own a home in 2007q4 for each county, interacted with year-quarter fixed effects. For counties without the Saiz supply elasticity measure, the measure is set to zero, and an additional dummy for missing supply elasticity is interacted with year-quarter fixed effects. Column 4 repeats the same regression, but with a set of location controls interacted with year-quarter fixed effects: the share of Democratic voters in 2004, the maximum unemployment insurance benefit, the share of college-educated individuals in a county, the share of the population that is under the age of 45 , the average debt-to-income ratio for the state in 2007, and the predicted exposure to local unemployment shocks during the Great Recession. Finally, Column 5 repeats Column 4, but excludes the "sand states," or Arizona, California, Nevada, and New Mexico. All regressions are weighted by county population as of 2007 and cluster the standard errors at the state level. Standard errors are clustered at the state level. See the text for additional details on the specification. 
Appendix Table A8: Effects of Bankruptcy Protections on Inflation

\begin{tabular}{|c|c|c|c|c|c|}
\hline \multirow[b]{2}{*}{ Panel A: 2008q1-2010q4 } & \multirow{2}{*}{$\frac{\text { Avg Change }}{(1)}$} & \multicolumn{4}{|c|}{ Effect of Bankruptcy Protections } \\
\hline & & $(2)$ & (3) & (4) & (5) \\
\hline Non-Tradable CPI & $\begin{array}{c}4.985 \\
(1.810)\end{array}$ & $\begin{array}{c}0.257 \\
(0.251)\end{array}$ & $\begin{array}{c}0.241 \\
(0.265)\end{array}$ & $\begin{array}{r}-0.046 \\
(0.311)\end{array}$ & $\begin{array}{c}-0.047 \\
(0.353)\end{array}$ \\
\hline Tradable CPI & $\begin{array}{c}3.167 \\
(1.246)\end{array}$ & $\begin{array}{r}-0.077 \\
(0.214)\end{array}$ & $\begin{array}{c}-0.064 \\
(0.182)\end{array}$ & $\begin{array}{r}-0.159 \\
(0.096)\end{array}$ & $\begin{array}{c}-0.104 \\
(0.118)\end{array}$ \\
\hline Total CPI & $\begin{array}{c}4.292 \\
(1.270)\end{array}$ & $\begin{array}{c}0.095 \\
(0.133)\end{array}$ & $\begin{array}{c}0.093 \\
(0.138)\end{array}$ & $\begin{array}{c}-0.122 \\
(0.185)\end{array}$ & $\begin{array}{r}-0.096 \\
(0.207)\end{array}$ \\
\hline \multicolumn{6}{|l|}{ Panel B: 2011q1-2013q4 } \\
\hline Non-Tradable CPI & $\begin{array}{c}6.417 \\
(1.087)\end{array}$ & $\begin{array}{c}0.116 \\
(0.426)\end{array}$ & $\begin{array}{c}0.099 \\
(0.452)\end{array}$ & $\begin{array}{r}-0.399 \\
(0.607)\end{array}$ & $\begin{array}{r}-0.359 \\
(0.693)\end{array}$ \\
\hline Tradable CPI & $\begin{array}{c}6.503 \\
(1.052)\end{array}$ & $\begin{array}{c}0.052 \\
(0.334)\end{array}$ & $\begin{array}{c}0.029 \\
(0.376)\end{array}$ & $\begin{array}{c}-0.037 \\
(0.213)\end{array}$ & $\begin{array}{c}0.077 \\
(0.229)\end{array}$ \\
\hline Total CPI & $\begin{array}{c}6.462 \\
(0.806) \\
\end{array}$ & $\begin{array}{c}0.070 \\
(0.236) \\
\end{array}$ & $\begin{array}{c}0.056 \\
(0.251)\end{array}$ & $\begin{array}{r}-0.230 \\
(0.357)\end{array}$ & $\begin{array}{r}-0.159 \\
(0.398)\end{array}$ \\
\hline \multicolumn{2}{|l|}{ Number of Observations } & 11,804 & 11,804 & 11,804 & 11,388 \\
\hline \multicolumn{2}{|l|}{ County F.E. } & Y & Y & Y & Y \\
\hline \multicolumn{2}{|c|}{ Year-Quarter F.E. } & Y & Y & $\mathrm{Y}$ & Y \\
\hline \multicolumn{2}{|c|}{ Housing Controls × YQ F.E. } & $\mathrm{N}$ & $\mathrm{Y}$ & $\mathrm{Y}$ & Y \\
\hline \multicolumn{2}{|c|}{ Additional Controls $\times$ YQ F.E. } & $\mathrm{N}$ & $\mathrm{N}$ & $\mathrm{Y}$ & Y \\
\hline Exclude Sand States & & $\mathrm{N}$ & $\mathrm{N}$ & $\mathrm{N}$ & $\mathrm{Y}$ \\
\hline
\end{tabular}

Note: This table reports estimates of the effect of cross-state bankruptcy protections on log regional consumer price index. The first row of each panel reports results for the non-tradable price index, which is defined using the Services index. The second row reports results for tradable price index, which is defined using the commodities index. The third row reports results for the overall price index. Our definitions for the price indices follow Mian, Sufi and Verner (2017). Column 1 reports the cross-county average and standard deviation of the change in the dependent variable from 2007q4-2010q4 or 2010q42013q4. Columns 2-5 report coefficients on the average effect of a one standard deviation decrease in the log financial cost of filing for bankruptcy protection, pooled over the periods 2008q1-2010q4 in Panel A and and 2011q1-2013q4 in Panel B. All estimates should be interpreted as the relative effect compared to 2007q4. Column 2 reports estimates with county and year-quarter fixed effects. Column 3 repeats the regression, adding the Saiz supply elasticity and share of the population who own a home in 2007q4 for each county, interacted with year-quarter fixed effects. For counties without the Saiz supply elasticity measure, the measure is set to zero, and an additional dummy for missing supply elasticity is interacted with yearquarter fixed effects. Column 4 repeats the same regression, but with a set of location controls interacted with year-quarter fixed effects: the share of Democratic voters in 2004, the maximum unemployment insurance benefit, the share of collegeeducated individuals in a county, the share of the population that is under the age of 45 , the average debt-to-income ratio for the state in 2007, and the predicted exposure to local unemployment shocks during the Great Recession. Finally, Column 5 repeats Column 4, but excludes the "sand states," or Arizona, California, Nevada, and New Mexico. All regressions are weighted by county population as of 2007 and cluster the standard errors at the state level. Standard errors are clustered at the state level. See the text for additional details on the specification. 


\section{Appendix Figure A1: Stability of Exemptions Over Time}

\section{Panel A: 2007 Homestead Exemption vs. 1991 Homestead Exemption}

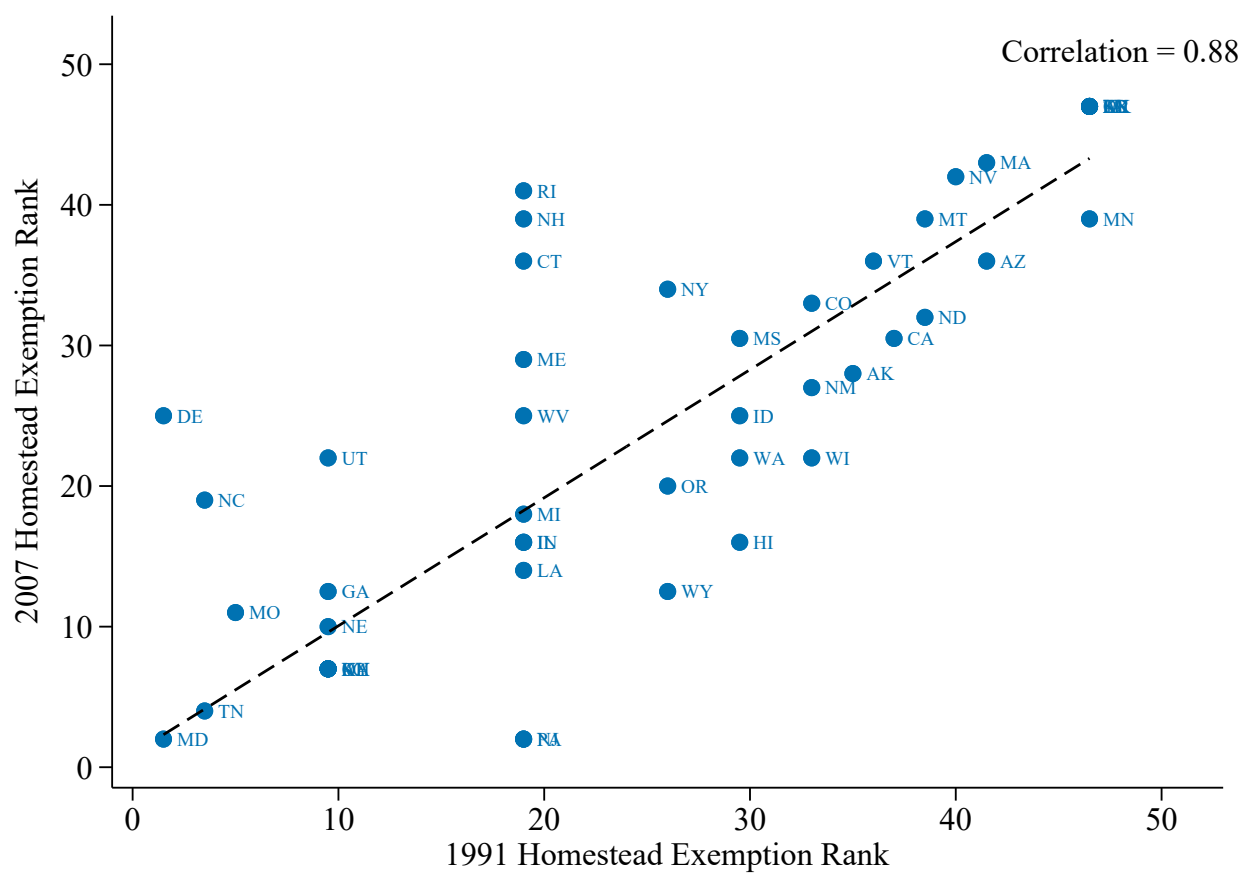

Panel B: 2007 Homestead Exemption vs. 1920 Homestead Exemption

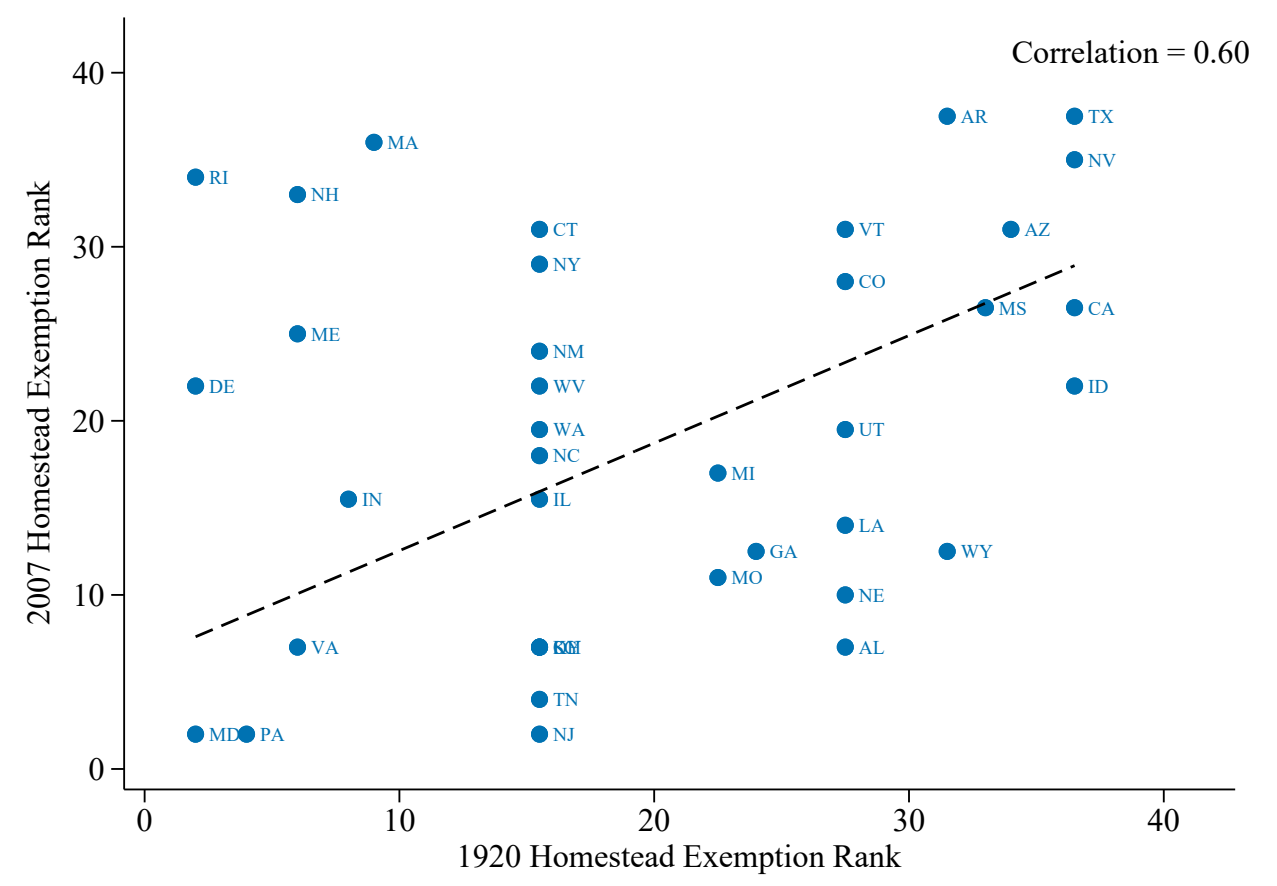

Note: This figure shows the stability of the Chapter 7 bankruptcy exemptions over time. Panel A plots 2007 homestead exemption ranks against 1991 homestead exemption ranks for all 50 states. Panel B plots 2007 homestead exemption ranks against 1920 homestead exemption ranks, excluding states that did not exist in 1920 and states with acre-based homestead exemptions. We use state populations in 2007 as weights and assign a value of $\$ 1,000,000$ to states with unlimited 2007 homestead exemptions. 


\section{Appendix Figure A2: Geography of the Financial Cost of Bankruptcy Filing}

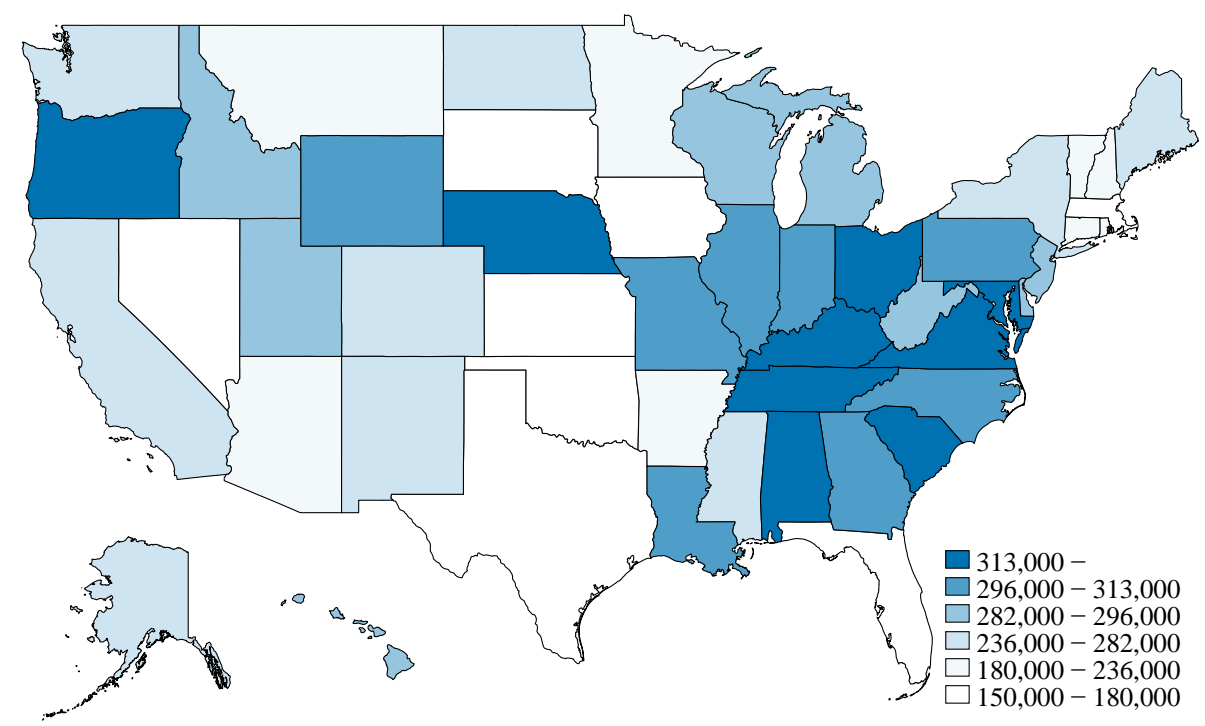

Note: This map shows the geographic distribution of financial cost of filing for Chapter 7 bankruptcy in 2007. See the text for additional details on the construction of this measure. 


\section{Appendix Figure A3: Correlation of Exemptions and Financial Cost of Bankruptcy}

Panel A: Homestead Exemption

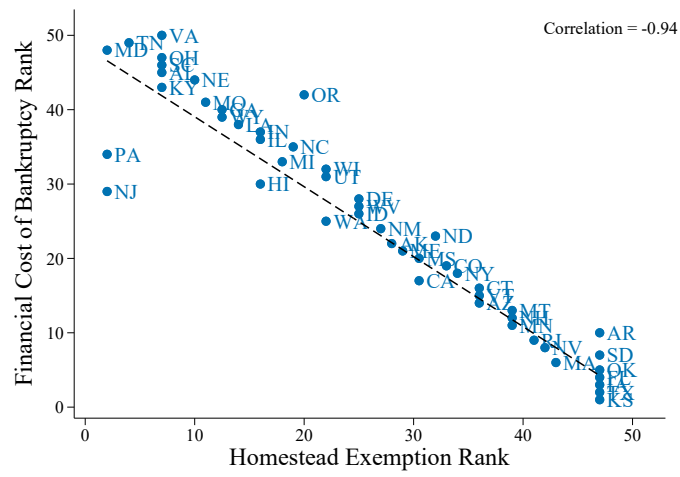

Panel C: Savings Exemption

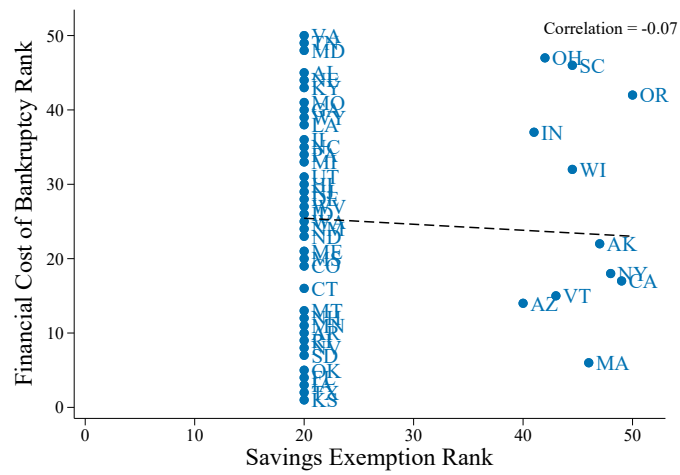

Panel B: Vehicle Exemption

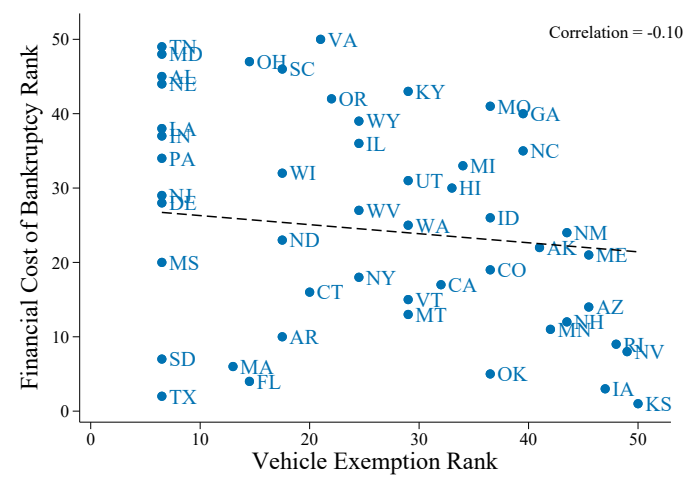

Panel D: Wildcard Exemption

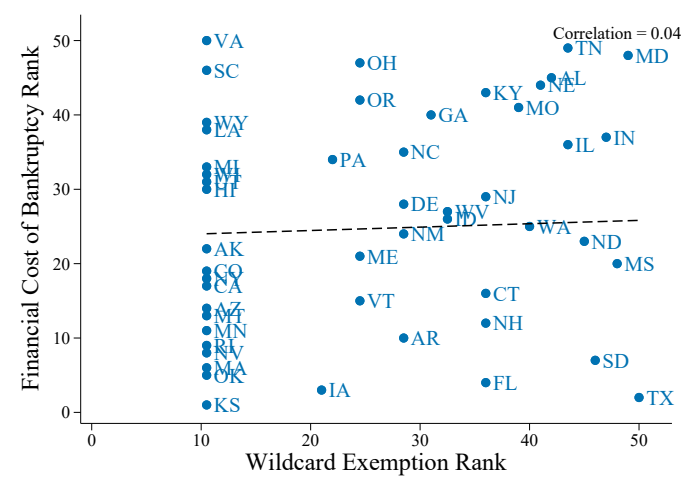

Note: This figure shows the correlation of the financial cost of bankruptcy measure described in the text and the different Chapter 7 bankruptcy exemptions. Each panel plots the state-specific rank for the financial cost of bankruptcy against the state-specific rank for each Chapter 7 asset exemption category. We also plot the line of best fit, weighted by states' population. See the text for additional details. 


\section{Appendix Figure A4: Debt Relief Multiplier as a Function of Monetary Policy Responsive- ness}
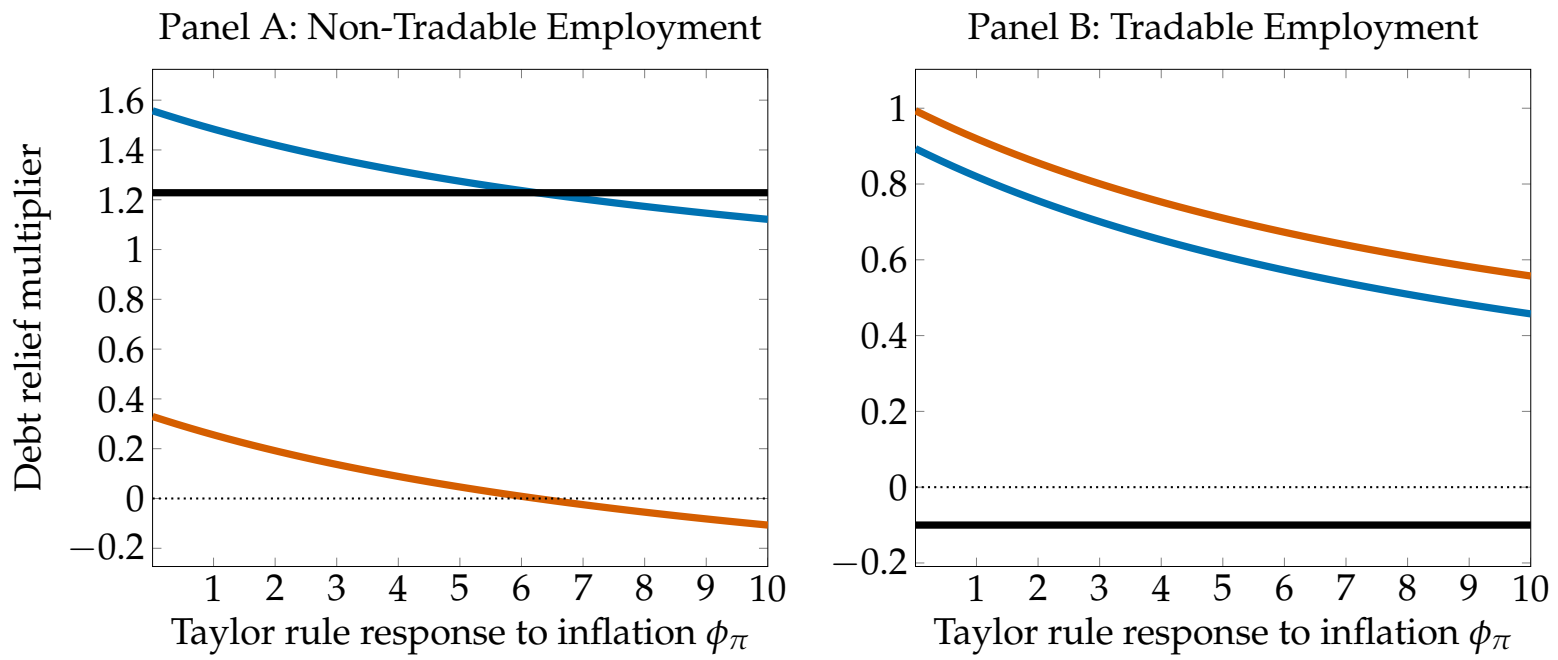

- Home multiplier $\left(\mathcal{M}_{H}\right)$ - Foreign multiplier $\left(\mathcal{M}_{F}\right)$ - Relative multiplier $\left(\mathcal{M}_{\text {rel }}\right)$

Note: This figure plots the debt relief multiplier in our model for non-tradable and tradable employment in high- and lowexemption regions as a function of the degree of responsiveness of monetary policy to inflation $\phi_{\pi}$. The blue line is the debt relief multiplier in the home region ("high-exemption"), the red line is the debt relief multiplier in the foreign region ("lowexemption"), and the black line represents the difference between the home and the foreign regions. Zero responsiveness $\left(\phi_{\pi}=0\right)$ corresponds to the zero lower bound, where nominal interest rates are unchanged as debt relief changes. The level effect of debt relief on employment is decreasing in $\phi_{\pi}$, while the relative multiplier is independent of the monetary policy response, as in Nakamura and Steinsson (2014). 


\section{Appendix Figure A5: Impulse Response to a Debt Relief Shock under Flexible Prices}
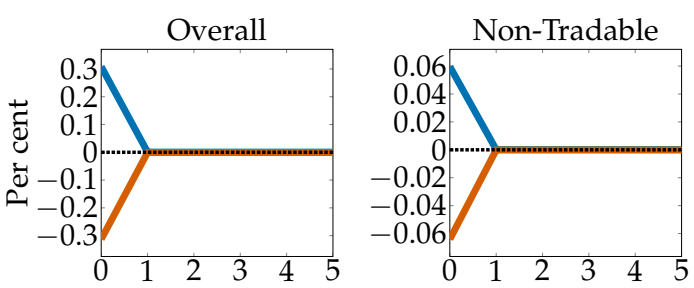

Panel A: Consumption
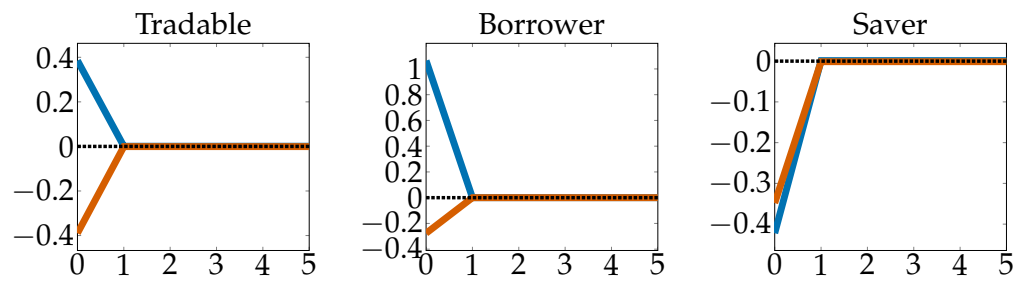

Panel B: Employment
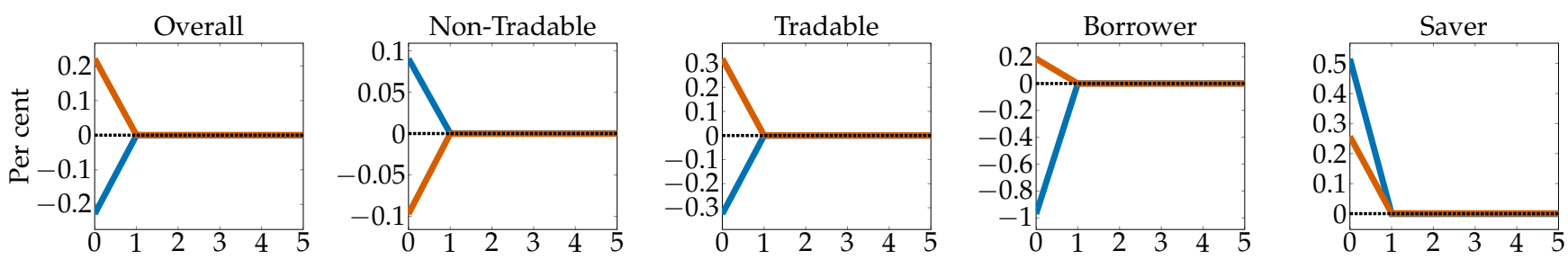

\section{Panel C: Other Outcomes}
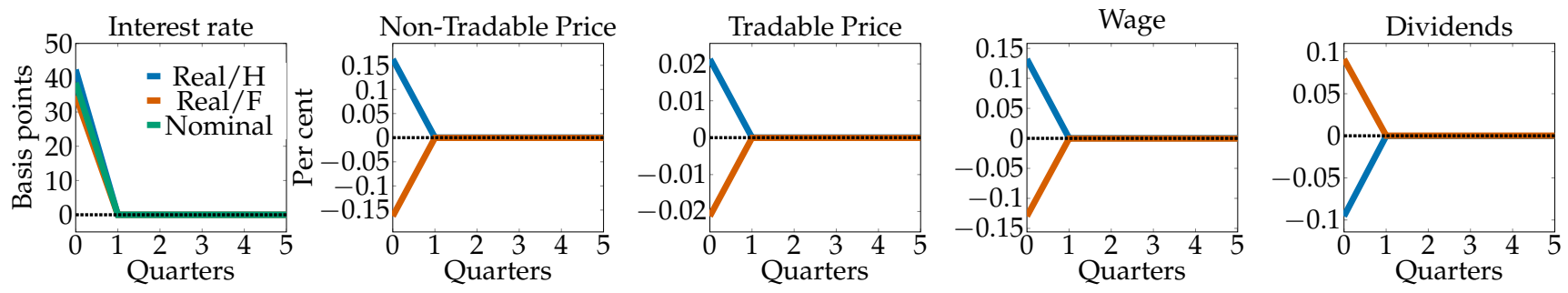

- Home - Foreign

Note: This figure plots the effect in our model of a debt relief shock that reduces borrower debts in the high exemptions regions by 1 percent of PCE on aggregate outcomes under the assumption that prices are flexible $(\theta=0)$ instead of sticky $(\theta=0.8)$ as in our baseline parameterization shown in Figure 4 . The blue line represents outcomes in the home region ("high-exemption"), and the red line is outcomes in the foreign region ("low-exemption"). Panel A plots consumption outcomes, where the first column plots aggregate consumption, the second and third columns plot non-tradable and tradable consumption, and the fourth and fifth columns plot borrower and saver consumption. Panel B plots employment outcomes, where the first column again plots aggregate employment, the second and third columns plot non-tradable and tradable employment, and the fourth and fifth columns plot borrower and saver employment. Panel C plots price outcomes, where the first column plots nominal and real interest rates, the second and third columns plot non-tradable and tradable prices, the fourth column plots nominal wages, and the fifth column plots aggregate dividends from firms. 


\section{Appendix Figure A6: Debt Relief Multiplier as a Function of Openness to Trade}
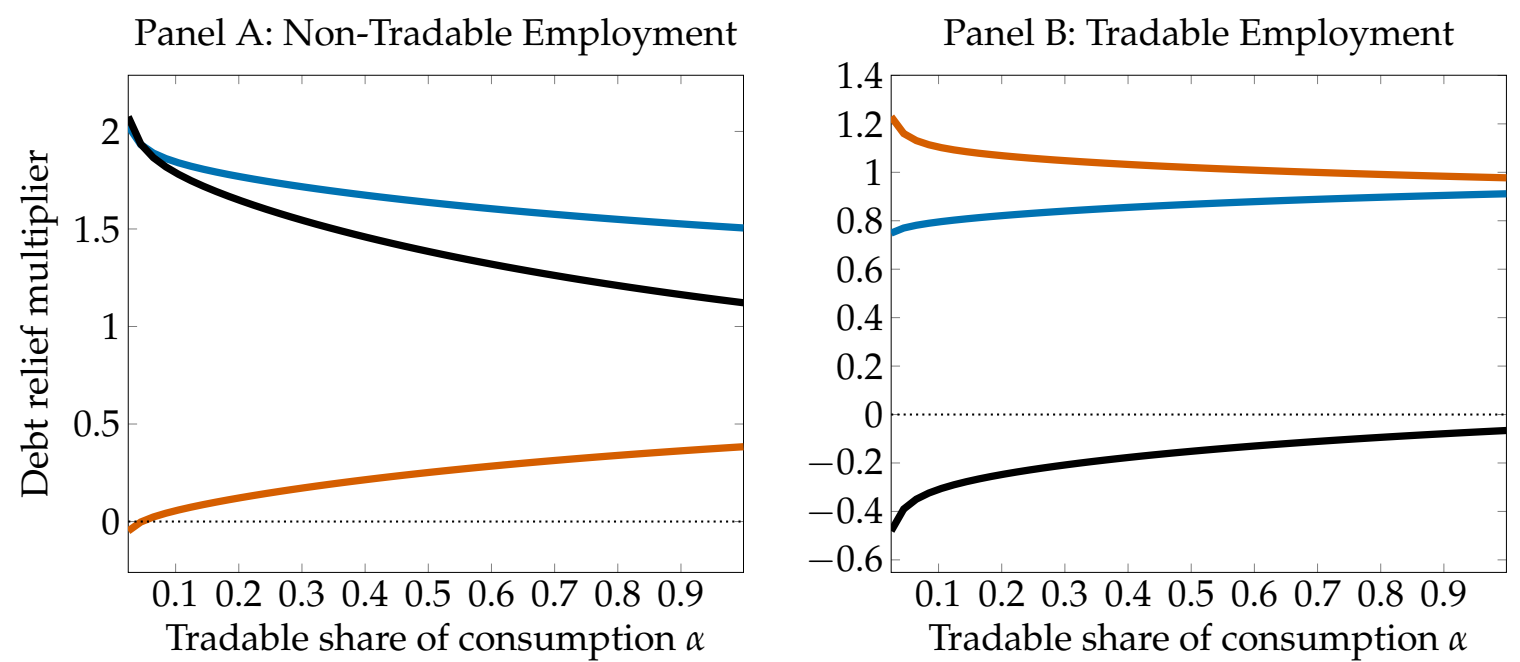

- Home multiplier $\left(\mathcal{M}_{H}\right)$ - Foreign multiplier $\left(\mathcal{M}_{F}\right)-$ Relative multiplier $\left(\mathcal{M}_{\text {rel }}\right)$

Note: This figure plots the debt relief multiplier in our model for non-tradable and tradable employment in the home and the foreign regions as a function of the degree of openness to trade $\alpha$. The blue line is the debt relief multiplier in the home region ("high-exemption"), the red line is the debt relief multiplier in the foreign region ("low-exemption"), and the black line represents the difference between the multipliers in the home and the foreign regions. More home bias reduces the amount of foreign demand "leakage," increasing the local non-tradable multiplier and lowering the foreign non-tradable multiplier, so that the relative non-tradable multiplier rises. 


\section{Appendix Figure A7: Debt Relief Multiplier as a Function of the Degree of Price Rigidity $\theta$ for GHH preferences}
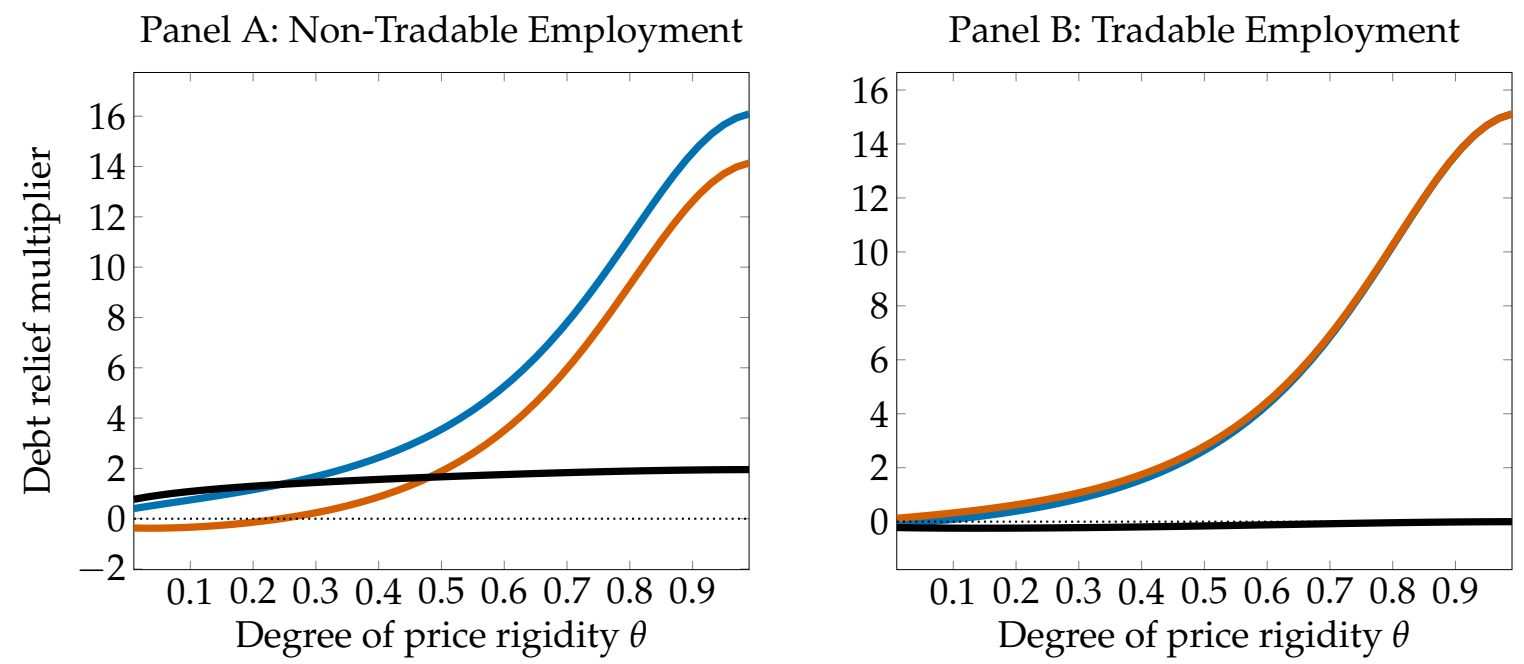

- Home multiplier $\left(\mathcal{M}_{H}\right)$ - Foreign multiplier $\left(\mathcal{M}_{F}\right)-$ Relative multiplier $\left(\mathcal{M}_{\text {rel }}\right)$

Note: This figure plots the home, foreign and relative debt relief multipliers in our model for non-tradable and tradable employment as a function of the degree of price rigidity, under the assumption of GHH preferences $u^{h}(C, N)=$ $\log \left(C-\chi_{h} N^{2}\right)$. The blue line is the response of log employment in the home region ("high-exemption") to a reduction in home borrowers' debts of 1 percent of PCE. The red line is the response of log employment in the foreign region ("lowexemption") to the same shock. The black line is the difference between the responses in the home and the foreign region ("relative multiplier"), which corresponds to the debt relief multiplier identified by our difference-in-differences research design. To draw this figure, we assume that monetary policy follows a Taylor rule with a coefficient $\phi_{\pi}=0.8$ that is sufficient to guarantee determinacy. This guarantees that the outcome converges to flexible prices as $\theta \rightarrow 0$. As we show in Section IV.E, the relative multipliers are independent of monetary policy. The GHH model is able to generate a relative multiplier for non-tradable employment $\mathcal{M}_{N T, \text { rel }}$ that is large as that observed in the data when $\theta$ is sufficiently large, but that relative multiplier masks very large home and foreign multipliers for both non-tradable and tradable employment. 


\section{Appendix Figure A8: Debt Relief Multiplier as a Function of the Degree of Local Financing}
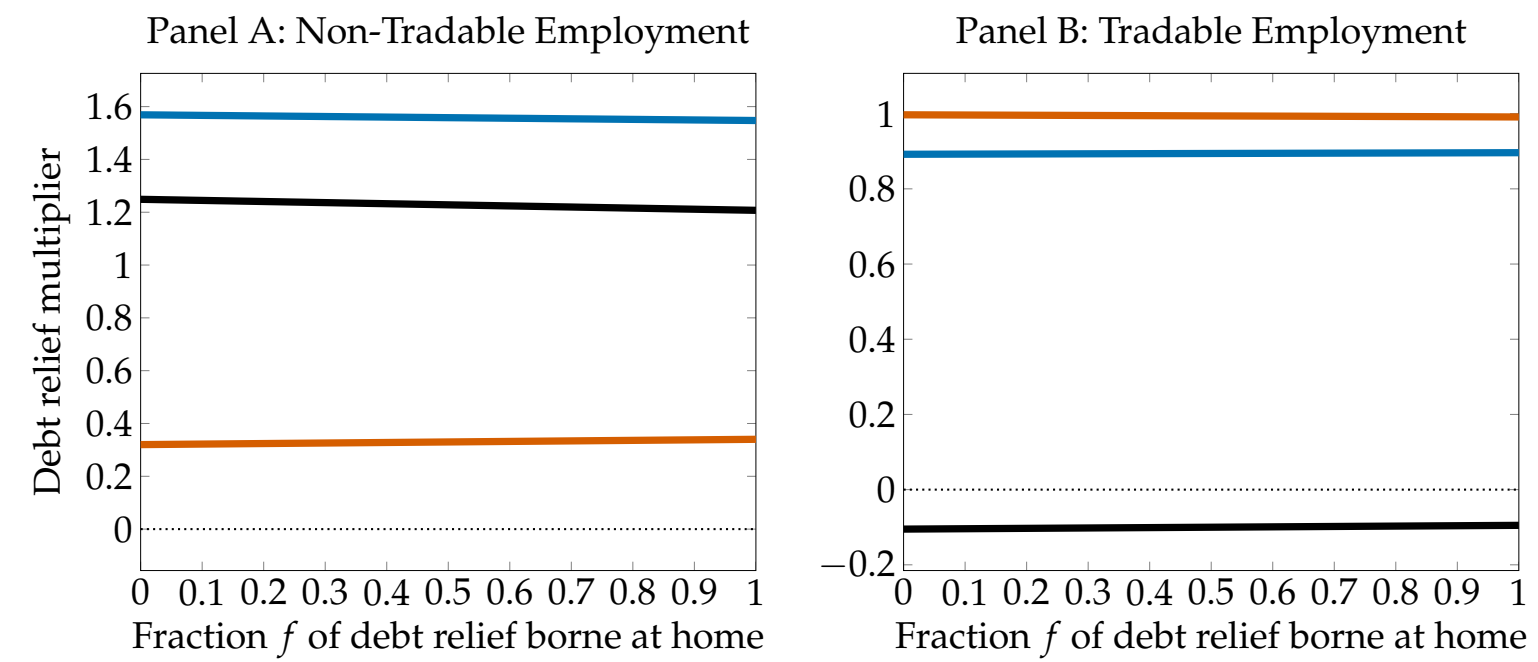

- Home multiplier $\left(\mathcal{M}_{H}\right)$ - Foreign multiplier $\left(\mathcal{M}_{F}\right)$ - Relative multiplier $\left(\mathcal{M}_{\text {rel }}\right)$

Note: This figure shows the debt relief multiplier in our model for non-tradable and tradable employment in the home and the foreign regions as a function of the fraction $f$ of debt relief that is paid for by savers in the high exemption region. The blue line is the debt relief multiplier in the home region ("high-exemption"), the red line is the debt relief multiplier in the foreign region ("low-exemption"), and the black line represents the difference between the multipliers in the home and the foreign regions. The incidence of debt relief has little impact on either the aggregate or relative debt relief multipliers. 


\section{Appendix B. Model Details}

This appendix derives our model, details our calibration strategy and explains our solution method. Here, we allow for a slightly more general version of the model in which:

1. The size of the home region can be an arbitrary number $n \in(0,1)$ (with $n=\frac{1}{2}$ in the main text).

2. Borrowers and savers may own different shares in firms; we denote these shares by $v^{B}, v^{S}$ (with $v^{B}=$ $v^{S}=1$ in the main text).

3. Tradable and non-tradable goods firms may have different degrees of diminishing returns to production $\gamma_{T}, \gamma_{N T}$ (with $\gamma_{T}=\gamma_{N T}=\gamma$ in the main text).

\section{A. Derivation of Equations}

Households. As described in Section IV, our general household problem is:

$$
\begin{array}{ll}
\max & \mathbb{E} \sum_{t=0}^{\infty}\left(\beta^{h}\right)^{t} u^{h}\left(C_{i, t}^{h}, N_{i, t}^{h}\right) \\
\text { s.t. } & P_{i, t} C_{i, t}^{h}+B_{i, t-1}^{h}-\Delta_{i, t}^{h} \leq \frac{B_{i, t}^{h}}{1+I_{t}}+W_{i, t} N_{i, t}^{h}+v^{h} D_{i, t}, \\
& B_{i, t}^{h} \leq \bar{b} P_{T, t}
\end{array}
$$

This yields standard first-order conditions: a labor supply decision:

$$
\frac{W_{i, t}}{P_{i, t}}=\frac{u_{N}^{h}\left(C_{i, t}^{h}, N_{i, t}^{h}\right)}{u_{C}^{h}\left(C_{i, t}^{h} N_{i, t}^{h}\right)}
$$

and an intertemporal Euler equation:

$$
\beta \frac{u_{C}^{h}\left(C_{i, t+1}^{h}, N_{i, t+1}^{h}\right)}{u_{C}^{h}\left(C_{i, t}^{h}, N_{i, t}^{h}\right)}=\frac{P_{i, t+1}}{P_{i, t}} \frac{1}{1+I_{t}}\left(1-\left(1+I_{t}\right) \mu_{i, t}^{h}\right)
$$

where $\mu_{i, t}$ is the Lagrange multiplier on the borrowing constraint; when $\mu_{i, t}^{h}>0$ this constraint binds and:

$$
B_{i, t}^{h}=\bar{b} P_{T, t}
$$

Static maximization of the allocation of consumption across goods also yields standard first-order conditions: for both $h \in\{S, B\}$,

$$
\begin{aligned}
\frac{C_{T, H, j, t}^{h}}{C_{H, t}^{h}} & =\alpha\left(\frac{P_{T, j, t}}{P_{T, t}}\right)^{-\epsilon}\left(\frac{P_{T, t}}{P_{H, t}}\right)^{-\eta} \\
\frac{C_{N T, H, j, t}^{h}}{C_{H, t}^{h}} & =(1-\alpha)\left(\frac{P_{N T, H, j, t}}{P_{N T, H, t}}\right)^{-\epsilon}\left(\frac{P_{N T, H, t}}{P_{H, t}}\right)^{-\eta} \\
\frac{C_{T, F, j, t}^{h}}{C_{F, t}^{h}} & =\alpha\left(\frac{P_{T, j, t}}{P_{T, t}}\right)^{-\epsilon}\left(\frac{P_{T, t}}{P_{F, t}}\right)^{-\eta} \\
\frac{C_{N T, F, j, t}^{h}}{C_{F, t}^{h}} & =(1-\alpha)\left(\frac{P_{N T, F, j, t}}{P_{N T, F, t}}\right)^{-\epsilon}\left(\frac{P_{N T, F, t}}{P_{F, t}}\right)^{-\eta}
\end{aligned}
$$


Separable preferences. Under separable preferences, $u^{h}(C, N)=\frac{C^{1-\sigma}}{1-\sigma}-\chi^{h} \frac{N^{1+\psi}}{1+\psi}$, (B.1) reads:

$$
\frac{\chi^{h}\left(N_{i, t}^{h}\right)^{\psi}}{\left(C_{i, t}^{h}\right)^{-\sigma}}=\frac{W_{i, t}}{P_{i, t}}
$$

and (B.2) reads:

$$
\beta \frac{\left(C_{i, t+1}^{h}\right)^{-\sigma}}{\left(C_{i, t}^{h}\right)^{-\sigma}}=\frac{P_{i, t+1}}{P_{i, t}} \frac{1}{1+I_{t}}\left(1-\left(1+I_{t}\right) \mu_{i, t}^{h}\right)
$$

GHH preferences. Under GHH preferences, $u^{h}(C, N)=\frac{1}{1-\sigma}\left(C-\chi^{h} \frac{N^{1+\psi}}{1+\psi}\right)^{1-\sigma}$, instead, (B.1) reads:

$$
\chi^{h}\left(N_{i, t}^{h}\right)^{\psi}=\frac{W_{i, t}}{P_{i, t}}
$$

and (B.2) reads:

$$
\beta \frac{\left(C_{i, t+1}-\chi \frac{N_{i t+1}^{1+\psi}}{1+\psi}\right)^{-\sigma}}{\left(C_{i, t}-\chi \frac{N_{i t}^{1+\varphi}}{1+\varphi}\right)^{-\sigma}}=\frac{P_{i, t+1}}{P_{i, t}} \frac{1}{1+I_{t}}\left(1-\left(1+I_{t}\right) \mu_{i, t}^{h}\right)
$$

Generic firm problem. A generic firm has monopoly power; its maximization problem is:

$$
\max _{p(i)} D(i) \equiv p(i) y(i)-W n(i)
$$

where $W$ is the local wage it faces, $p(i)$ is its price, $n(i)$ is its employment, $y(i)=A n(i)^{\gamma}$ is its production function. The firm faces a demand constraint of the form:

$$
p(i)=P Y^{\frac{1}{\epsilon}} y(i)^{-\frac{1}{\epsilon}}
$$

Under fully flexible prices each period, the firm sets $n(i)$ optimally to maximize static profits, this yields:

$$
P Y^{\frac{1}{\epsilon}} \gamma \frac{\epsilon-1}{\epsilon}\left[A n(i)^{\gamma}\right]^{\frac{\epsilon-1}{\epsilon}} \frac{1}{n(i)}-W=0
$$

where $n(i)=\left(\frac{y(i)}{A}\right)^{\frac{1}{\gamma}}$; hence:

$$
\frac{W}{P}=\gamma \frac{\epsilon-1}{\epsilon} A^{\frac{1}{\gamma}} Y^{\frac{1}{\varepsilon}} y(i)^{1-\frac{1}{\epsilon}-\frac{1}{\gamma}}
$$

All firms in the same industry have the same price $p(i)=P$ and therefore produce the same amount, so $y(i)=Y$ and every period:

$$
\frac{W_{t}}{P_{t}}=\gamma \frac{\epsilon-1}{\epsilon} A_{t}^{\frac{1}{\gamma}} Y_{t}^{1-\frac{1}{\gamma}}
$$

Under sticky Calvo prices, a standard derivation yields a firm's optimal reset price $P_{t}^{*}$ at time $t$, relative to its industry's price index $P_{t}$, as: 


$$
\left(\frac{P_{t}^{*}}{P_{t}}\right)^{1+\frac{\varepsilon(1-\gamma)}{\gamma}}=\frac{\varepsilon}{\varepsilon-1} \frac{\sum_{k=0}^{\infty} \theta^{k} E\left[\left(\beta^{S}\right)^{k} u_{C, t+k}^{S} Y_{t+k}\left(\frac{P_{t+k}}{P_{t}}\right)^{\varepsilon+\frac{\varepsilon(1-\gamma)}{\gamma}} \overline{M C}_{t}^{r}\right]}{\sum_{k=0}^{\infty} \theta^{k} E\left[\left(\beta^{S}\right)^{k} u_{C, t+k}^{S} Y_{t+k}\left(\frac{P_{t+k}}{P_{t}}\right)^{\varepsilon-1}\right]}
$$

where the firm discounts future real flows using the saver's stochastic discount factor $\left(\beta^{S}\right)^{k} u_{C, t+k}^{S}$ since the saver is always on his Euler equation, $Y_{t}$ is industry demand, and $\overline{M C}_{t}^{r}$ are average real marginal costs at time $t$, defined as:

$$
\overline{M C}_{t}^{r} \equiv \frac{W_{t}}{P_{t}} \frac{1}{\gamma A_{t}^{\frac{1}{\gamma}} Y_{t}^{1-\frac{1}{\gamma}}}
$$

note that in the limit of flexible prices, $\theta=0, P_{t}=P_{t}^{*}$ and we recover (B.12). Linearization for inflation $\Pi_{t}=\frac{P_{t}}{P_{t-1}}$ around a steady-state with zero inflation results in the standard New Keynesian Phillips curve:

$$
\hat{\pi}_{t}=\beta^{S} E\left[\hat{\pi}_{t+1}\right]+\frac{(1-\theta)\left(1-\theta \beta^{S}\right)}{\theta} \frac{1}{1+\frac{\varepsilon(1-\gamma)}{\gamma}} \hat{m} c_{t}^{r}
$$

where:

$$
\hat{m} c_{t}^{r}=\hat{w}_{t}-\hat{p}_{t}+\frac{1-\gamma}{\gamma} \hat{y}_{t}
$$

We now specify this generic problem to non-traded and traded goods firms in the home and the foreign region.

Non-tradable goods firm problem. A firm $j$ in the non-tradable sector of region $i \in\{H, F\}$ operates its technology subject to a demand constraint:

$$
\left(\frac{p_{N T, i, j, t}}{P_{N T, i, t}}\right)^{-\epsilon} C_{N T, i, t}=y_{N T, i, j, t}=A_{N T, t}\left(n_{N T, i, j, t}\right)^{\gamma_{N T}}
$$

where

$$
C_{N T, i, t}=(1-\alpha)\left(\frac{P_{N T, i, t}}{P_{i, t}}\right)^{-\eta} C_{i, t}^{h}
$$

is non-traded goods demand in region $i$, taken as exogenous by the firm. Write $N_{N T, i, t}$ for aggregate employment in the non-tradable sector of region $i$ at time $t$. Market clearing for each input $N_{N T, i, t}=\int_{j=0}^{1} n_{N T, i, j, t} d j$ implies:

$$
N_{N T, i, t}=\int_{j}\left(\frac{p_{N T, i, j, t}}{P_{N T, i, t}}\right)^{-\frac{\epsilon}{\gamma_{N T}}} d j \cdot\left(\frac{C_{N T, i, t}}{A_{N T, t}}\right)^{\frac{1}{\gamma_{N T}}}
$$

Hence, at the aggregate level, consumption and employment are related via:

$$
C_{N T, i, t}=\frac{A_{N T, t}}{\triangle_{N T, i, t}}\left(N_{N T, i, t}\right)^{\gamma_{N T}}
$$

where $\Delta_{N T, i, t}=\left[\int_{j=0}^{1}\left(\frac{p_{N T, i, j, t}}{P_{N T, i, t}}\right)^{-\frac{\epsilon}{\gamma_{N T}}} d j\right]^{\gamma_{N T}} \geq 1$.

This has the form of the generic problem described above. Under flexible prices $\Delta_{N T, i, t}=1$ and we obtain:

$$
\frac{W_{i, t}}{P_{N T, i, t}}=\gamma_{N T} \frac{\epsilon-1}{\epsilon} A_{N T, t}^{\frac{1}{\gamma_{N T}}} Y_{N T, i, t}^{1-\frac{1}{\gamma_{N T}}}=\gamma_{N T} \frac{\epsilon-1}{\epsilon} A_{N T, t} N_{N T, i, t}^{\gamma_{N T}-1}
$$


Under sticky prices, the Phillips curves are:

$$
\hat{\pi}_{N T, i, t}=\beta^{S} E\left[\hat{\pi}_{N T, i, t+1}\right]+\kappa_{N T}\left(\hat{w}_{i, t}-\hat{p}_{N T, i, t}+\frac{1-\gamma}{\gamma} \hat{y}_{N T, i, t}\right)
$$

where $\kappa_{N T} \equiv \frac{(1-\theta)\left(1-\theta \beta^{S}\right)}{\theta} \frac{1}{\left(1+\frac{\varepsilon\left(1-\gamma_{N T}\right)}{\gamma_{N T}}\right)}$.

Tradable goods firm problem. A firm $j$ in the tradable sector of region $i \in\{H, F\}$ operates its technology subject to a demand constraint:

$$
\left(\frac{p_{T, i, j, t}}{P_{T, i, t}}\right)^{-\epsilon}\left(\frac{P_{T, i, t}}{P_{T, t}}\right)^{-\epsilon} C_{T, t}=y_{T, i, j, t}=A_{T, t}\left(n_{T, i, j, t}\right)^{\gamma_{N T}}
$$

The difference with (B.15) is that goods demand is global, namely:

$$
C_{T, t}=n \cdot \alpha\left(\frac{P_{T, t}}{P_{H, t}}\right)^{-\eta} C_{H, t}+(1-n) \cdot \alpha\left(\frac{P_{T, t}}{P_{F, t}}\right)^{-\eta} C_{F, t}
$$

Write $N_{T, i, t}$ for aggregate employment in the tradable sector of region $i$ at time $t$. Market clearing at home and abroad, $N_{T, H, t}=\int_{j=0}^{n} n_{T, i, j} d j$ and $N_{T, F, t}=\int_{j=n}^{1} n_{T, i, j} d j$, implies:

$$
\begin{gathered}
N_{T, H, t}=\int_{j=0}^{n}\left(\frac{p_{T, i, j, t}}{P_{T, H, t}}\right)^{-\frac{\epsilon}{\gamma_{T}}} d j\left(\frac{\left(\frac{P_{T, H, t}}{P_{T, t}}\right)^{-\epsilon} C_{T, t}}{A_{T, t}}\right)^{\frac{1}{\gamma_{T}}} \\
\left(\frac{P_{T, H, t}}{P_{T, t}}\right)^{-\epsilon} C_{T, t}=\frac{A_{T, t}}{\triangle_{T, H, t}}\left(N_{T, H, t}\right)^{\gamma_{T}} \\
\left(\frac{P_{T, F, t}}{P_{T, t}}\right)^{-\epsilon} C_{T, t}=\frac{A_{T, t}}{\triangle_{T, F, t}}\left(N_{T, F, t}\right)^{\gamma_{T}}
\end{gathered}
$$

where $\Delta_{T, H, t}=\left[\int_{j=0}^{n}\left(\frac{P_{T, H, j, t}}{P_{T, H, t}}\right)^{-\frac{\epsilon}{\gamma_{T}}} d j\right]^{\gamma_{T}} \geq 1$ and $\Delta_{T, H, t}=\left[\int_{j=n}^{1}\left(\frac{P_{T, F, j, t}}{P_{T, F, t}^{F}}\right)^{-\frac{\epsilon}{\gamma_{T}}} d j\right]^{\gamma_{T}} \geq 1 .^{39}$

This problem also has the form of the generic problem described above. Under flexible prices $\Delta_{T, i, t}=1$ and we obtain:

$$
\frac{W_{i, t}}{P_{T, i, t}}=\gamma_{T} \frac{\epsilon-1}{\epsilon} A_{T, t}^{\frac{1}{\gamma_{T}}} Y_{T, i, t}^{1-\frac{1}{\gamma_{T}}}=\gamma_{T} \frac{\epsilon-1}{\epsilon} A_{T, t} N_{T, i, t}^{\gamma_{T}-1}
$$

in particular, combining with (B.16), we obtain relative labor demand as:

$$
\frac{P_{N T, i, t}}{P_{T, i, t}}=\frac{\gamma_{T}}{\gamma_{N T}} \frac{A_{T, t}}{A_{N T, t}} \frac{\left(N_{N T, i, t}\right)^{1-\gamma_{N T}}}{\left(N_{T, i, t}\right)^{1-\gamma_{T}}}
$$

Under sticky prices, the Phillips curves are:

$$
\hat{\pi}_{T, i, t}=\beta^{S} E\left[\hat{\pi}_{T, i, t+1}\right]+\kappa_{T}\left(\hat{w}_{i, t}-\hat{p}_{T, i, t}+\frac{1-\gamma}{\gamma} \hat{y}_{T, i, t}\right)
$$

\footnotetext{
${ }^{39} \mathrm{We}$ have defined the local tradable price indices as $\left(P_{T, H}\right)^{1-\epsilon}=\frac{1}{n} \int_{j=0}^{n}\left(p_{j, T}\right)^{1-\epsilon} d j$ and $\left(P_{T, F}\right)^{1-\epsilon}=$ $\frac{1}{1-n} \int_{j=n}^{1}\left(p_{j, T}\right)^{1-\epsilon} d j$ so that the overall traded goods price index is $P_{T}^{1-\epsilon}=n\left(P_{T, H}\right)^{1-\epsilon}+(1-n)\left(P_{T, F}\right)^{1-\epsilon}$.
} 
where $\kappa_{T} \equiv \frac{(1-\theta)\left(1-\theta \beta^{S}\right)}{\theta} \frac{1}{\left(1+\frac{\varepsilon\left(1-\gamma_{N T}\right)}{\gamma_{N T}}\right)}$

\section{B. Steady state}

Our flexible-price steady state has 29 equations, as detailed below:

1) Our numeraire is the price index for tradables, which we normalize to $P_{T}=1$

2) The definition of the tradable price index $P_{T}$ implies:

$$
\frac{P_{T H}}{P_{T}}=\left[n+(1-n)\left(\frac{P_{T F}}{P_{T H}}\right)^{1-\epsilon}\right]^{\frac{-1}{1-\epsilon}}
$$

where recall that $n$ denotes the size of the home region; in the main text $n=\frac{1}{2}$.

3-4) Consumer price indices at home and foreign:

$$
\begin{aligned}
& P_{H}=\left[\alpha\left(P_{T}\right)^{1-\eta}+(1-\alpha)\left(P_{N T, H}\right)^{1-\eta}\right]^{\frac{1}{1-\eta}} \\
& P_{F}=\left[\alpha\left(P_{T}\right)^{1-\eta}+(1-\alpha)\left(P_{N T, F}\right)^{1-\eta}\right]^{\frac{1}{1-\eta}}
\end{aligned}
$$

5-8) Household intratemporal first-order conditions: in the case of separable preferences this is given by (B.8):

$$
\begin{aligned}
\chi^{B}\left(C_{H}^{B}\right)^{\sigma}\left(N_{H}^{B}\right)^{\psi} & =\frac{W_{H}}{P_{H}} \\
\chi^{B}\left(C_{F}^{B}\right)^{\sigma}\left(N_{F}^{B}\right)^{\psi} & =\frac{W_{F}}{P_{F}} \\
\chi^{S}\left(C_{H}^{S}\right)^{\sigma}\left(N_{H}^{S}\right)^{\psi} & =\frac{W_{H}}{P_{H}} \\
\chi^{S}\left(C_{F}^{S}\right)^{\sigma}\left(N_{F}^{S}\right)^{\psi} & =\frac{W_{F}}{P_{F}}
\end{aligned}
$$

in the case of GHH preferences, replace with (B.10) instead.

9-10) Labor market clearing conditions at Home and in Foreign, exploiting $\Delta_{T, i}=\Delta_{N T, i}=1$ at steady state:

$$
\begin{aligned}
\varphi^{B} N_{H}^{B}+\varphi^{S} N_{H}^{S} & =N_{T, H}+N_{N T, H}=\left(\frac{Y_{T, H}}{A_{T}}\right)^{\frac{1}{\gamma_{T}}}+\left(\frac{Y_{N T, H}}{A_{N T}}\right)^{\frac{1}{\gamma_{N T}}} \\
\varphi^{B} N_{F}^{B}+\varphi^{S} N_{F}^{S} & =N_{T, F}+N_{N T, F}=\left(\frac{Y_{T, F}}{A_{T}}\right)^{\frac{1}{\gamma_{T}}}+\left(\frac{Y_{N T, F}}{A_{N T}}\right)^{\frac{1}{\gamma_{N T}}}
\end{aligned}
$$

11-14) Goods market clearing conditions for tradables and non-tradables at Home and in Foreign:

$$
\begin{aligned}
Y_{T, H} & =\left(\frac{P_{T, H}}{P_{T}}\right)^{-\epsilon}\left(n C_{T, H}+(1-n) C_{T, F}\right) \\
Y_{T, F} & =\left(\frac{P_{T, F}}{P_{T}}\right)^{-\epsilon}\left(n C_{T, H}+(1-n) C_{T, F}\right) \\
Y_{N T, H} & =C_{N T, H} \\
Y_{N T, F} & =C_{N T, F}
\end{aligned}
$$


15-18) Consumer demand at Home and in Foreign, (B.4)-(B.7):

$$
\begin{aligned}
\frac{C_{T, H}}{C_{H}} & =\alpha\left(\frac{P_{T}}{P_{H}}\right)^{-\eta} \\
\frac{C_{N T, H}}{C_{H}} & =(1-\alpha)\left(\frac{P_{N T, H}}{P_{H}}\right)^{-\eta} \\
\frac{C_{T, F}}{C_{F}} & =\alpha\left(\frac{P_{T}}{P_{F}}\right)^{-\eta} \\
\frac{C_{N T, F}}{C_{F}} & =(1-\alpha)\left(\frac{P_{N T, F}}{P_{F}}\right)^{-\eta}
\end{aligned}
$$

19-20) Aggregate demand at Home and in Foreign:

$$
\begin{aligned}
& C_{H}=\varphi_{B} C_{H}^{B}+\left(1-\varphi_{B}\right) C_{H}^{S} \\
& C_{F}=\varphi_{B} C_{F}^{B}+\left(1-\varphi_{B}\right) C_{F}^{S}
\end{aligned}
$$

21-24) Tradable and non-tradable goods firms FOCs, at Home and in Foreign, (B.16) and (B.18):

$$
\begin{aligned}
\frac{W_{H}}{P_{T, H}} & =\frac{\epsilon-1}{\epsilon} \gamma_{T} A_{T}^{\frac{1}{\gamma_{T}}}\left(Y_{T, H}\right)^{-\frac{(1-\gamma)}{\gamma}} \\
\frac{W_{F}}{P_{T, F}} & =\frac{\epsilon-1}{\epsilon} \gamma_{T} A_{T}^{\frac{1}{\gamma_{T}}}\left(Y_{T, F}\right)^{-\frac{(1-\gamma)}{\gamma}} \\
\frac{W_{H}}{P_{N T, H}} & =\frac{\epsilon-1}{\epsilon} \gamma_{N T} A_{N T}^{\frac{1}{\gamma_{N T}}}\left(Y_{N T, H}\right)^{-\frac{(1-\gamma)}{\gamma}} \\
\frac{W_{F}}{P_{N T, F}} & =\frac{\epsilon-1}{\epsilon} \gamma_{N T} A_{N T}^{\frac{1}{\gamma_{N T}}}\left(Y_{N T, F}\right)^{-\frac{(1-\gamma)}{\gamma}}
\end{aligned}
$$

25-26) Total firm dividends, at Home and in Foreign:

$$
\begin{aligned}
D_{H} & =\left(P_{T, H} Y_{T, H}-W_{H} N_{T, H}\right)+\left(P_{N T, H} Y_{N T, H}-W_{H} N_{N T, H}\right) \\
D_{F} & =\left(P_{T, F} Y_{T, F}-W_{F} N_{T, F}\right)+\left(P_{N T, F} Y_{N T, F}-W_{F} N_{N T, F}\right)
\end{aligned}
$$

27-29) Three budget constraints for Home and Foreign borrower and Home saver:

$$
\begin{aligned}
P_{H} C_{H}^{B} & =W_{H} N_{H}^{B}+v^{B} D_{H}-\frac{I}{1+I} \bar{b} P_{H} \\
P_{H} C_{H}^{S} & =W_{H} N_{H}^{S}+v^{S} D_{H}-\frac{I}{1+I} B_{H}^{S} \\
+P_{F} C_{F}^{B} & =W_{F} N_{F}^{B}+v^{B} D_{F}-\frac{I}{1+I} \bar{b} P_{F}
\end{aligned}
$$

The Foreign saver's budget constraint follows by Walras's law.

Calibration. Our primitives are $n$ (country size), $\varphi^{B}$ (fraction of borrowers), $v^{B}$ (number of shares per borrower), the preference parameters $\alpha, \sigma, \psi, \epsilon, \eta, \beta^{S}$ and $\beta^{B}$, the production elasticities $\gamma_{T}$ and $\gamma_{N T}$, as well as a normalization for total PCE $C$, and the debt-to-PCE ratio $\frac{B}{P C}$. Given these, we now solve for $A_{T}, A_{N T}, \chi^{S}$ and $\chi^{B}$ to reach a symmetric steady state with zero inflation, so $\Pi=1$ and $R=1+I$, where all relative prices equal to 1 , and where hours worked for savers and borrowers in both regions are also both equal to 1 . 
Given our normalization of $P_{T}=1$, our restriction of unit relative prices implies:

$$
P_{N T, H}=P_{N T, F}=P_{T, H}=P_{T, F}=P_{H}=P_{F}=1
$$

In the symmetric steady state, per capita consumption in each region is the same:

$$
C_{H}=C_{F}=C
$$

given (B.4)-(B.7), this implies:

$$
C_{T}=\alpha C \quad C_{N T}=(1-\alpha) C
$$

as well as:

$$
Y_{T}=\alpha C \quad Y_{N T}=(1-\alpha) C
$$

Our normalization for hours implies:

$$
N_{H}^{B}=N_{H}^{S}=N_{F}^{B}=N_{F}^{S}=1
$$

Given (B.16) and (B.18), this implies equalization of the value of the marginal product of labor within regions:

$$
P_{T} \gamma_{T} A_{T} N_{T}^{\gamma_{T}-1}=P_{N T} \gamma_{N T} A_{N T} N_{N T}^{\gamma_{N T}-1}
$$

Together with:

$$
N_{N T}+N_{T}=1
$$

this equation pins down relative employment in each sector as a function of the degree of decreasing returns and technology.

Next, production implies:

$$
Y_{T}=A_{T} N_{T}^{\gamma_{T}} \quad Y_{N T}=A_{N T} N_{N T}^{\gamma N T}
$$

Combining with (B.21) and (B.22), we obtain:

$$
\frac{\alpha}{1-\alpha}=\frac{A_{T}}{A_{N T}} \frac{N_{T}^{\gamma_{T}}}{N_{N T}^{\gamma_{N T}}}=\frac{\gamma_{N T}}{\gamma_{T}} \frac{N_{T}^{1-\gamma_{T}}}{N_{N T}^{1-\gamma_{N T}}} \frac{N_{T}^{\gamma_{T}}}{N_{N T}^{\gamma_{N T}}}=\frac{\gamma_{N T}}{\gamma_{T}} \frac{N_{T}}{N_{N T}}
$$

hence, given (B.23), tradable goods employment $N_{T}$ in either region solves:

$$
\frac{N_{T}}{N_{N T}}=\frac{\alpha}{1-\alpha} \frac{\gamma_{T}}{\gamma_{N T}}=\frac{N_{T}}{1-N_{T}}
$$

Solving for $N_{T}$ and $N_{N T}$, we obtain:

$$
\begin{aligned}
N_{T} & =\frac{\alpha \gamma_{T}}{(1-\alpha) \gamma_{N T}+\alpha \gamma_{T}} \\
N_{N T} & =\frac{(1-\alpha) \gamma_{N T}}{(1-\alpha) \gamma_{N T}+\alpha \gamma_{T}}
\end{aligned}
$$

This delivers $A_{T}$ and $A_{N T}$, as desired:

$$
A_{T}=\frac{\alpha C}{N_{T}^{\gamma_{T}}} \quad A_{N T}=\frac{(1-\alpha) C}{N_{N T}^{\gamma / N T}}
$$

Symmetry also implies that relative wages are equated across regions:

$$
W_{H}=W_{F}=W
$$


The labor share in the tradable sector and non-tradable sectors are, respectively:

$$
\begin{gathered}
\frac{W N_{T}}{P C}=\frac{P_{T}}{P} \frac{\epsilon-1}{\epsilon} \gamma_{T} \alpha=\frac{\epsilon-1}{\epsilon} \gamma_{T} \alpha \\
\frac{W N_{N T}}{P C}=\frac{\epsilon-1}{\epsilon} \gamma_{N T}(1-\alpha)
\end{gathered}
$$

This implies that the level of the wage must be:

$$
W=\frac{\epsilon-1}{\epsilon}\left(\gamma_{T} \alpha+\gamma_{N T}(1-\alpha)\right) C=\omega C
$$

where $\omega \equiv \frac{\epsilon-1}{\epsilon}\left(\gamma_{T} \alpha+\gamma_{N T}(1-\alpha)\right)$, and that dividends are:

$$
\begin{aligned}
\frac{D}{P} & =Y_{T}+Y_{N T}-W N \\
& =C-W N \\
& =C(1-\omega)
\end{aligned}
$$

Finally, budget constraints together with a binding borrowing constraint for borrowers, $B^{B}=\bar{b}$, imply:

$$
\begin{aligned}
& C_{H}^{B}=W+v^{B} D-\frac{I}{1+I} \bar{b} \\
& C_{H}^{S}=W+v^{S} D-\frac{I}{1+I} B^{S} \\
& C_{F}^{S}=W+v^{S} D-\frac{I}{1+I} B^{S}
\end{aligned}
$$

Market clearing for domestic debt implies:

$$
\varphi^{B} \frac{\bar{b}}{C}+\left(1-\varphi^{B}\right) \frac{B^{S}}{C}=0
$$

so

$$
\frac{B^{S}}{C}=-\frac{\varphi^{B}}{1-\varphi^{B}} \frac{\bar{b}}{C}
$$

We finally obtain $\chi^{B}$ and $\chi^{S}$ to our normalization for hours worked by setting:

$$
\begin{aligned}
& \chi^{B}=\frac{W}{\left(C^{B}\right)^{\sigma}}=\frac{\omega C}{\left[\left(\omega+v^{B}(1-\omega)-(I-1) \frac{\bar{b}}{C}\right) C\right]^{\sigma}} \\
& \chi^{S}=\frac{W}{\left(C^{S}\right)^{\sigma}}=\frac{\omega C}{\left[\left(\omega+v^{S}(1-\omega)+(I-1) \frac{\varphi^{B}}{1-\varphi^{B}} \bar{b}\right) C\right]^{\sigma}}
\end{aligned}
$$

Note that aggregate household debt, as a share of aggregate consumption, is $\frac{\varphi^{B} \bar{b}}{C}$.

\section{Impulse responses}

Our model admits two regimes depending on the set of constraints that binds. When all agents are unconstrained:

$$
u_{C, H, t}^{B}=\beta^{B}\left(1+I_{t}\right) \frac{P_{H, t}}{P_{H, t+1}} u_{C, H, t+1}^{B}
$$




$$
\begin{aligned}
& u_{C, H, t}^{S}=\beta^{S}\left(1+I_{t}\right) \frac{P_{H, t}}{P_{H, t+1}} u_{C, H, t+1}^{S} \\
& u_{C, F, t}^{B}=\beta^{B}\left(1+I_{t}\right) \frac{P_{F, t}}{P_{F, t+1}} u_{C, F, t+1}^{B} \\
& u_{C, F, t}^{S}=\beta^{S}\left(1+I_{t}\right) \frac{P_{F, t}}{P_{F, t+1}} u_{C, F, t+1}^{S}
\end{aligned}
$$

and all agents are on their budget constraints:

$$
P_{i, t} C_{i, t}^{h}+B_{i, t-1}^{h}-\Delta_{i, t}^{h}=\frac{B_{i, t}^{h}}{1+I_{t}}+W_{i, t} N_{i, t}^{h}+v^{h} D_{i, t}
$$

When home borrowers are constrained, (B.27) is replaced by:

$$
B_{H, t}^{B}=\bar{b} P_{T, t}
$$

and similarly when foreign borrowers are constrained (B.29) is replaced by:

$$
B_{F, t}^{B}=\bar{b} P_{T, t}
$$

\section{Loglinearization}

Assuming separable preferences, loglinearization of our model around the steady state defined above results in the following equations holding at every time $t$ :

$$
\begin{aligned}
p_{T H}-p_{T} & =(1-n)\left(p_{T H}-p_{T F}\right) \\
p_{H} & =\alpha p_{T}+(1-\alpha) p_{N T, H} \\
p_{F} & =\alpha p_{T}+(1-\alpha) p_{N T, F} \\
\sigma c_{H}^{B}+\psi n_{H}^{B} & =w_{H}-p_{H} \\
\sigma c_{F}^{B}+\psi n_{F}^{B} & =w_{F}-p_{F} \\
\sigma c_{H}^{S}+\psi n_{H}^{S} & =w_{H}-p_{H} \\
\sigma c_{F}^{S}+\psi n_{F}^{S} & =w_{F}-p_{F} \\
n_{H} & =\frac{N_{T, H}}{\gamma_{T}} y_{T, H}+\frac{N_{N T, H}}{\gamma_{N T}} y_{N T, H} \\
n_{F} & =\frac{N_{T, F}}{\gamma_{T}} y_{T, F}+\frac{N_{N T, F}}{\gamma_{N T}} y_{N T, F} \\
n_{H} & =\varphi^{B} n_{H}^{B}+\varphi^{S} n_{H}^{S} \\
n_{F} & =\varphi^{B} n_{F}^{B}+\varphi^{S} n_{F}^{S} \\
y_{T, H} & =-\epsilon\left(p_{T, H}-p_{T}\right)+n c_{T, H}+(1-n) c_{T, F} \\
y_{T, F} & =-\epsilon\left(p_{T, F}-p_{T}\right)+n c_{T, H}+(1-n) c_{T, F} \\
y_{N T, H} & =c_{N T, H} \\
y_{N T, F} & =c_{N T, F} \\
c_{T, H}-c_{H} & =-\eta\left(p_{T}-p_{H}\right) \\
c_{T, F}-c_{F} & =-\eta\left(p_{T}-p_{F}\right) \\
c_{N T, H}-c_{H} & =-\eta\left(p_{N T, H}-p_{H}\right) \\
c_{N T, F}-c_{F} & =-\eta\left(p_{N T, F}-p_{F}\right)
\end{aligned}
$$




$$
\begin{aligned}
c_{H} & =\varphi^{B} \frac{C^{B}}{C} c_{H}^{B}+\varphi^{S} \frac{C^{S}}{C} c_{H}^{S} \\
c_{F} & =\varphi^{B} \frac{C^{B}}{C} c_{F}^{B}+\varphi^{S} \frac{C^{S}}{C} c_{F}^{S} \\
d_{H} & =\frac{P_{T} Y_{T}}{D}\left(p_{T H}+y_{T H}\right)+\frac{P_{N T} Y_{N T}}{D}\left(p_{N T H}+y_{N T H}\right)-\frac{W N}{D}\left(w_{H}+n_{H}\right) \\
d_{F} & =\frac{P_{T} Y_{T}}{D}\left(p_{T F}+y_{T F}\right)+\frac{P_{N T} Y_{N T}}{D}\left(p_{N T F}+y_{N T F}\right)-\frac{W N}{D}\left(w_{F}+n_{F}\right)
\end{aligned}
$$

This completes the static equations. In addition we have, when both borrowers are constrained (reference regime):

$$
\begin{aligned}
c_{H t}^{S} & =c_{H t+1}^{S}-\frac{1}{\sigma}\left(i_{t}-\pi_{H, t+1}\right) \\
c_{F t}^{S} & =c_{F t+1}^{S}-\frac{1}{\sigma}\left(i_{t}-\pi_{F, t+1}\right)
\end{aligned}
$$

together with the budget constraints:

$$
\begin{aligned}
p_{H t}+c_{H t}^{S} & =\frac{B^{S}}{R P C^{S}}\left(b_{H t}^{S}-i_{t}\right)-\frac{B^{S}}{P C^{S}} b_{H t-1}^{S}+\frac{W N}{P C^{S}}\left(w_{H t}+n_{H t}^{S}\right)+v^{S} \frac{D}{P C^{S}} d_{H t} \\
p_{F t}+c_{F t}^{S} & =\frac{B^{S}}{R P C^{S}}\left(b_{F t}^{S}-i_{t}\right)-\frac{B^{S}}{P C^{S}} b_{F t-1}^{S}+\frac{W N}{P C^{S}}\left(w_{F t}+n_{F t}^{S}\right)+v^{S} \frac{D}{P C^{S}} d_{F t}
\end{aligned}
$$

and

$$
\begin{aligned}
p_{H t}+c_{H t}^{B} & =\frac{B^{B}}{R P C^{B}}\left(b_{H t}^{B}-i_{t}\right)-\frac{B^{B}}{P C^{S}} b_{H t-1}^{B}+\frac{W N}{P C^{B}}\left(w_{H t}+n_{H t}^{B}\right)+v^{B} \frac{D}{P C^{B}} d_{H t} \\
p_{F t}+c_{F t}^{B} & =\frac{B^{B}}{R P C^{B}}\left(b_{H t}^{B}-i_{t}\right)-\frac{B^{B}}{P C^{S}} b_{F t-1}^{B}+\frac{W N}{P C^{B}}\left(w_{F t}+n_{F t}^{B}\right)+v^{B} \frac{D}{P C^{B}} d_{F t}
\end{aligned}
$$

When both borrowers are unconstrained, instead we have:

$$
\begin{aligned}
& c_{H t}^{B}=c_{H t+1}^{B}-\frac{1}{\sigma}\left(i_{t}-\pi_{H, t+1}\right) \\
& c_{F t}^{B}=c_{F t+1}^{B}-\frac{1}{\sigma}\left(i_{t}-\pi_{F, t+1}\right)
\end{aligned}
$$

The dynamics are completed by a description of the evolution of inflation in both regions:

$$
\begin{gathered}
\hat{\pi}_{H T, t}=\beta^{S} E\left[\hat{\pi}_{H T, t+1}\right]+\frac{(1-\theta)\left(1-\theta \beta^{S}\right)}{\theta} \frac{1}{\left(1+\frac{\varepsilon(1-\gamma)}{\gamma}\right)}\left(\hat{w}_{H T, t}-\hat{p}_{H T, t}+\frac{1-\gamma}{\gamma} \hat{y}_{H T, t}\right) \\
\hat{\pi}_{H N T, t}=\beta^{S} E\left[\hat{\pi}_{H N T, t+1}\right]+\frac{(1-\theta)\left(1-\theta \beta^{S}\right)}{\theta} \frac{1}{\left(1+\frac{\varepsilon(1-\gamma)}{\gamma}\right)}\left(\hat{w}_{H N T, t}-\hat{p}_{H N T, t}+\frac{1-\gamma}{\gamma} \hat{y}_{H N T, t}\right) \\
\hat{\pi}_{F T, t}=\beta^{S} E\left[\hat{\pi}_{F T, t+1}\right]+\frac{(1-\theta)\left(1-\theta \beta^{S}\right)}{\theta} \frac{1}{\left(1+\frac{\varepsilon(1-\gamma)}{\gamma}\right)}\left(\hat{w}_{F T, t}-\hat{p}_{F T, t}+\frac{1-\gamma}{\gamma} \hat{y}_{F T, t}\right) \\
\hat{\pi}_{F N T, t}=\beta^{S} E\left[\hat{\pi}_{F N T, t+1}\right]+\frac{(1-\theta)\left(1-\theta \beta^{S}\right)}{\theta} \frac{1}{\left(1+\frac{\varepsilon(1-\gamma)}{\gamma}\right)}\left(\hat{w}_{F N T, t}-\hat{p}_{F N T, t}+\frac{1-\gamma}{\gamma} \hat{y}_{F N T, t}\right)
\end{gathered}
$$


together with the monetary policy rule: either

$$
i_{t}=0
$$

at the ZLB, or:

$$
i_{t}=\phi_{\pi}\left(\pi_{H, t}+\pi_{F, t}\right)
$$

when monetary policy follows at Taylor rule.

\section{E. Solution Method}

Since our model has occasionally binding borrowing constraints, we solve it using the Dynare "OccBin" package developed by Matteo Iacoviello and Luca Guerrieri (Guerrieri and Iacoviello 2015).

Whenever the model is in the indeterminacy region (with low $\phi_{\pi}$, as in our main case of the zero lower bound), we resolve this indeterminacy by assuming that the economy returns to steady state by the end of horizon $\tau$ of our impulse responses. Practically, since there is a single dimension of indeterminacy, this involves parametrizing the expectation error in one of the Phillips curves with one "sunspot" shock. We set

$$
\hat{\pi}_{H T, t+1}=\mathbb{E}_{t}\left[\hat{\pi}_{H T, t+1}\right]+\epsilon_{t+1}
$$

and simulate the model twice. We first obtain the full set of impulse responses to a debt relief shock assuming that the initial expectational error in inflation is $\epsilon_{0}=0$ (call this $\mathbb{I}^{0}$, where $\mathbb{I}^{0}(X, t)$ is the impulse response of variable $X$ at time $t$ ). We then obtain the full set of impulse responses to a zero debt relief shock, assuming that the expectational error in inflation is $\epsilon_{0}=1$ (call this $\left.\mathbb{I}^{1}\right)$. We then find the scalar $\lambda$ such that the impulse response of inflation is exactly zero at date $\tau$, ie $\mathbb{I}^{0}\left(\pi_{H T}, \tau\right)+\lambda \mathbb{I}^{1}\left(\pi_{H T}, \tau\right)=0$. Our impulse responses to all shocks are then simply $\mathbb{I}^{0}+\lambda \mathbb{I}^{1}$. We verify that this delivers continuity at the boundary of indeterminacy (see for example figure A4).

\section{F. MPCs Out of Debt Relief}

Here we show why the consumption function out of debt relief is concave and highlight the determinants of MPCs out of debt relief. The analysis is complementary to Achdou et al. (2017), who provide an alternative and very elegant derivation, and extend it to a case where borrowers face idiosyncratic income risk.

For this section, we work in continuous time. An impatient agent faces the real interest rate $r$ and has discount rate $\rho<r$

$$
\begin{array}{ll}
\max & \int e^{-\rho t}\left\{u\left(c_{t}\right)-v\left(n_{t}\right)\right\} d t \\
\text { s.t. } & \dot{b_{t}}=r b_{t}+w n_{t}+y-c_{t} \\
& b_{t} \geq-d
\end{array}
$$

where $u(c)=\frac{c^{1-\sigma}-1}{1-\sigma}$ and $v(n)=\chi \frac{n^{1+\psi}}{1+\psi}$. Her wage $w$, nonlabor income $y$ and the real interest rate $r$ are all constants.

Steady state. In a steady-state the constraint binds: the agent is at his borrowing limit $b=-d$. Consumption is equal to income from labor and nonlabor income net of interest payments:

$$
c=w n+y-r d
$$

The steady-state levels of consumption $c$ and labor supply $n$ solve (B.32) jointly with the optimality condition for labor vs consumption:

$$
c^{\sigma} n^{\psi}=\frac{w}{\chi}
$$


write this solution $\left(c^{*}, n^{*}\right)$.

Debt relief. Debt relief for this agent means restarting her at level $b_{0}=-d_{0}$, in other words, forgiving the amount $D=d_{0}-d$. The agent will plan to return to the constraint at time $T$. In the meantime, her consumption solves the Euler equation:

$$
\frac{\dot{c_{t}}}{c_{t}}=\frac{1}{\sigma}(r-\rho)
$$

implying

$$
c_{t}=c_{0} e^{-\frac{1}{\sigma}(\rho-r) t}
$$

Along the way, the intratemporal condition:

$$
c_{t}^{\sigma} n_{t}^{\psi}=w
$$

holds at all times, implying in particular:

$$
n_{t}=n_{0} e^{\frac{1}{\psi}(\rho-r) t}
$$

Hence consumption decays exponentially and labor supply increases exponentially back towards their respective steady-state levels. Moreover, by continuity

$$
c_{T}=c_{0} e^{-\frac{1}{\sigma}(\rho-r) T}=c^{*}
$$

which relates the time it takes to hit the constraint to the initial level of consumption $c_{0}$ :

$$
\frac{1}{\sigma}(\rho-r) T=\ln \left(\frac{c_{0}}{c^{*}}\right)
$$

and similarly

$$
-\frac{1}{\psi}(\rho-r) T=\ln \left(\frac{n_{0}}{n^{*}}\right)
$$

The integrated version of the budget constraint (B.31) between $t=0$ and $t=T$ (where their asset level is back at the constraint $b_{T}=-d$ ) reads:

$$
d_{0}+\int_{0}^{T} c_{t} e^{-r t} d t=\int_{0}^{T} y e^{-r t} d t+\int_{0}^{T} w n_{t} e^{-r t} d t+d e^{-r T}
$$

Define

$$
a \equiv \frac{1}{\sigma}(\rho-r) \quad b \equiv \frac{1}{\psi}(\rho-r)
$$

Using (B.34) and (B.36)

$$
d_{0}+\frac{c_{0}}{r+a}\left(1-e^{-(r+a) T}\right)=\frac{y}{r}\left(1-e^{-r T}\right)+\frac{w n_{0}}{r-b}\left(1-e^{-(r-b) T}\right)+d e^{-r T}
$$

recognizing that $d e^{-r T}=d-\frac{r d}{r}\left(1-e^{-r T}\right)$ we obtain

$$
\frac{c_{0}}{r+a}\left(1-e^{-(r+a) T}\right)-\frac{y-r d}{r}\left(1-e^{-r T}\right)-\frac{w n_{0}}{r-b}\left(1-e^{-(r-b) T}\right)=d-d_{0}
$$

noting that $c_{0}^{\sigma} n_{0}^{\psi}=w$, this gives us a second relation between $c_{0}$ and $T$. Solving for both gives us the full solution to our dynamic optimization problem. 
Approximation. We first solve out for $c_{0}$ and $n_{0}$ as functions of $T$,

$$
\frac{c^{*} e^{a T}}{r+a}\left(1-e^{-(r+a) T}\right)-\frac{y-r d}{r}\left(1-e^{-r T}\right)-\frac{w n^{*} e^{-b T}}{r-b}\left(1-e^{-(r-b) T}\right)=d-d_{0}
$$

and use the steady state budget constraint $y-r d=c^{*}-w n^{*}$ to rewrite this as:

$$
c^{*}\left[\frac{e^{a T}}{r+a}\left(1-e^{-(r+a) T}\right)-\frac{1}{r}\left(1-e^{-r T}\right)\right]+w n^{*}\left[\frac{1}{r}\left(1-e^{-r T}\right)-\frac{e^{-b T}}{r-b}\left(1-e^{-(r-b) T}\right)\right]=d-d_{0}
$$

Note that, to a second-order approximation,

$$
\begin{aligned}
\frac{e^{a T}}{r+a}\left(1-e^{-(r+a) T}\right)-\frac{1}{r}\left(1-e^{-r T}\right) & =\left(1+a T+\frac{a^{2} T^{2}}{2}+O\left(T^{3}\right)\right)\left(T-\frac{(a+r) T^{2}}{2}+O\left(T^{3}\right)\right)-\left(T-\frac{r T^{2}}{2}\right) \\
& =\frac{a T^{2}}{2}+O\left(T^{3}\right)
\end{aligned}
$$

and symmetrically for labor supply by substituting $a=-b$. We obtain:

$$
\left(a c^{*}+b w n^{*}\right) \frac{T^{2}}{2}+O\left(T^{3}\right)=d-d_{0} \equiv D
$$

In other words

$$
\frac{1}{2}\left(\frac{1}{\sigma}(\rho-r)+\frac{1}{\psi}(\rho-r) \frac{w n^{*}}{c^{*}}\right) T^{2} \simeq \frac{D}{c^{*}}
$$

so that the solution for $T$ is:

$$
T \simeq \sqrt{\frac{2}{\rho-r}\left(\frac{1}{\sigma}+\frac{1}{\psi} \frac{w n^{*}}{c^{*}}\right)^{-1} \frac{D}{c^{*}}}
$$

and hence we obtain two approximations for the consumption effect of a given amount of debt relief $D=$ $d-d_{0}$. Our first approximation is in logs:

$$
\ln \left(\frac{c_{0}}{c^{*}}\right)=\frac{1}{\sigma}(\rho-r) T \simeq \sqrt{2 \frac{\rho-r}{\sigma^{*}} \frac{D}{c^{*}}}
$$

with effective risk aversion

$$
\sigma^{*} \equiv \sigma\left(1+\frac{\sigma}{\psi} \frac{w n^{*}}{c^{*}}\right)
$$

We can also obtain a (less accurate) expression in percentage terms:

$$
\frac{c_{0}-c^{*}}{c^{*}} \simeq \sqrt{2 \frac{\rho-r}{\sigma^{*}} \frac{D}{c^{*}}}
$$

Equations (B.40) and (B.41) show that the log change in borrower consumption (or its approximation as a percent change $\left.\frac{c_{0}-c^{*}}{c^{*}}\right)$ is proportional to the square root of the ratio of debt relief to consumption $\frac{D}{c^{*}}$. As is intuitive, the more impatient the borrower is relative to the risk-free rate and the higher the effective elasticity of intertemporal substitution $\frac{1}{\sigma^{*}}$, the higher the slope of this relationship.

In addition, the labor supply response is negative and proportional to square root of the ratio of debt relief to labor income:

$$
\frac{n_{0}-n^{*}}{n^{*}} \simeq \ln \left(\frac{n_{0}}{n^{*}}\right) \simeq-\sqrt{2 \frac{\rho-r}{\psi^{*}} \frac{D}{w n^{*}}}
$$


where we similarly have defined effective $\psi$ as

$$
\psi^{*} \equiv \psi\left(1+\frac{\psi}{\sigma} \frac{c^{*}}{w n^{*}}\right)
$$

which is larger, the larger the Frisch elasticity $\psi^{-1}$.

MPCs out of debt relief in discrete time. In discrete time, debt relief $D$ leads borrowers to go back to their borrowing constraints in a number of discrete periods $T$, instead of a continuous $T$ approximated by (B.39). When $D$ is low enough, the continuous-time $T$ is small and the discrete $T$ equals 1 . In this case, the discrete time $M P C$ and the MPN solve

$$
M P C=w M P N+1
$$

as well as (differentiating B.35)

$$
w M P N=-\frac{w n}{c} \frac{\psi}{\sigma} M P C
$$

so that, for small enough, the MPC out of debt relief is simply

$$
M P C=\frac{1}{1+\frac{w n}{c} \frac{\psi}{\sigma}}
$$

This number is constant for $D$ sufficiently small that $T=1$, explaining the flat part of figure 7. Equation (B.39) shows that the lenght of this flat part, as a function of $D$, depends on several of our parameter values, chiefly the borrower discount factor $\rho$ relative to the interest rate $r$. 